

\section{Toward healthier, sustainable, medium density housing, through a return to natural materials.}

BY

STEVEN JAYCOCK

A thesis submitted to the Victoria University of Wellington in fulfilment of the requirements for the degree of Master of Architecture(Professional)

Victoria University of Wellington

(2014) 
'I want to be over the edge, environmentally, aesthetically, and technically.'

Samuel Mockbee, 2002 


\section{Position Statement}

In an ideal world there would be no need to concern ourselves with housing density as there would be plenty of room for living, agriculture and nature. As the worlds population increases and natural resources diminish it is essential that we consider ways to minimise the impact we have on our environment whilst still striving to provide, healthy, comfortable and stimulating habitats for all.

In a technology driven world, where it is assumed that newer must be better, the most fundamental of solutions are often overlooked, and knowledge of great value can be lost in the past.

Natural building materials offer healthy sustainable economical solutions for housing todays and future generations. 
'The architectural profession

should challenge the status quo into making responsible environmental and social changes'

Samuel Mockbee, 2002 
Medium density housing can be built sustainably using natural materials. These homes are healthy to live in and have minimal impact on the environment.

Increasing demand, diminishing available land, climate change and unsustainable building practices all contribute to a growing housing crisis. The list of manufactured materials such as asbestos, PVC and formaldehyde, that are hazardous to us and our planet continues to grow. Many modern homes are not fit for purpose, being poorly insulated, damp mould inducing toxic buildings, recognised as a major contributor to poor health, and being detrimental in their manufacture to the environment. Until recently, natural building materials, perceived as inferior to modern manufactured products, have been considered unsuitable for modern building.

The RADIUS ${ }^{1}$ solution cycle is developed from this research as an organised design led process. Research driven by design, then through Analysis and Discussion, Inform Design, so as to Utilise new findings to Solve the conundrum.

Historically, natural material structures last for hundreds and in some cases thousands of years. Just as ancient history can show us the way with materials, perhaps recent history can suggest answers to better medium density design, the hexagon is trialed here as one possible alternative site configuration. Global interest in natural materials in developed countries is growing, the higher labour cost is no longer considered problematic, being offset by the significant material cost and environmental impact savings, health benefits and an estimated building life expectancy exceeding 200 years. New Zealand as an advocate of healthy living and conservation of nature should lead the world by example in this field in which it is currently under-represented.

A composite wall and floor of straw, clay, aggregate, sand and lime is readily available, renewable, sustainable and works synergistically to maintain correct moisture levels and inhibit mould. I present two housing developments as proof of concept that natural building materials offer new typologies and a healthy sustainabale way forward.

1 Research, Analyse, Discuss, Inform, Utilise, Solve RADIUS 
'It is time for more experiment in the way we plan, build and own our communities. For example, new initiatives are needed to try and find ways to ensure that our surroundings are not entirely sacrificed to the car.

Prince Charles, 1989 


\section{Contents}

Position Statement

Abstract

Contents

Introduction

1. Methodology

2. Predesign

3. Design Phase 1

4. Research

5 Design Phase 2

6 Research

7 Design Phase 3

8 Solution 1

9 Solution 2

63

10 Conclusion

71

11 Projection

85

Works Cited

89

Image List

Appendices 
'You can use an eraser on the drafting table or a sledgehammer on the construction site'

\author{
Frank Lloyd Wright,
}




\section{Introduction}

The Earth's population is growing by over 200,000 persons a day. The United Nations $\mathrm{FAO}^{2}$, states 0.22 hectares of land needs to be cultivated to feed one person. In 2003 there were 5.9 billion people on earth and 155 million hectares of productive land, equating to 0.26 hectares per person. This could double by 2039 halving individual theoretical allocation to 0.13 hectares, well short of the calculated minimum for a sustainable global population. We could say that each hectare covered by buildings reduces the earth's ability to feed five persons. We already fall short of the required minimum productive land available for sustainable living.

Low density suburban subdivisions are not sustainable. Subdivisions compete with agriculture for land that is easy to develop. One million hectares of Australia and New Zealand are committed to settlement and infrastructure. Globally 152 million hectares of land is committed to settlement and infrastructure.

Demand for medium density housing in New Zealand is growing, as outlined by Holly Walker in her article 'A tour of Auckland's housing challenges':

'Not only is medium density housing potentially more affordable, if done right, it can also be more sustainable, and produce more liveable neighbourhoods and communities that give the people who live in them real enhanced quality of life.' ${ }^{3}$

Recent New Zealand medium density housing has had limited success, often being associated with the 1990-2000 leaky home crisis. Prior to 1990, and more recently, successful medium density housing projects in cities such as Wellington have become some of the more desirable and sought after properties, their compact design adding to affordability, being close to amenities, having multiple transport options, and often still having ample space for greenery and recreation areas. One such development is Peter Beaven's 'Thorndon Mews' which has maintained its popularity, despite now being

2 Food and Agriculture Organization of the United Nations. World Agriculture: Towards 2015/2030: An FAO Perspective. London: Earthscan Publications, 2003. Print.

3 'A Tour of Auckland's Housing Challenges.' Frogblog. n.d. Web. 2 June 2013. 
somewhat dated. This can be attributed to the carefully thought out functional design and the effort put into making each home unique.

In 2011 in recognition of the growth in medium-density housing the Ministry for the Environment released a 'Medium Density Housing Assessment Methodology.' Their definition of medium density housing was:

... comprehensive developments including four or more dwellings with an average density of less than $350 \mathrm{~m}^{2}$ per unit. It can include standalone dwellings, semi-detached (or duplex) dwellings, terraced housing or apartments within a building of four storeys or less. These can be located on either single or aggregated sites, or as part of larger master planned developments' ${ }^{4}$

Sustainable houses, with reduced negative impact on human health and the environment are referred to as ecohomes, and are often built from natural materials, preferably locally sourced. One of the first medium density ecohousing developments in New Zealand is Earthsong, conceived in 1995 and developed in co-operation with the Waitakere District Council, being predominantly constructed from rammed earth. Earthsong medium density co-housing development succeeds due to careful planning and the incorporation of parkland within the development. By clustering two storey houses and restricting vehicle access in favour of walkways, Earthsong has minimised impervious surfaces and almost doubled their building density, when compared to their surrounding suburbs, whilst increasing the park and garden areas within the development.

Nelson City Council, one of the more progressive councils in New Zealand, agrees in principle to medium density ecohousing, and recognise that they can be high standard homes at low cost, ${ }^{5}$ as have other councils internationally.

United Kingdom (UK) councils were first to see the potential of adopting natural building materials in their social housing programs. Low initial material cost along with health benefits to occupants and the significant savings in

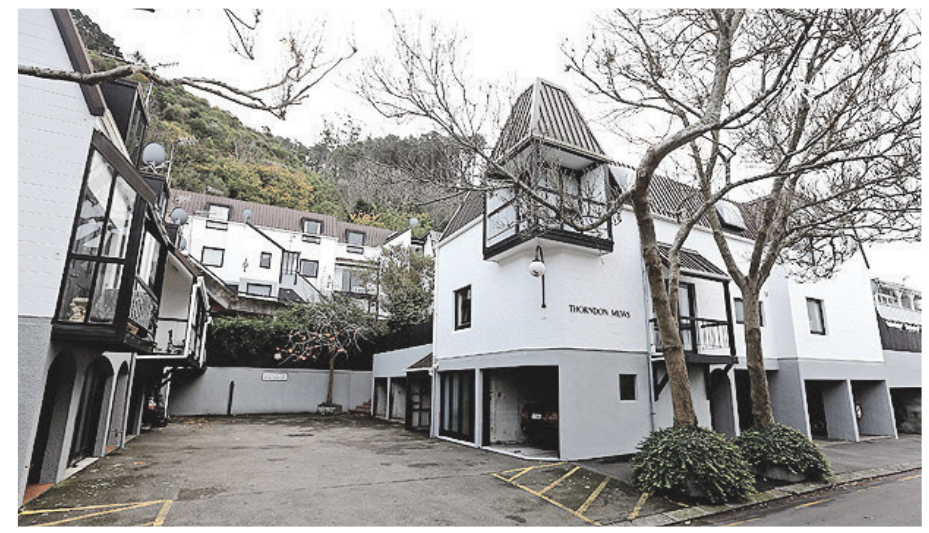

Image 1.

Peter Beven's 'Thorndon Mews' in Wellington have maintianed their popularity over the years.

4 'Medium-density Housing in New Zealand.' Ministry for the Environment. n.d. Web. 2 June 2013.

5 'Eco Housing Plan Gains Council Support.' Stuff.co.nz. n.d. Web. 3 June 2013. 


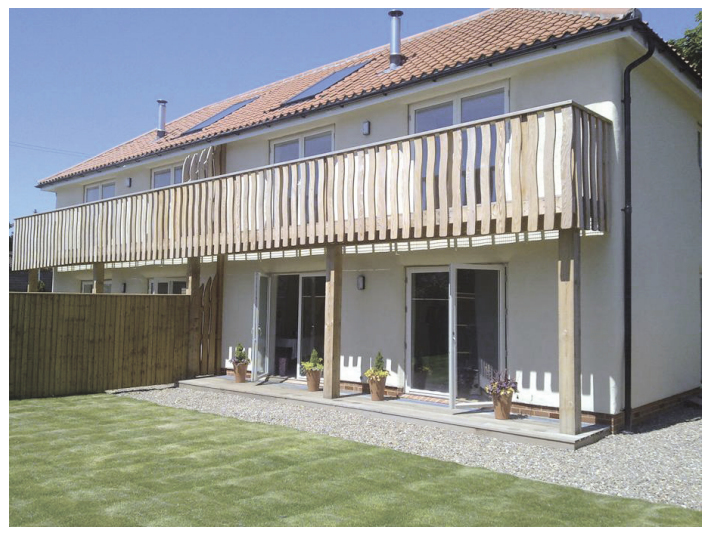

Image 3.

North Kesteven's straw bale council housing estimated to remain in use for 200 years.

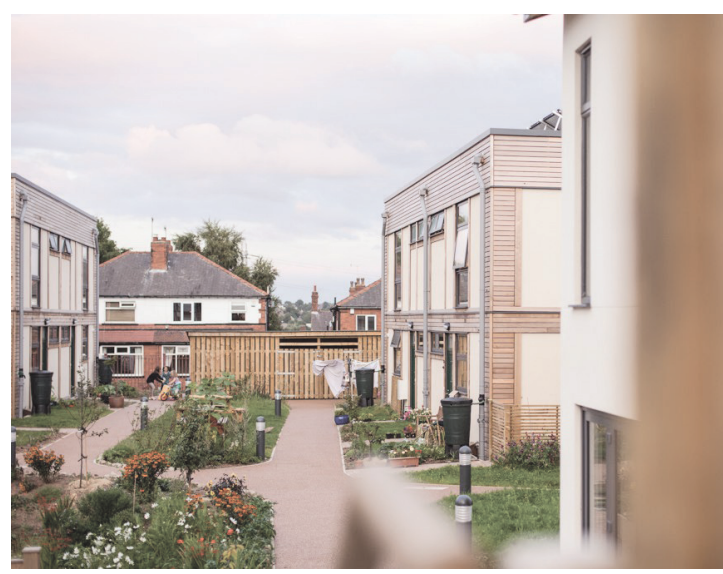

Image 4.

LILAC Straw bale co-housing (LEEDS) heating were all quickly realised. England's first straw bale council houses have proven a great success. In interviews Councillor Stewart Ogden said:

"North Kesteven's straw houses are designed to last around 200 years and have so far proven to be low costing and energy-efficient for the tenants.' 6

An article in the Economist notes the European Commission wanting 5\% of new house builds to be straw by 2020 states:

'Builders boast of their low construction costs: one straw house was recently built in Scotland for $\$ 6400$ US, one twentieth of the cost of the average new build in Britain. '... 'a study by the University of Bath found that a straw house's energy costs could be as much as $85 \%$ lower than those of a conventionally built home.' $^{7}$

In September 2013 LILAC $^{8}$ (Low Impact Living Affordable Community) opened their 20 home green co-housing project in Leeds, England. The straw bale, timber and lime plaster complex significantly reduced its impact on the environment, using 'earth-friendly' construction materials based on the BathHaus modular straw bale system.

By integrating and adapting elements of medium density housing, traditional natural building systems and materials, alternative subdivision design, with modern technology and building methods, affordable, high standard eco housing can be produced, along with the associated environmental and health benefits.

6 'Straw House North Kesteven'. North Kesteven District Council. n.d. Web. 7 Sept. 2013.

7 R, C. 'Why Are Straw Houses Making a Come Back'. The Economist 28 Nov. 2013: n. pag. Print.

8 'LILAC: UK's First Strawbale Co-Housing Project Opens in Leeds | Inhabitat - Sustainable Design Innovation, Eco Architecture, Green Building'. N. p., n.d. Web. 20 Jan. 2014. 
'Design is a way of inquiring, a way of producing knowing and knowledge; this means it is a way of researching.'

\author{
Peter Downton, 2004
}




\section{Methodology}

DESIGN RESEARCH PATH

DESIGN RESEARCH CYCLE

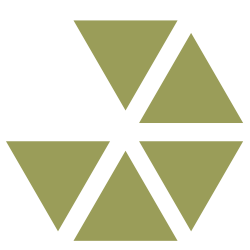

Based on Peter Downton's premise, 'Design is a way of inquiring... this means it is a way of researching ${ }^{\prime 9}$ the RADIUS method for design and research evolved from this thesis and as a re-iterative process provides a framework within which design directs research to inform further design development.

Following this path from the first design idea; RADIUS (Research, Analyse, Discuss/Dispose, Inform, Utilise, Solve) stimulates potential solutions which are analysed then disposed of or utilised, and if necessary the process repeated with a new round of investigative research, until a suitable response is achieved.

The diagram on the following page charts the design research path from project conception through to two solutions and, in the true nature of a reiterative process takes the design beyond the scope of this project by identifying new threads of inquiry.

The diagram on page 17 visually demonstrates the RADIUS design cycle being six stages, which relates well to this thesis.

9 Downton, Peter. Design research. Melbourne: RMIT Pub., 2003. Print. 


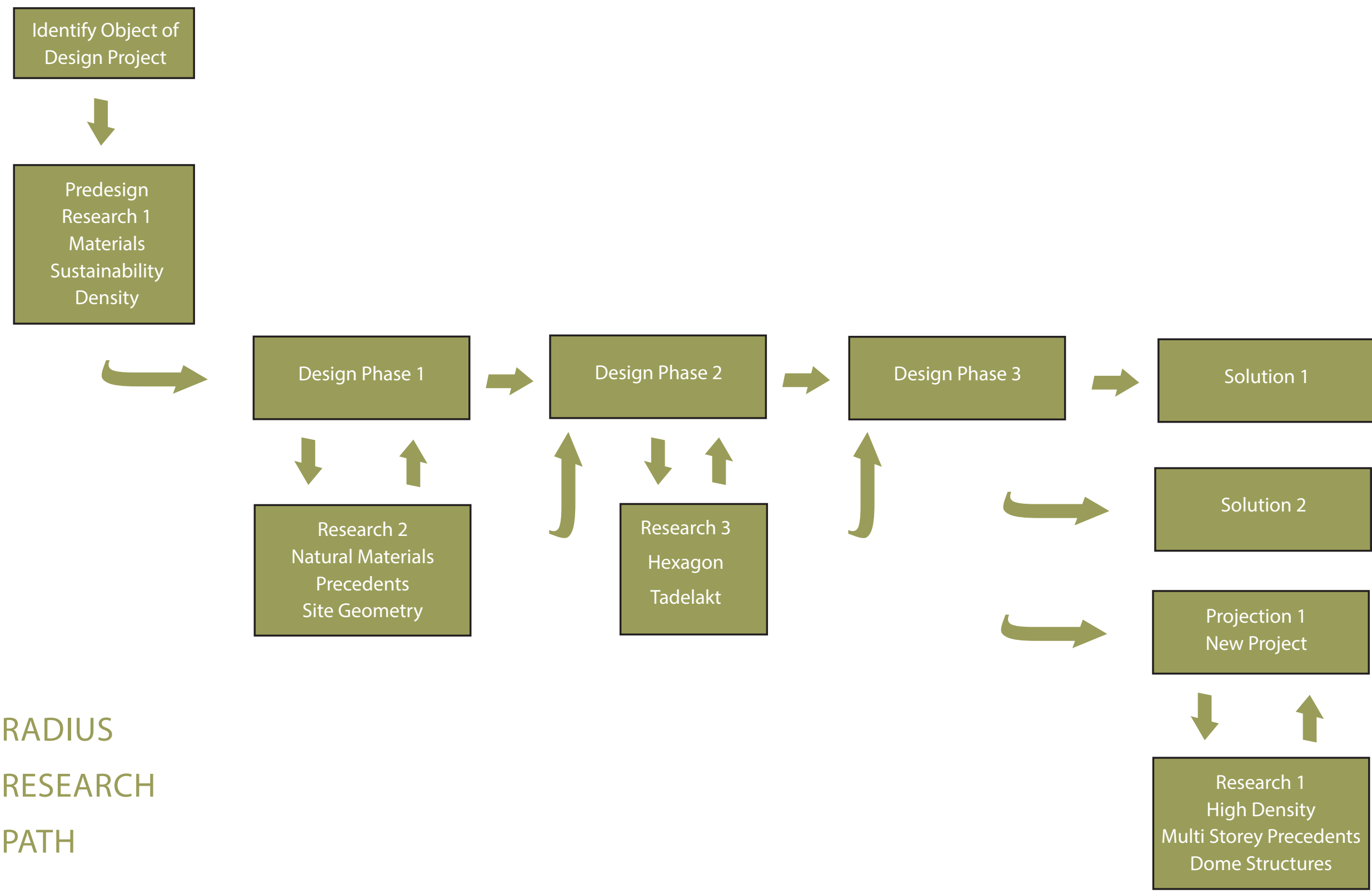



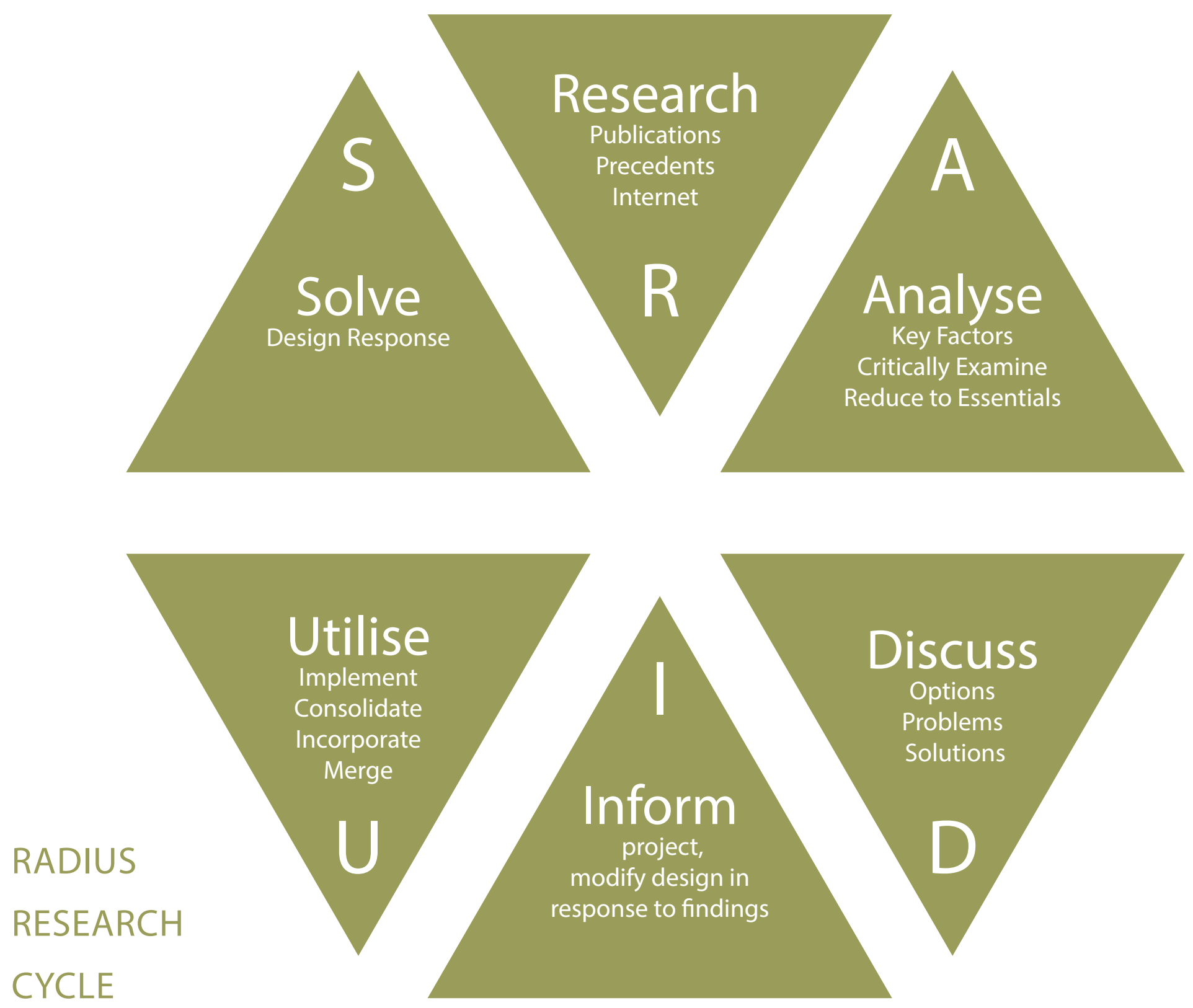
In the sweep of history, the twentieth-century American house will probably be regarded as a temporary aberration, an embarrassment to enlightened builders and planners. It will be called the "out of place house" or "the utterly dependent home"'

\section{Michael Potts}

'Architects working under capitalism today continue to be seduced by the new technologies and materials it produces and the luxuries they enable.'

Robin Schulenfrei. 2014 


\section{Predesign}

\section{MATERIALS}

SUSTAINABILITY

DENSITY

REFLECTION

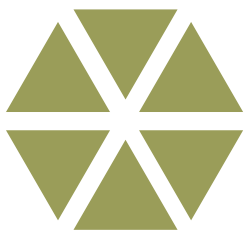

Recent historic and current practices in building material choices and land subdivision impact how healthy and sustainable residential housing is designed. The current situation is reviewed under the headings Materials, Sustainability, and Density

\section{Materials}

Over the last century, building and building materials have become more specialised and increasingly mass produced in factories, then transported to sites around the world. Specialisation has increased the speed of construction at the expense of variety in building style. Variation, often based on locally sourced materials, once gave us local vernacular or regional identity. Currently materials are standardised through mass production and distributed globally resulting in a loss of local identity, in particular in western developed countries where buildings are often indistinguishable one from another, despite being continents apart. These mass produced materials are not always suited to the local environment, contribute to a higher 'eco footprint' than is necessary for the building, and have not always stood the test of time, each house being another experiment in durability and effect on occupant health.

In the case of a home, it is usual to expect that a building should last a minimum of 50 years, although the majority of incorporated elements will often only be guaranteed for 25 or 15 years or even less. Our current consumer driven society dictates that materials, planned for obsolescence, should keep the wheels of capitalism turning. Historically, houses constructed from local materials native to the region, regularly last well in excess of this arbitrary and recent 50-year period, which has unfortunately been adopted as maximum standard, contrary to the intention that it be a minimum requirement.

New Zealand state houses are a point in fact. These homes were built mainly of basic natural local materials, (predominantly timber, a renewable local resource,) and are easily outliving houses currently being constructed using what must be considered inferior materials constructed. The author suggests that if New Zealand had continued building state style homes the multimilliondollar leaky home debacle would never have occurred. 
Many modern materials are suspected of contributing to the health problems of building occupants. This phenomenon is currently in the international spotlight with much discussion on the extent of the problem. 'Sick Building Syndrome' (SBS) is not new, The Building Biology and Ecology Institute was founded in Germany in 1976 in order to research this and other building and health related issues. In 'Healthy Home and Healthy Office' Reinhard Kanuka-Fuchs elaborates:

'With over 300,000 chemicals on the market today one cannot reliably predict how possible combinations may affect an organism, even if the responses to all the individual agents could be perfectly assessed. Our nervous and immune systems have become the target of many toxic assaults of long-term, low dose chemical exposure' 10

Over time, many of these materials and systems have been exposed for the dangers they present to biological life. PVC (poly vinyl chloride) is used extensively in flooring, to store and transport potable water, and for window frames, despite common knowledge that phthalate, a known cancer and birth defect-causing substance offgasses into its environs, as there is no covalent bond preventing its migration, is still in common use. In Sweden PVC has been banned since 1995. There are calls to ban PVC and associated products since the detrimental effects to humans have been proven.

'The CHEG (Centre for Health, Environment \& Justice) states on their website:

'Restrictions or bans have been placed on phthalates ... in the entire European Union, Austria, Denmark, Finland, France, Germany, Greece, Italy, Japan, Iceland Mexico, Norway, and Sweden.' 11

10 Kanuka-Fuchs, Reinhard. Healthy Home and Healthy Office: Sick Building Syndrome, Indoor Pollution and Solutions. Bermagui, N.S.W. H. Tietze, 1996. Print. See Appendix 1 for a partial list of materials of concern in relation to cancer.

11 'PVC Governmental Policies.' Center for Health, Environment \& Justice. n.d. Web. 3 Sept. 2013.
Another relatively new material, which was adopted on a massive scale with mimimal understanding of the long-term consequences was asbestos. Asbestos has been used extensively as insulation and in composite wall and roof panels until it too was found to be detrimental to biological entities as it is a carcinogen. Asbestos is now banned, and strict precautions must be taken when removing and disposing of it. Roof tiles, wall claddings, vinyl floor coverings, sprayed fire protection, decorative ceilings, roofing and roofing membranes, adhesives and paints were all produced containing asbestos during the 1920's to 1980's. BRANZ discusses asbestos in relation to health risks on their website saying:

'Asbestos can cause asbestosis (lung disease) and lung cancer when inhaled. However, as symptoms often do not appear until 15-20 years after exposure, the danger of asbestos is easily underestimated.' 12

Formaldehyde is a substance that occurs naturally, although in high doses it can be harmful to humans. High levels of formaldehyde often used in glues and wood treatments was also found to be leeching out into houses. Once again this was not adequately researched and home owners were the guinea pigs that had to suffer before levels were moderated.

Historically as new products, these and others were thought to be safe when they came to market, probably due to insufficient research, with little or no warnings or handling precautions prescribed. Since what is bad for us is also bad for the environment, we would do well to reconsider using many of the products currently available to us. 
One point in case is gypsum board, a staple of modern housing, has been associated with the promotion of damp mould inducing environments due to gypsums tendency to absorb and retain up to $200 \%$ of its weight in moisture ${ }^{13 a}$ combined with the paper facing providing ample readily available nutrients for mold growth. ${ }^{13 \mathrm{~b}}$

This is of particular concern as New Zealand is known to have the second highest incidence of asthma in the world ${ }^{14}$. The relationship between asthma, and other health problems, and our home environment is well researched and documented. The world's largest-ever study, 'The International Study of Asthma and Allergies in Childhood ${ }^{\prime 15}$ was carried out in over fifty countries on more than 700,000 children. Otago University study analysis found:

'study involving 46,000 children in 20 countries, including New Zealand, found living in damp or mouldy homes was associated with asthma, allergies, hayfever and eczema. And, significantly, the findings suggest dampness itself, rather than dust mites associated with dampness, may be the problem.' 16
Currently New Zealand has a population health problem and it is highly likely that poor material research and unsatisfactory house design are contributing to the problem and yet the same materials and the same building methods continue to be used.

If we do not change materials and methods, we will most assuredly have another leaky home type disaster or worse still, health problems to epidemic proportions. Will it be fibreglass insulation, a man made vitreous mineral fibre (MMVF), that becomes our next housing disaster? ${ }^{17}$ Although there is no conclusive evidence, concerns are growing that it has the same harmful properties as asbestos, with its tendency to break down into miniscule airborne glass fibres which could be inhaled just as easily as asbestos.

Materials such as concrete and steel do not pose health risks to people, once in place and finished, however, there is a cost to the environment in part due to the high carbon emissions released during their manufacture. From every ton of raw materials used to make cement, for use in concrete, over one-half a ton is lost as carbon dioxide emissions into the atmosphere, and there is additional cost depending on how the 90 to $150 \mathrm{kWh}$ per ton of energy is produced. ${ }^{18}$ Concrete and steel are essential elements in modern construction without which many structures would not have been possible. We must mitigate their impact by reducing our dependence on them, considering natural and more sustainable substitutes whenever possible. 13a Plescia, Silvio. Relationship between Moisture Content and Mechanical Properties of Gypsum Sheathing Canada: Canada mortgage and housing corporation, 2007. Print. Research Highlights.

$13 \mathrm{~b}$ Yost, Nathan. Frequently Asked Questions about Mold. Washington, DC: National Association of Realtors, 2011. Print.

14 'Asthma in New Zealand | Asthma Foundation New Zealand'. N. p., n.d. Web. 15 Feb. 2014.

15 Asher, M.I. et al. 'International Study of Asthma and Allergies in Childhood (ISAAC): Rationale and Methods'. European Respiratory Journal 8.3 (1995): 483-491. CrossRef. Web. 24 Mar. 2014.

16 '27 June 2013 Media Release.'University of Otago, New Zealand. N. p., n.d. Web. 15 Feb. 2014.
17 De Vuyst, P. et al. 'Respiratory Health Effects of Man-Made Vitreous (mineral) Fibres'. European Respiratory Journal 8.12 (1995): 2149-2173. CrossRef. Web. 24 Mar. 2014.

18 Stajanca M, Estokova A. Environmental Impacts of Cement Production. N. p., 2012. Print. 
'In a bitter irony, modern homes not only threaten the health of the planet, they threaten the health of those they are intended to shelter'

\author{
Daniel Chiras
}




\section{Sustainability}

The 1995 report 'A Building Revolution' studied the impact of housing and life in industrialised countries revealing that nearly twenty years ago we were already consuming around $40 \%$ of the worlds energy and resources for building alone, that $30 \%$ of new and renovated buildings suffered sick building syndrome, and $55 \%$ of felled timber was in use for construction. The report indicates that if we were to reconsider materials and technologies that have recently been discarded, historically speaking, and apply recent knowledge and techniques we could:

'create a synthesis that is better for the environment, and better for humanity.' 19

In the following chapter I discuss the symbiosis of ancient materials and modern technologies and argue that this synthesis still offers excellent benefits to humanity and the environment. Sustainability has become a vital component in housing design and is considered or at least mentioned in most current architectural projects. The Cambridge Dictionary describes sustainability as:

'causing little or no damage to the environment and therefore able to continue for a long time' 20

Some resources are renewable, meaning they can be regrown, such as trees and grasses, whereas other resources are finite although sometimes plentiful, such as minerals used in manufacture. Most materials are either reproducible or recyclable. A sustainable design sources and uses materials

19 Roodman, David Malin, Nicholas K Lenssen, and Jane A Peterson. A Building Revolution: How Ecology and Health Concerns Are Transforming Construction. Washington, DC: Worldwatch Institute 1995. Print.

20 'Sustainable Adjective - Definition in the British English Dictionary \& Thesaurus.' Cambridge Dictionaries Online. N. p., n.d. Web. 29 Mar. 2014. responsibly, ensuring that replacement strategies are in place or that materials are able to be recycled, so as not to diminish the basic raw materials.

'Eco-design or Sustainable design (also called environmental design, environmentally sustainable design, environmentally conscious design) is the philosophy of designing physical objects, the built environment, and services to comply with the principles of economic, social, and ecological sustainability.' ${ }^{21}$

'Evaluating the life cycle of a material can enlighten us as to its suitability for use as sustainable eco material. In a life cycle assessment, a product is divided into procurement, manufacture, use and disposal.'22 A life cycle assessment assesses the impact of the material, taking into account its acquisition as a finite material such as a mineral resource, or produced as a potentially infinite source such as plant based products. The manufacture and implementation of a product is considered, the level of processing along with the energy and chemicals needed to prepare it for use and install it. Finally its disposal at the end of its useful life may be as simple as letting it degrade or break down biologically, or may entail re-tasking the material for another use. Uses such as plastic milk bottles being re moulded for more permanent use ${ }^{23}$, or it may be difficult to re-use or recycle which is more problematic as these items often end up in landfills taking many decades to decompose if at all. This process is a difficult decision, balancing costs financially and environmentally, against the longevity and ease of use of materials.

Sustainable ecodesign is of paramount importance to the building industry at this time as more people demand a reasonable level of housing. We will see greater pressure on resources, which must be managed if we intend to provide for everyone in the future. This is particularly important, as it has been calculated that up to $40 \%$ of all global waste is from the construction industry.

21 'Ecodesign.' Wikipedia. n.d. Web. 10 July 2013.

22 'Ecodesign.' Wikipedia. n.d. Web. 10 July 2013.

23 'Benefits of the Cupolex Dome System / Cupolex Building Systems'. N.p., n.d. Web. 19 Oct. 2014. 
The 'National Association of Home Builders (NAHB) study, estimated 8,000 lbs of waste is created from the construction of a 2,000 square foot home.'24

Lesser processed and locally sourced natural materials offer sustainable eco friendly options which are often overlooked when a new building is considered, particularly in developed countries where manufactured products and systems are readily available. This is self evident by the low number of natural houses in developed countries. Poorer countries often use cheap or free locally sourced materials as they have little choice and yet they are potentially building healthier more environmentally considerate structures.

One outstanding example of a resource poor country capitalising on natural building materials is Pakistan. In 2005 northern Pakistan was devastated by a magnitude 7.6 earthquake. Four million people were left homeless, over 80,000 died and nearly 70,000 were injured. PAKSBAB ${ }^{25}$ (Pakistan Straw Bale and Appropriate Building) set about developing a low cost solution which whether by design or default is highly sustainable and eco friendly. In association with NEES (Network for Earthquake Engineering Simulation) PAKSBAB proved the seismic performance for an earth plastered timber framed low cost strawbale building solution. The NEES website acknowledged the success of the experiment, after eight incremental quake simulations increasing in $25 \%$ steps of severity and exceeding the 7.6 magnitude of the quake in 2005 , Stating on their website:

'Although severely damaged, the building did not appear in danger of collapse, even at the end of the test sequence.' 26

By combining abundant natural materials and modern technologies we can build healthy, sustainable and affordable homes right now with many benefits. In my next chapter I discuss some of the more commonly used natural materials and the advantages of their use.

24 Green Building Elements | From Brick and Mortar Shops to City Planning, We Cover Sustainable Trends in Construction, Renovation, and More.' N. p., n.d. Web. 9 Dec. 2013.

25 'PAKSBAB - Pakistan Straw Bale and Appropriate Building | PAKSBAB - Home'. N. p., n.d. Web. 19 Feb. 2014

26 'Straw Bale House: NEES@Nevada: University of Nevada, Reno'. N. p., n.d. Web. 19 Feb. 2014 


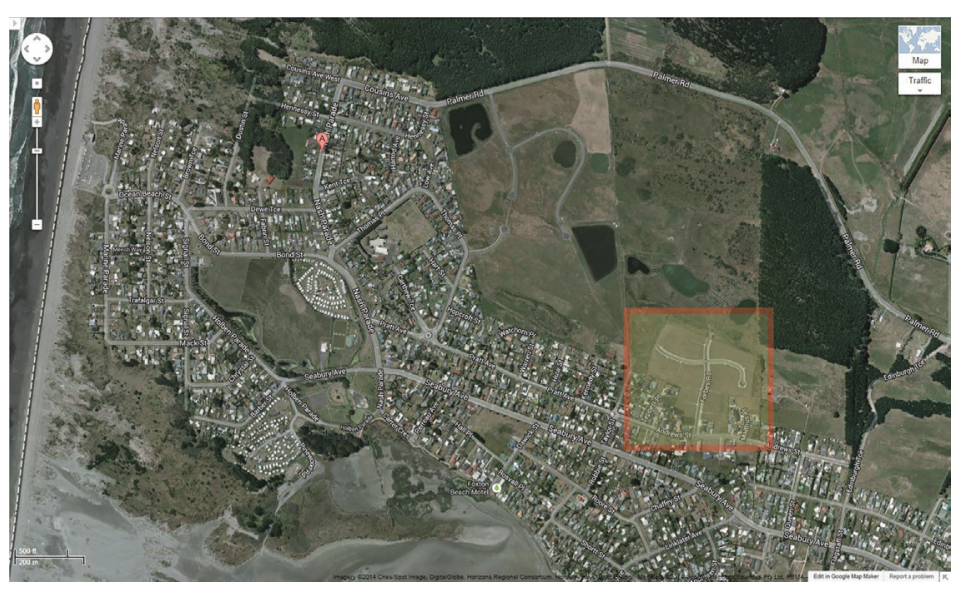

Image 5.

Above: Foxton Beach Township with forest and agriculture to the north and east, the Tasman Sea to the west and the Manawatu River estuary to the south.

Below : The Forbes Road greenfield subdivision (hightlighed above) adjoining existing housing,varying from sixty to eighty year-old to new.

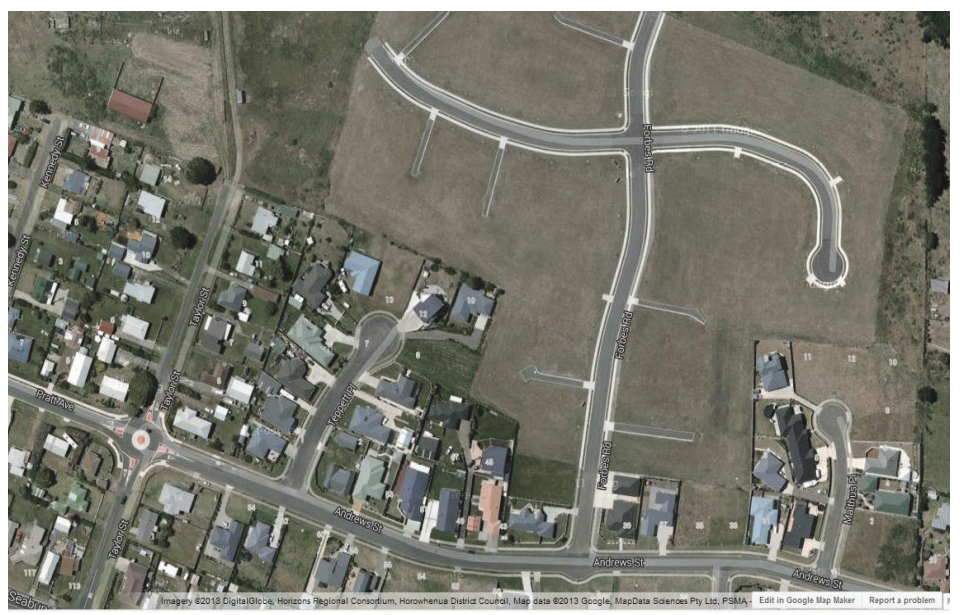

\section{Density}

Foxton Beach, having been settled for nearly one hundred years, represents most suburban scenarios, including traditional quarter acre lineal street designs, infill subdivision of these same sites, cul-de-sac style subdivision, and lifestyle blocks. It is an ideal 'snapshot' on which to study density in relation to site configuration in context.

In New Zealand, with its excess of useable land, privately owned sections with detached homes often referred to as 'the quarter acre dream' has been an easy option. This resulted in a spreading characteristic often referred to as 'urban sprawl' where poorly designed, land hungry subdivisions have proliferated. More recently, population growth, demand for agricultural land, and larger houses requiring larger sites, this once generous home and land package is being steadily squeezed out, pushing land prices beyond the budget of many New Zealanders.

This is a global issue, not just a New Zealand one. As responsible residents of this planet we need to do what we can to improve humanities relationship with planet earth, and reducing our impact by moderating our land needs is one way. The current 600 to 800 square metre intermediate sized land parcel is losing its significance. It is neither large enough for current farming technology, or small enough to be affordable or manageable for a home owner. Owning and caring for land is a lifestyle choice that many either cannot afford, or do not wish to assume, the latter preferring to opt for work and leisure activities more closely associated with a modern city environment. Smaller or shared land parcels with intensified housing could work together to ease this problem.

The Concise Oxford Dictionary describes density as:

'The quantity of people or things in a given area or space.' ${ }^{27}$

27 'Density: Definition of Density in Oxford Dictionary (British \& World English)'. N. p., n.d. Web. 24 Mar. 2014 
The hectare, (( $\mathrm{Ha}) 10,000$ square metres), is used to measure the land and is related to the number of dwellings, referred to as dwellings per hectare (dph).

Historically western cultures began building as community clusters, for protection, socialisation and convenience. The configuration often followed natural contours or features such as streams or ridges, and this pattern further developed into streets around town centres. This medieval contour following pattern, as discussed in 'The Saxon Villages of Transylvania, Romania' ${ }^{28}$ is similar to modern permaculture practices, with its diminishing distance in relation to levels of importance within the site. As demand builds this linear style of division may be further subdivided for infill housing, increasing the number of dwellings and consequently the density of housing. This straightforward solution to resolving the need for increased density works well when applied to the rectangular grid, the most prevalent format in China, India, Rome, Greece and all western cultures. For many years in the UK and USA in particular, consideration of alternative formats has been completely negated by legislation, specifying the grid iron plan be mandatory. Increases in density are not easily achieved with the currently popular cul-de-sac configuration, a seemingly random system of no exit lanes stemming from a central road, which fails in its objective to maximise the number of sections, and unless used in combination with a grid becomes one of the more wasteful designs for road and services. This format doesn't consider placement for solar access or privacy. The cul-de-sac, or lollipop, is also considered impractical for walkers or cyclers and is summarised in 'Responsive Environments: A manual for designers' as:

\section{'Cul-de-sacs' create land that is inefficient and impermeable.' 29}

Cars are creating crisis in our residential housing areas. In a catch 22 situation, more cars are needed as developments sprawl out, leading to more and bigger roads, spreading us out more, and so on it goes. Auckland is a perfect example with its sprawling suburbs and constantly growing road infrastructure. By concentrating parking on the side or edge of a housing development, much of

28 Wilkie, Kim. The Saxon Villages of Transylvania, Romania, A Future for the Mediaeval Landscape. The Mihai Eminescu Trust, 2001. Print.

29 Bentley, lan. Responsive Environments: A Manual for Designers. London: Architectural Press, 1985. Print.

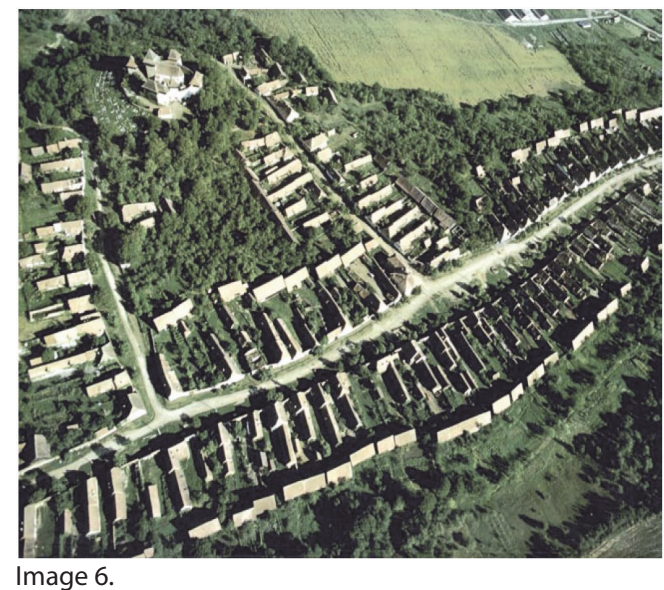

The mediaeval street and courtyard patterns of Viscri.
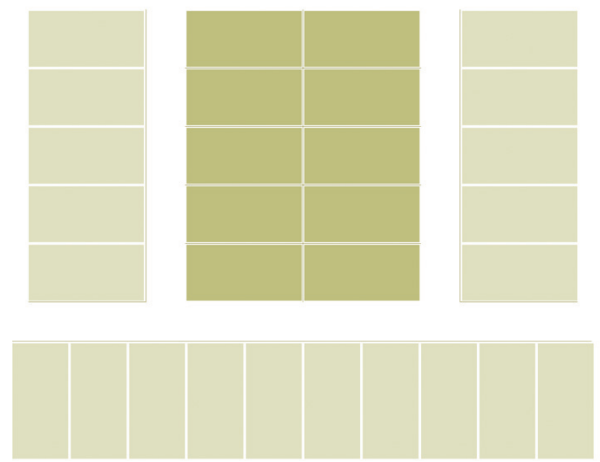

The grid iron has a density of ten dwellings per hectare (10 dph)

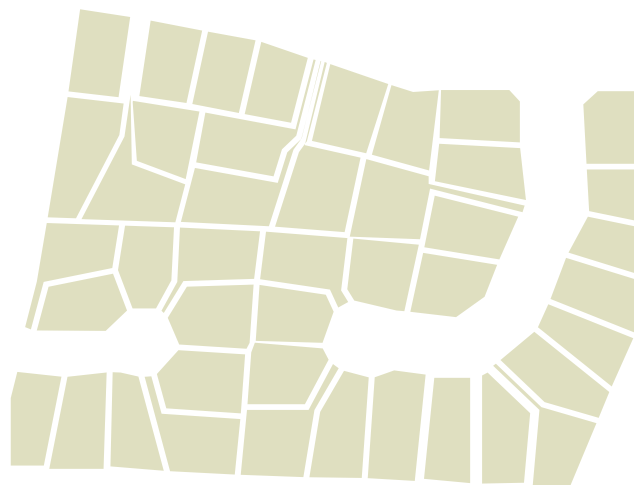

The cul-de-sac has a density of thirteen dwellings per hectare (13 dph) 


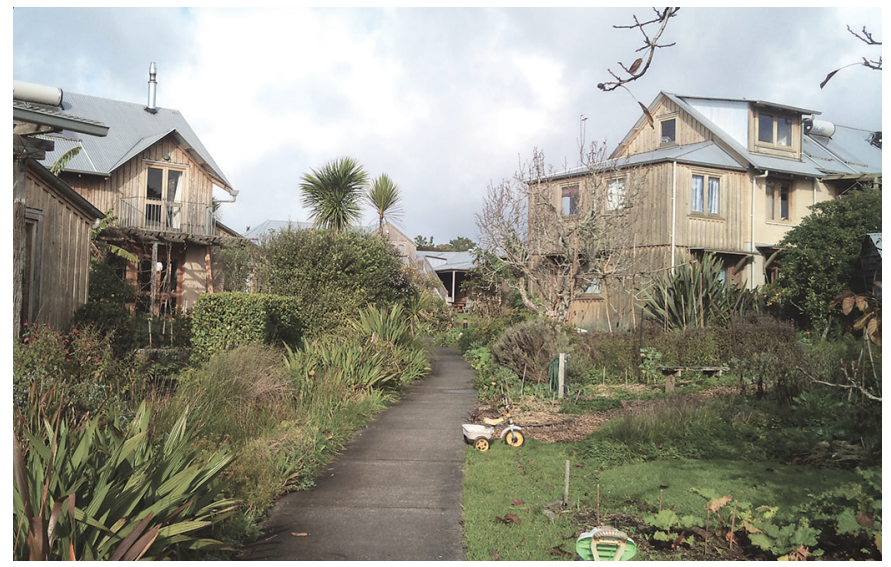

Image 7A. Earthsong is safe for all, the vehicle access stops at the carport shed just visible at the top end of the path.
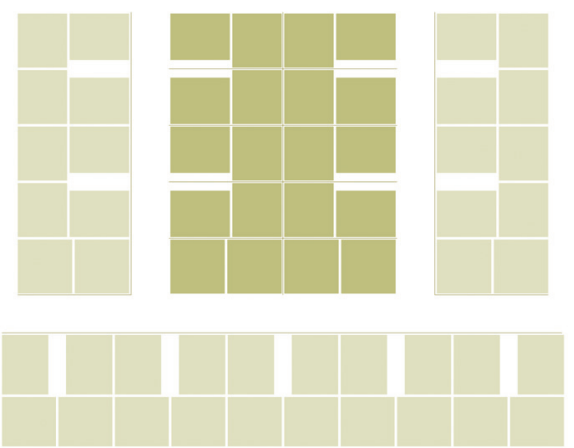

After infill subdivision the grid iron has a potential for up to twenty dwellings per hectare $(20 \mathrm{dph})$

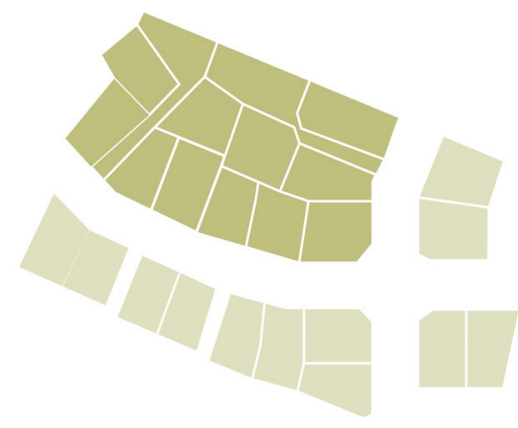

The cul-de-sac is not always suited to infill and rarely, if ever, will reach its full twenty-six dwellings per hectare potential (less than $26 \mathrm{dph}$ ) the wasted space onsite can be minimised. Earthsong, mentioned earlier, does this through the provision of long carport structures near the site entrance and no vehicle access to the internal site.

Current suburban densities are around 10-13 dph and as such are considered low density. If local bylaws allow it, some of these sites can be subdivided resulting in a potential doubling of density to between 20 and $26 \mathrm{dph}$. The irregular configuration of cul-de-sac designs mean they rarely, if ever, achieve their full $26 \mathrm{dph}$ potential. Current suburban sites are not designed to achieve medium density. A suburban site study (see appendix Site Studies p110) demonstrates current and tested variations of which the schematics on these two pages are derived.

A smaller house on a smaller site costs less and places less demand on land and resources, enabling more houses to be built at a reduced cost. This is the ecologically responsible action, also contributing to the sustainability of any project. By increasing building density we reduce the land requirement and consequently the cost to the house owner and the environment. Social and work patterns dictate where people want to live. Typically many want or need to be centrally located, close to activities, amenities and work. This also indicates the need for higher densities and careful consideration in regard to location of housing.

The Sustainable Housing Design Guide for Scotland says:

'Densities of 40-50 dph should be easily obtainable without damaging residential quality in most circumstances,....Most RSLs in Scotland are already building at high density because of land costs, but the environmental advantages of doing so should not be ignored. This illustrates how environmental considerations and cost effectiveness reinforce one another.' ${ }^{30}$

To date the rectangular grid has proven the most successful format for medium to higher density housing, partly because of the ease of linear construction methods and standardised modular material.

30 Stevenson, Fionn, and Nick Williams. Sustainable Housing Design Guide for Scotland. Sustainable Development Commission Scotland, 2007. Print. 


\section{Reflection}

Materials should not only be sustainable they should be as biologically and ecologically benign. Care should be taken when adopting new materials, as often only time can demonstrate their suitability. Sustainability reaches beyond material choices and will affect housing configuration and densities as the land itself, as a finite resource, is considered part of the sustainable equation, forcing us to look for higher density solutions without compromising quality of living. In design phase one alternative site and building configurations are developed.

In 'Research 2', natural building materials are introduced, many of which have been in use for thousands of years, as an environmentally and biologically sustainable alternative.

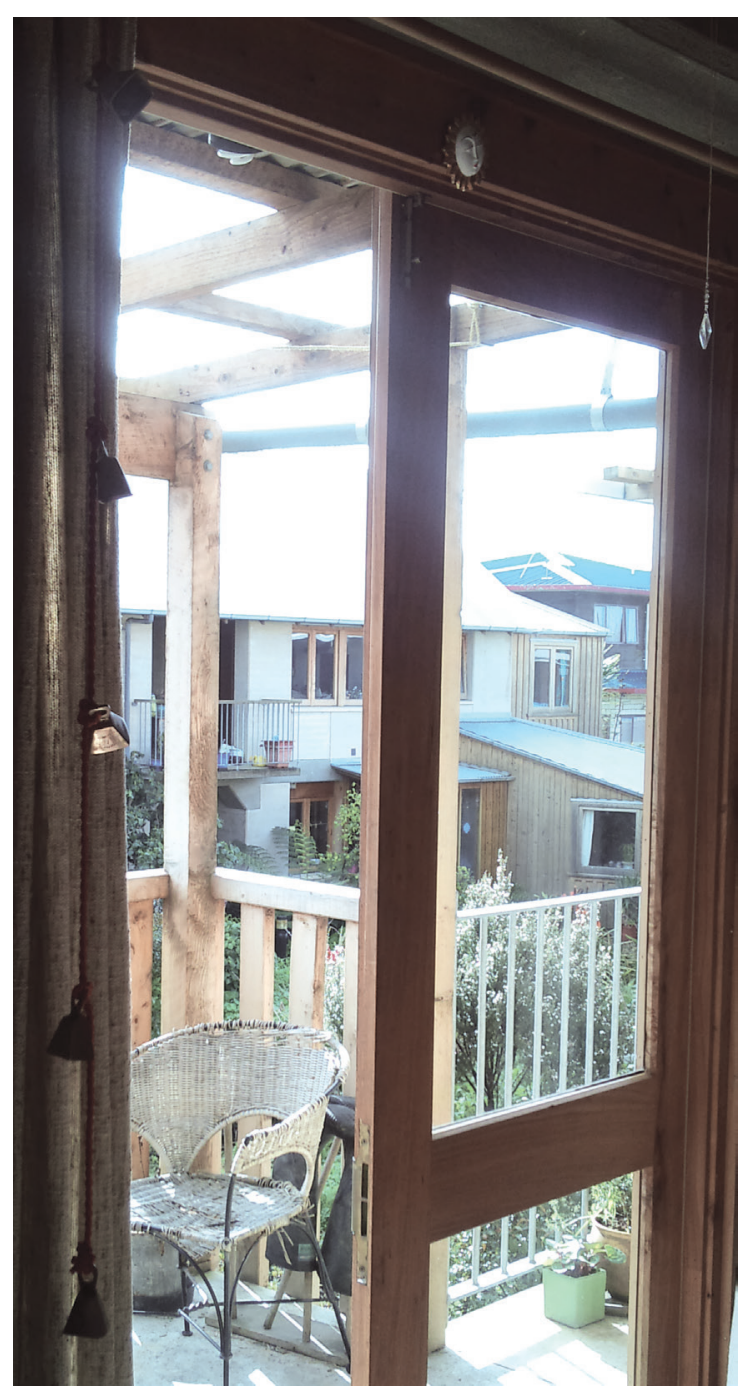



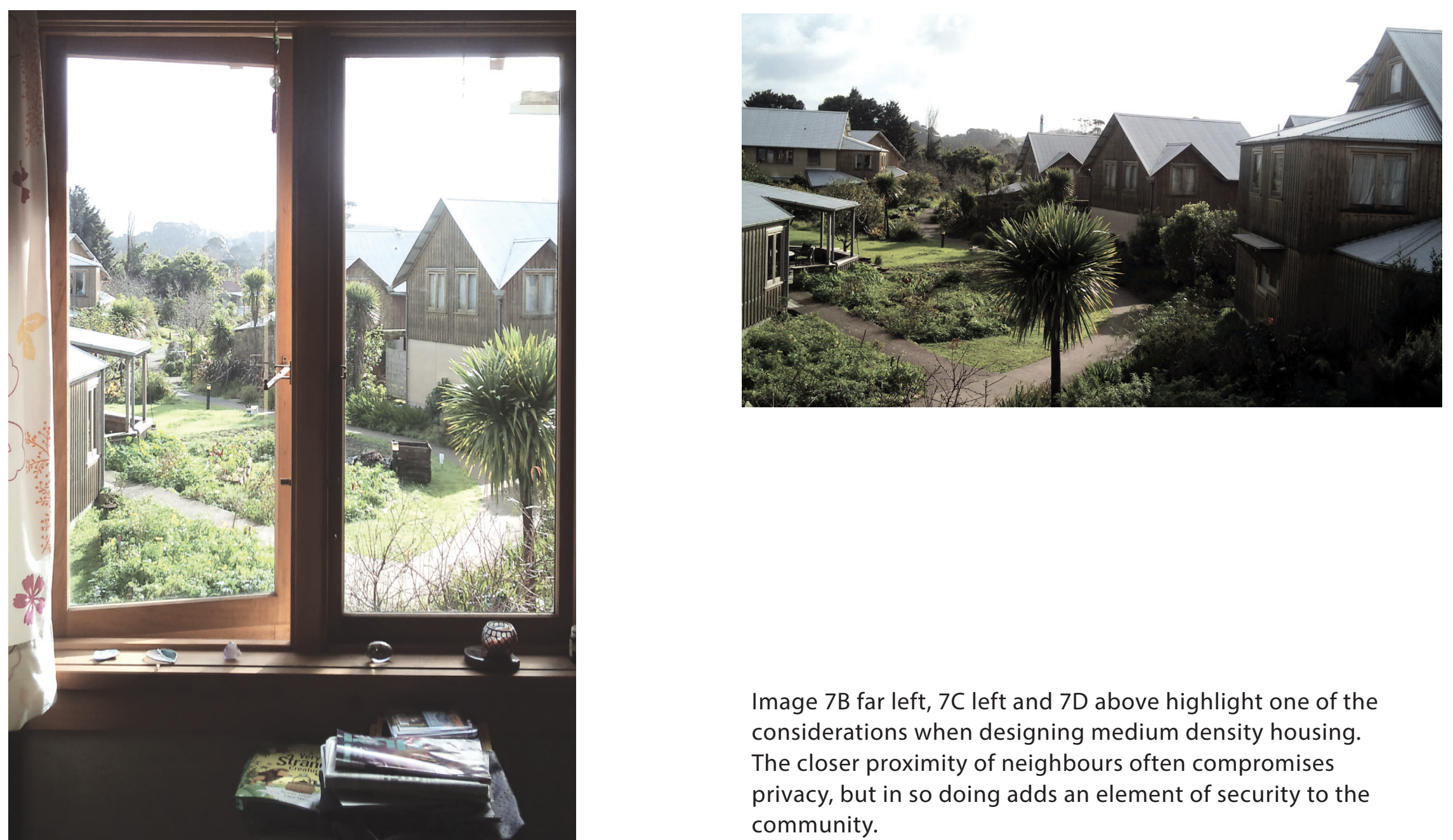

Image 7B far left, 7C left and 7D above highlight one of the considerations when designing medium density housing. The closer proximity of neighbours often compromises privacy, but in so doing adds an element of security to the community. 
Only those who attempt the absurd will achieve the impossible. I think it's in my basement... let me go upstairs and check.

Are you really sure that a floor can't also be a ceiling?

$$
\text { M.C. Escher. June } 1898 \text { - March } 1972
$$




\section{Design Phase 1}

HOUSING IN CONTEXT

ALTERNATIVE SITE GEOMETRY

\section{REFLECTION}

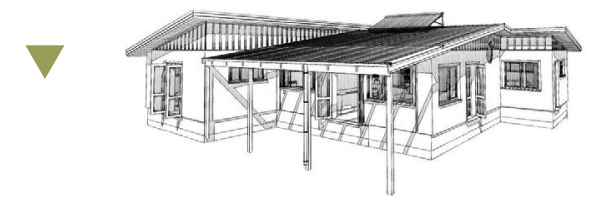

1. Detached Bungalow

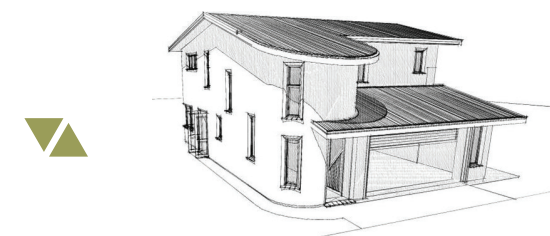

2. Detached Two Storey

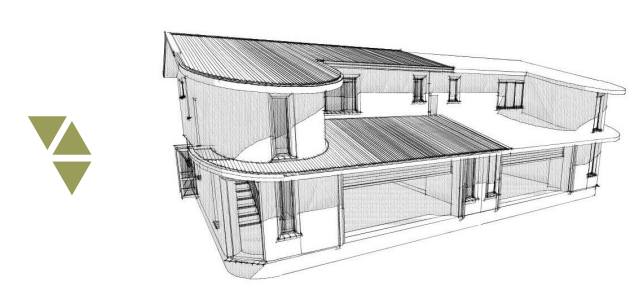

3. Semi Detached Two Storey 


\section{Housing In Context}

Typical three bedroom detached home with suburban set backs and height restrictions could be a conventional build or a natural home build, with any level of sustainability. The disadvantage to this typology regardless of the build style is, due in part to the additional area required for setbacks from roads and boundaries, the increased land costs.

By introducing second storeys, site coverage or 'building footprint' is reduced, enabling a smaller site for the same floor area of home. The additional structure required increases the financial cost per square metre, but allows for a smaller site requirement and consequently an improvement in relation to sustainable responsible land use.

By introducing a party wall on a zero lot boundary, the building cost and land required is reduced, benefitting financially and improving sustainability. No windows directly facing an adjoining home across a narrow site setback, means greater privacy and reduced heating costs, with one less external wall. Unfortunately, this loses direct sunlight, with its benefits to natural lighting and passive heating, whilst also limiting the outlook from the home. Conventional party walls can be expensive with the additional fireproofing and soundproofing necessary to meet code requirements.
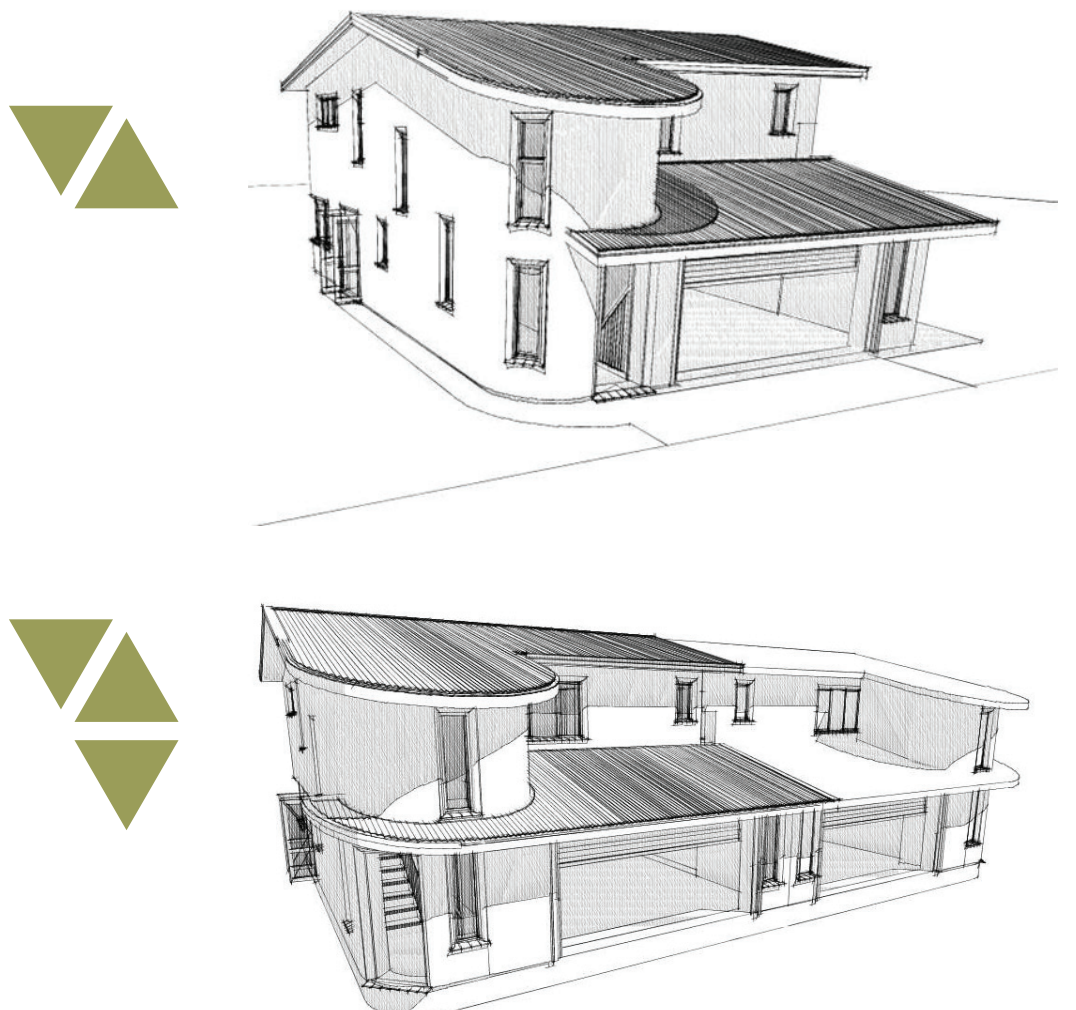


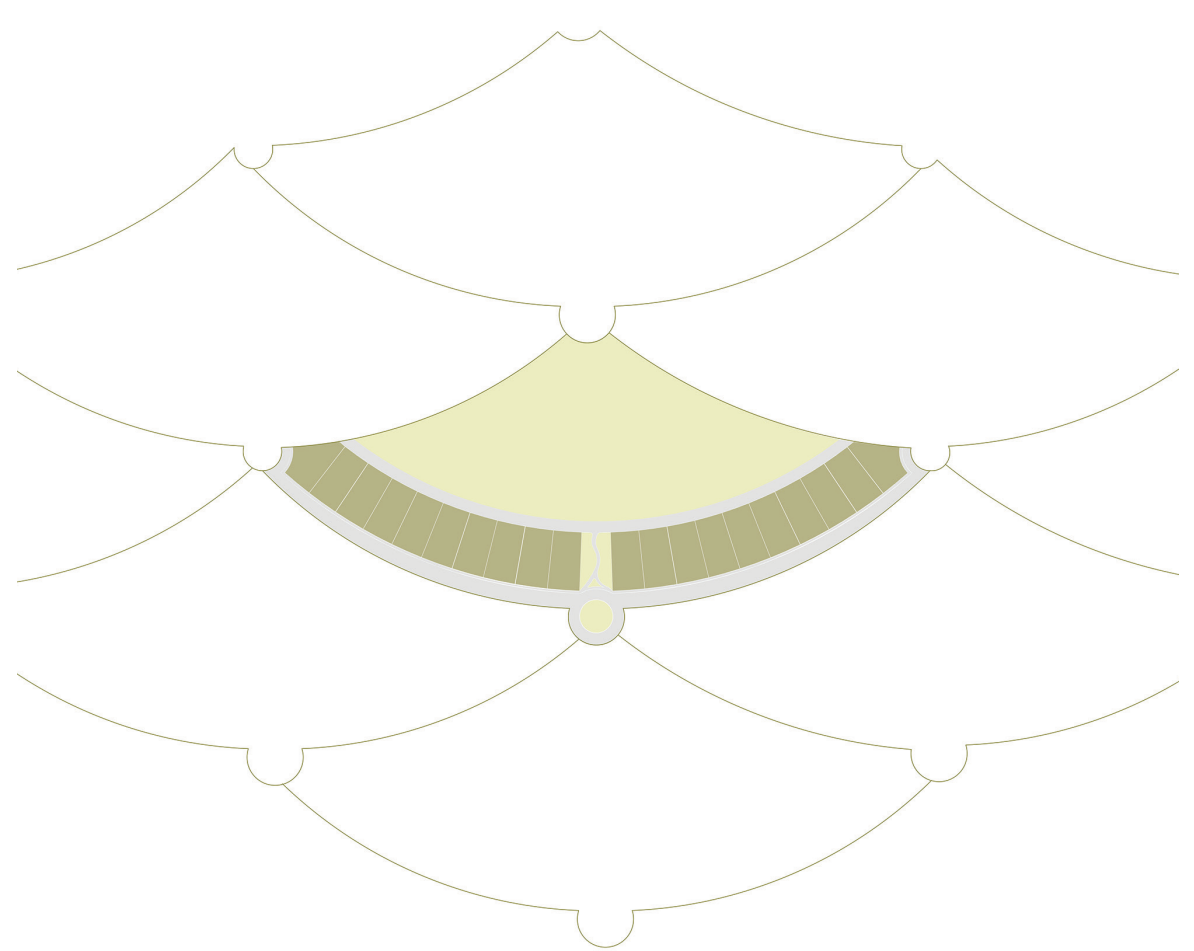

A fish scale tessellation provides excellent outlook and solar access but excessive open spaces and roading, both unsuitable for medium density housing.

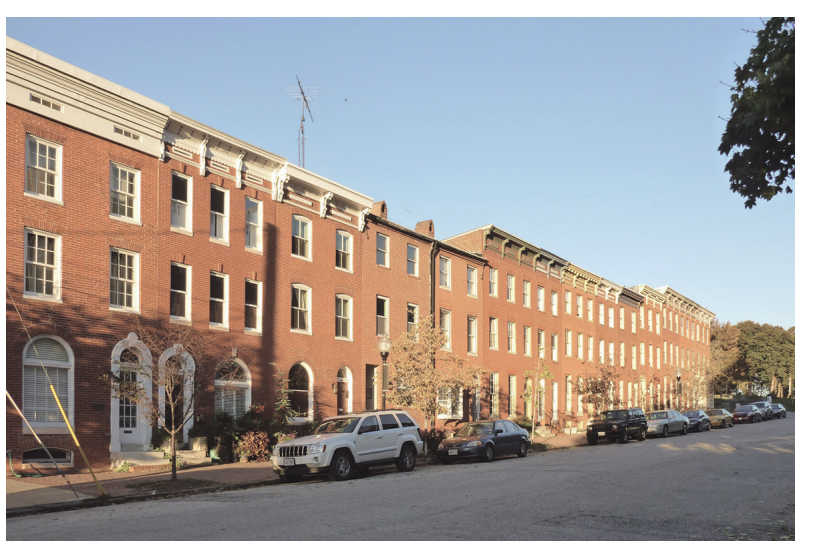

Image 8. Federal Hill Row houses achieve good densities at the expense of daylight and solar access with two sides completely enclosed.

\section{Alternative Site Geometry}

Dutch graphic artist M.C. Escher ${ }^{31}$ attended the Haarlem School of Architecture and Decorative Arts. After briefly studying architecture he switched to decorative arts and in later life became well known for his often geometric and symmetrical tessellated woodcut and lithograph designs. These designs suggested alternative site configurations, as they have no wasted space and the intersection lines between elements represent roads and pathways.

A repetitive 'Escheric' tessellation or fish scale, suggested possibilities as a site configuration by spreading semi detached houses around the bottom arc. A pleasing geometric pattern offered good space, excellent visibility, and a reasonable level of privacy, but fell far short of reducing land coverage unless significant tracts of open land could be developed agriculturally. Scaling down this design could reduce land coverage, but creates new problems for roading and infrastructure which would need to increase dramatically.

Progressing the fish scale design to row housing could further increase density and reduce building costs, through the elimination of another external wall and elimination of side yards. The resulting repetitive façade is often a grand feature of this building style, but with two walls windowless, the quality of interior spaces would be further compromised.

\section{Reflection}

Higher density housing can ease demand on land and needs to be done without reducing amenity value, occupants still need space for outdoor activities and a reasonable level of privacy preferably still with good solar access and outlook. Solutions for safer building materials need to be considered. Site setbacks and building restrictions make it difficult to increase density beyond $26 \mathrm{dph}$ without compromising privacy and limit the usefulness of the land immediately surrounding the house. Design phase two introduces natural materials as a safe affordable alternative for construction. Design phase three researches the hexagon another 'Esheric' tessellation in more depth as a site configuration.

31 Escher, M. C et al. M.C. Escher: His Life and Complete Graphic Work ; with a Fully Illustrated Catalogue. New York: Abradale Press/Harry N. Abrams, 1992. Print. 


\section{In the UK there are an estimated half a million inhabited earth buildings surviving in a range of types of construction and materials'}

\section{Adam Weismann \& Katy Bryce, 2006}

'It is estimated that between a third and a half of the worlds population - approximately three billion people on six contintents live in buildings constructed of earth'

Ronald Rael, 2010 


\section{Research}

\section{PRECEDENTS}

NATURAL MATERIALS

INCOMPATIBILITY ISSUES REFLECTION

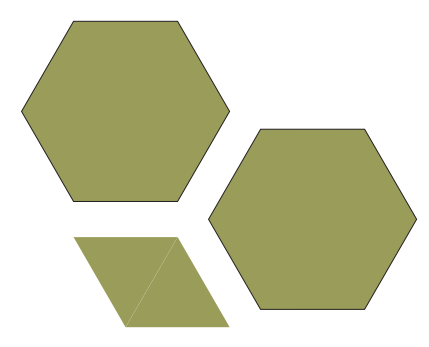

\section{Precedents}

In his book 'Earth Architecture' Ronald Rael quotes:

'It is estimated that between a third and a half of the worlds population - approximately three billion people on six contintents live in buildings constructed of earth' 32

Natural materials were originally used because they were plentiful and locally available, without acknowledgement of the health and sustainability benefits of their use which is now becoming evident. Precedents for natural building go back many thousands of years. In his 1922 book 'Cements, limes, and plasters; their materials, manufacture, and properties' Edwin Eckels notes that:

'there is direct proof that at a very early stage of human progress, say ten thousand or more years ago, both lime mortars and gypsum plasters were put to use in Egypt and elsewhere' ${ }^{33}$

The Pantheon in Rome has survived nearly two thousand years, and until 1436 it had the largest dome structure in the world, and it is certainly the largest dome surviving from antiquity. ${ }^{34}$ The dome is made from 'Roman Concrete' with no steel reinforcing. This type of lime concrete, as described by Vitruvius in his 'Ten Books on Architecture ${ }^{35}$ written around $25 \mathrm{BC}$, incorporated the use of pozzolan, a type of volcanic ash which enabled the material to set, even underwater.

Of the approximately one half million earth homes still in use in the UK many are of cob construction within a timber frame. Cob is a mix of clay, aggregate and fibre. Initially horse or human hair was used as fibre. Straw is now in common use, being more readily available, and its hollow core structure improving the wall's insulation properties. The straw is used for reinforcing and to improve tensile and shear strength.

32 Rael, Ronald. Earth Architecture. New York, N.Y.: Princeton Architectural Press, 2009. Print.

33 Clarence C Eckel. Cements, Limes and Plasters; Their Materials, Manufacture and Properties. second edition. London: Chapman \& Hall Ltd, 1922. Print. This out of print book has been recently re-released as it is still a preeminent volume on limes.

34 Holmes, Stafford. Building with Lime: A Practical Introduction. Rev. ed. London: ITDG, 2002. Print.

35 Vitruvius Pollio. The Ten Books on Architecture. [s.I.]: [Empire Books], 2011. Print. 
Good examples of these long lived homes still exist in abundance and date back as far as 1539. Modern cladding systems costing hundreds of times more, often struggle to last the 15 year minimum let alone the modest 50 year expectation for current residential builds in New Zealand, whereas humble cob (clay, straw, and lime) is historically proven to last many hundreds of years.

Timber, in particular for framing, has been in use for many thousands of years. It is ironic to consider the necessity for modern homes to treat timber with toxic chemicals to prevent decay over time. If ancient methods had been utilised this would not have been necessary as the combination of clay based plasters and lime coatings provide a natural preservative and wicking action which actively draws moisture away from the timber. This sentiment is in accord with Tom Woolley who in his book 'Low Impact Building, Housing Using Renewable Materials' says:

'Many building problems can be solved by using these materials, opening the possibility of significant benefits in terms of less pollution, less energy used, better and healthier buildings.' ${ }^{36}$

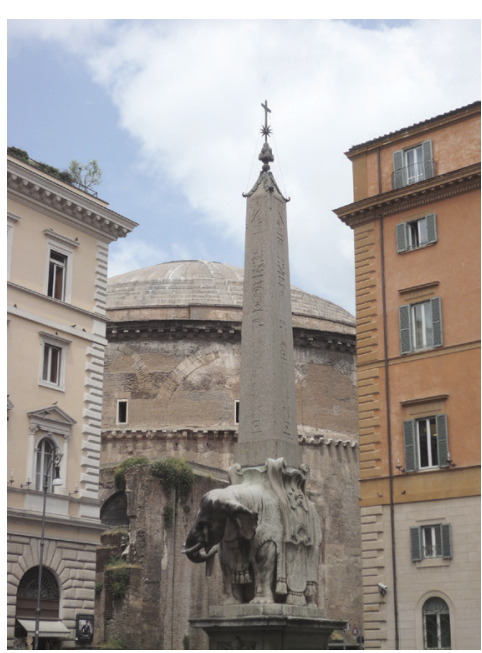

Image 9. Pantheon Chiesa Rome

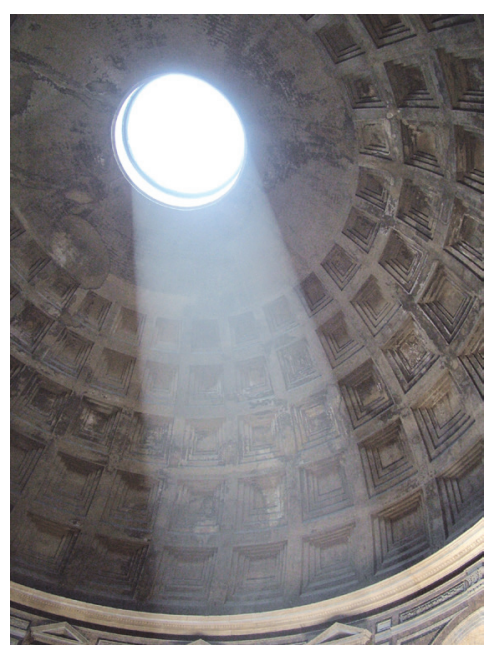

Image 10. The Oculus in the Pantheon. 

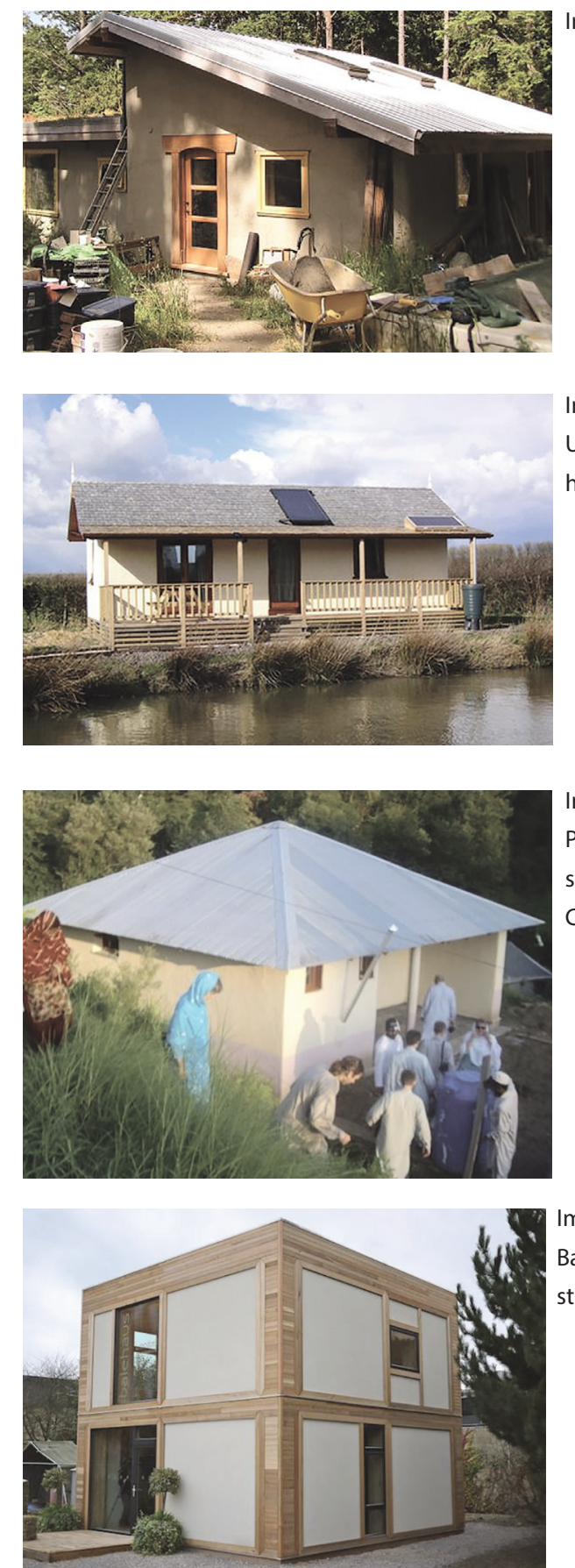

Image 12.

UK's first straw bale

holiday home

Image 13.

PAKSBAB earthquake resistant

straw bale home.

Cost $\$ 2250.00$ for materials.

Image 14.

Balehaus prefabricated

straw bale by Modcell
There is a contemporary renaissance of natural building material as architects and builders revive almost forgotten ideas and skills adapting them to work with todays' technologies.

'Ten Straw Bale Homes' ${ }^{37}$ displays an eclectic assortment of straw bale constructions (left) ranging from home made cob through to the 'balehaus', a contemporary modular construction using a system developed at Bath University, UK, that would be at home on any modern housing estate.

Some of these are depicted here as precedents. 
Part of my research involved travelling to Carbondale Colorado, a town with over 500 straw bale and natural homes and five schools either in part or completely straw bale construction, some of which are illustrated here as key precedents. There is a great diversity in design of these homes as local architects adopt alternative building materials and apply their skills and imaginations.

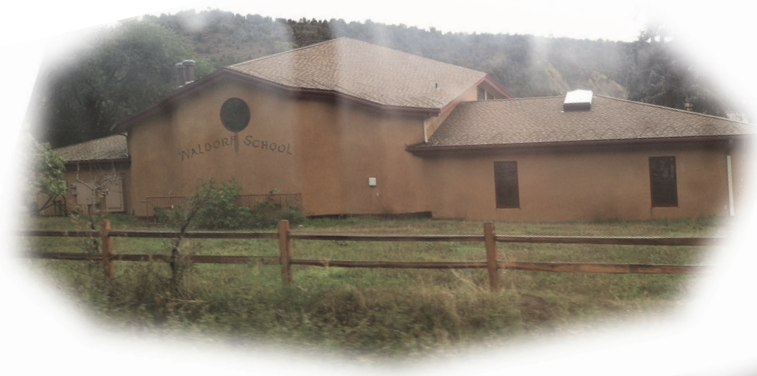

Image 14, 15, 16. Strawbale school, Carbondale, Colorado
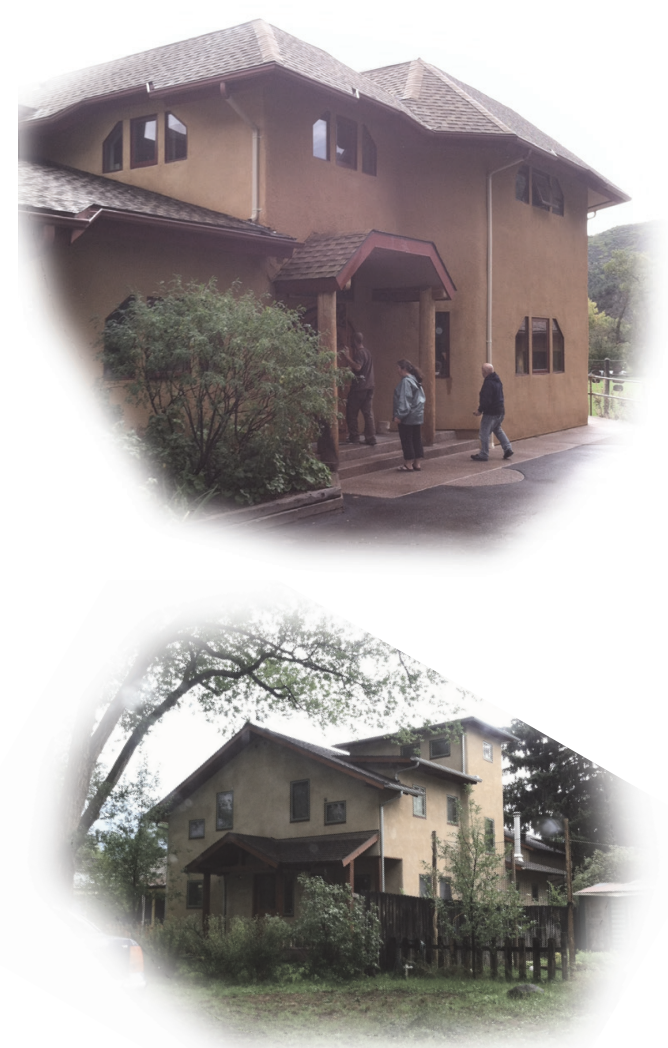

Image 17, 18, 19. Strawbale homes, Carbondale, Colorado
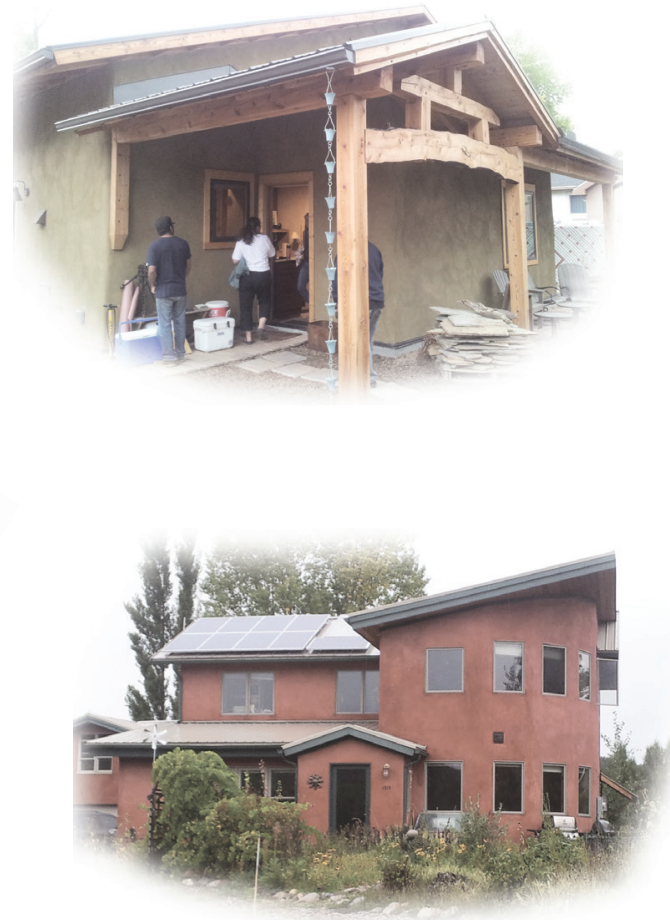

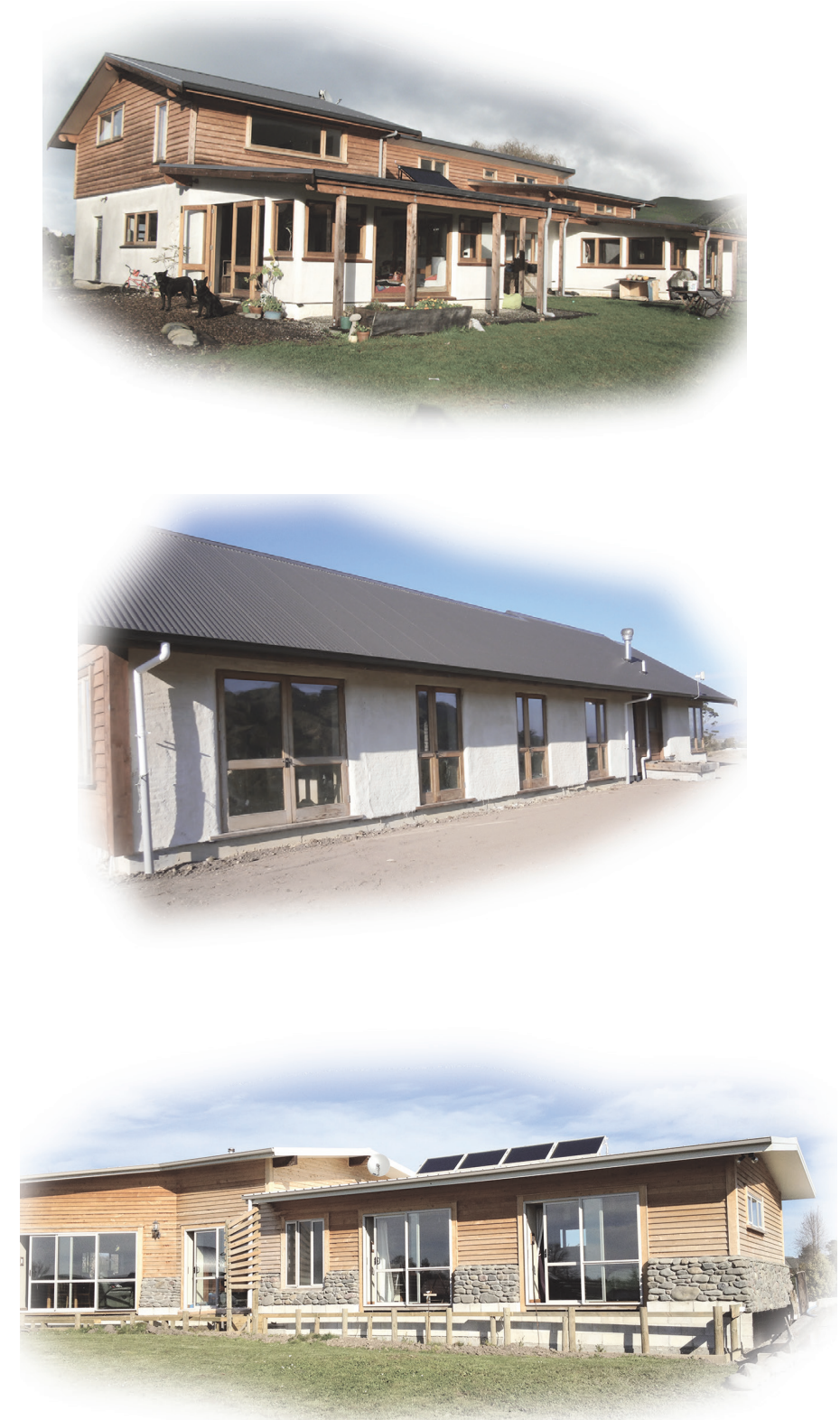

Image 20, 21, 22. Natural Material Homes,

Top, middle. Gisborne, New Zealand.

Bottom. Hawkes Bay, New Zealand.

\section{Natural Materials}

Natural and minimally processed materials are now seeing a resurgence in popularity as architects and builders look to reduce building costs, improve housing quality, improve indoor environments and consequently occupant health, and as a response to growing concerns about the impact the building industry has been having on the environment.

Historically, prior to mass production and efficient global transport networks, locally available natural materials were used in house construction. Natural houses, or buildings made primarily from non-manufactured materials, dominated the landscape for centuries, and had significant advantages. Natural materials are, in the most part, healthier, cheaper, and have little or no negative impact on the environment. Natural materials are generally more easily acquired for the initial build and for future repairs.

In an era when we have access to durable, reasonably priced, preformatted building materials why should natural building materials be considered? The predesign materials chapter indicated that many recently developed materials, over the last 50 years, pose real and potential dangers to building occupants. In addition, manufacturing and transporting these products has a significant impact on our environment, depleting finite resources, contributing to global climate change, and poisoning our air, water and earth.

Natural buildings are a sub set of green homes which come in many forms, having one thing in common, 'they provide shelter at a fraction of the environmental impact, and often at a fraction of the cost, of conventional housing. ${ }^{38}$ Daniel Chiras in 'The New Ecological Home' supports the hypothesis that natural materials and modern technology can be combined beneficially:

'...homes that meet human needs without depleting the planet's resources, polluting the environment, poisoning their occupants, and driving innocent species to extinction. Relying on new building principles, practices and technologies,... seeking to create shelter while protecting the life support systems of the planet that sustain people and economies' 38

38 Chiras, Daniel D. The new ecological home : a complete guide to green building options. White River Junction, Vt:: Chelsea Green Pub. Co., 2004. Print. 
Historically, buildings were made from materials close to hand, as transport was costly and time consuming. Some materials, stone in particular, may not always be readily available. Clay, timber, straw, sand and lime are inexpensive and readily available world wide, usually within reasonable access of any site.

As individual elements each has its own strengths and weaknesses but when combined they provide a superior wall and floor system of natural materials.

Clay is the most prolific of materials and forms the basis of most natural building protective plasters used for walls and floors. The Natural Plaster Book summarises earthen or clay plasters as:

'protection from wind rain and fire, unrivalled beauty to a home, fun to work with, safe to work with, easy to clean up, recyclable, repairable, permit artistic expression, softer quieter finish, many environmental benefits, inexpensive, protection from moisture, resistant to water penetration, and permeable (breathable), ${ }^{39}$

Clay will form the base for the cladding and floor, and the finishing work for the interior walls and floors. Clay weathers badly, eroding away if left unprotected. Clay draws moisture away from surrounding building elements, protecting them from moisture damage.

Lime is readily available worldwide, and is flexible, breathable, recyclable, biodegradeable, ${ }^{40}$ and sequesters carbon. ${ }^{41}$ It is summarised in 'Using Natural Finishes' as:

...brings benefits in the areas of decreased impact on the environment (their production, toxicity and ease of disposal), improved internal air quality, and by improving the look and general 'feel' of the building and spaces inside.' ${ }^{42}$

39 Guelberth, Cedar Rose. The Natural Plaster Book: Earth, Lime and Gypsum Plasters for Natural Homes. Gabriola, B.C: New Society Publishers, 2003. Print.

40 'Facts About Lime Plaster, the Benefits of It's Use and the History of Lime.' Albarius Heritage Limited. n.d. Web. 3 Sept. 2013

41 'Why Use Lime?' Traditional Lime Company. n.d. Web. 3 Sept. 2013

42 Weismann, Adam, and Katy Bryce. Using Natural Finishes: Lime- \& Earth-based Plasters, Renders \& Paints : a Step-by-step Guide. Totnes: Green, 2008. Print.

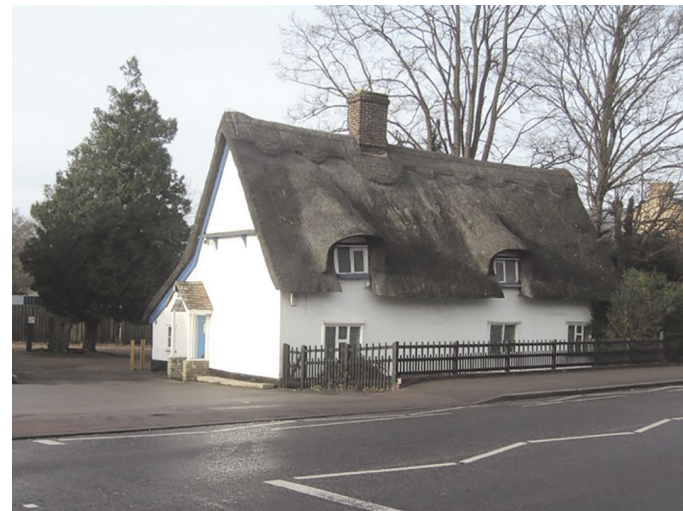

Image 23. A thatched cottage, probably one of the most natural of homes.

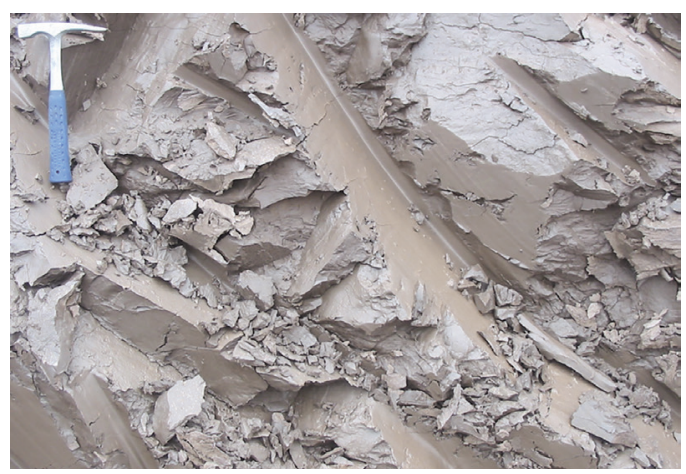

Image 24. Clay, an essential building material has been in use for thousands of years.

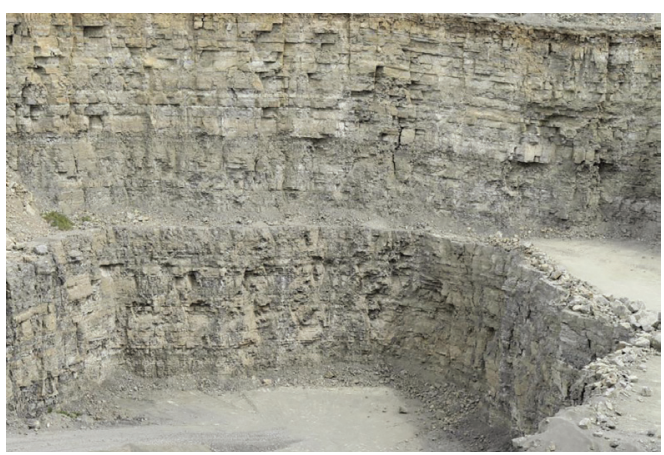

Image 25. Limestone once crushed forms the base for many natural building materials and if further processed is the main component in cement. 


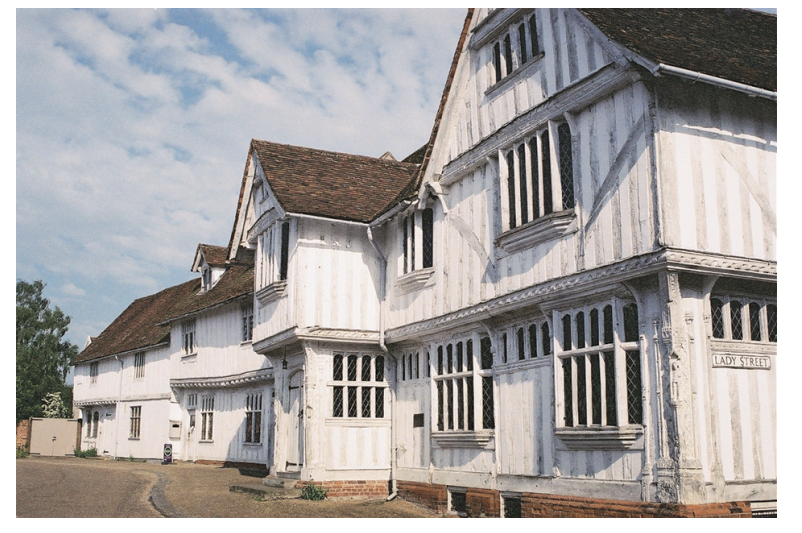

Image 26. Lavenham Guildhall is treated with limewash and is still in use 500 years on.

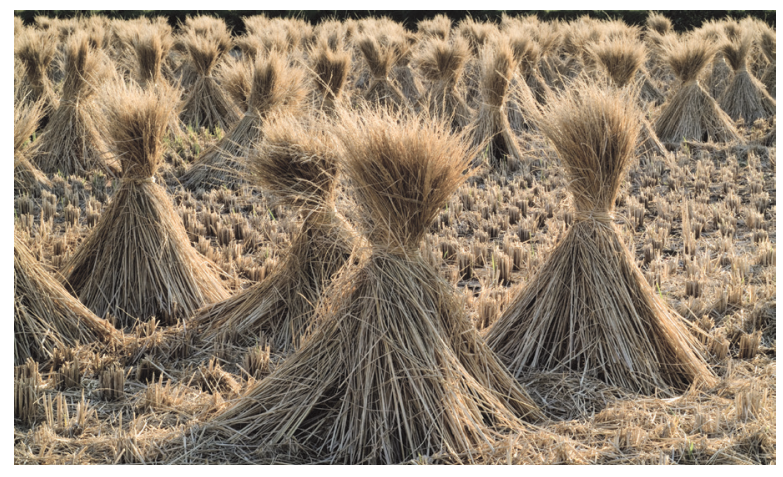

Image 27. Straw is an abundant and rapidly renewable natura material with many benefits including carbon sequestration.

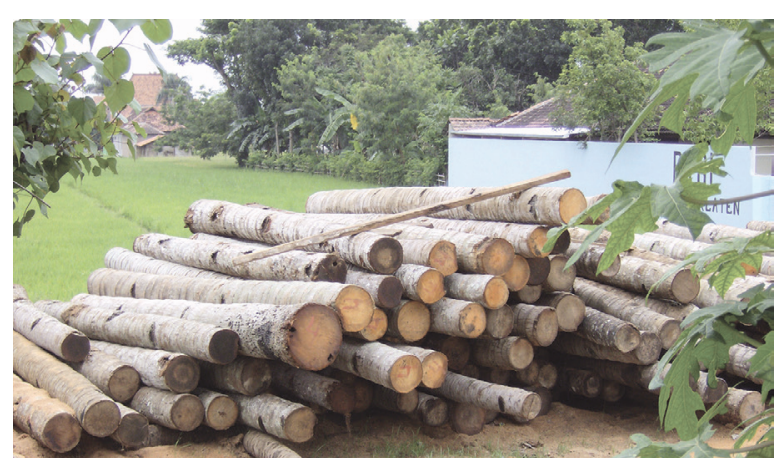

Image 28. Timber takes longer to regrow than straw but is still an excellent renewable, sustainable resource.
Lime as a building material, has been neglected since the introduction of cement based products. We do not know what knowledge may be lost as books such as 'Limestone \& Its Products' ${ }^{\prime 3}$ by Alfred Searle disappear from alibraries due to the misunderstanding that their content is obsolete in our modern world. This underated volume provided a key reference for this thesis.

Lime as a preservative has been in use for many centuries. Lavenham Guildhall in Sudbury England stands as proof with its exposed timbers coated once every five years with limewash. Built in 1529, nearly 500 years later it is still a sound structure in everyday use.

In 1899 an article in 'The Sydney Mail' points out:

'Lime has long been recognised as a preservative for timber. Ships which have carried cargoes of lime during their "lives" on the waters have remained seaworthy after 100 years of voyaging, and when this agent has been used for bridge timber it has proved about the best of preservatives; cheap enough to allow general application' ${ }^{44}$

Lime will be used wherever resilient erosion and weather resistant surfaces are required, and forms the basis for 'tadelakt', an interior/exterior waterproof finish, with antifungal and antibacterial properties, suitable for use in wet areas. Tadelakt is an ancient process recently rediscovered andwill be discussed in greater depth in chapter 6 'Research'.

Straw is recognised as the ultimate carbon sink in Andrew Alcorn and Michael Donn's Victoria University Paper titled 'Life Cycle Potential of Strawbale and Timber for Carbon Sequestration in House Construction', where they concluded:

'Strawbale and timber therefore represent a major opportunity to reduce annual CO2-e emissions from housing construction and operation. Their use should be considered, as sustainable materials, at the forefront of attempts to reduce construction and maintenance CO2-e emissions, and at least on a par with strategies to reduce operating emissions. By using strawbale and timber

43 Alfred B. Searle. Limestone \& Its Products Their Nature, Production, and Uses. London: Ernest Benn Ltd, 1935. Print. 44 Lana. 'Lime as a Timber Preservative'. The Sydney Mail 1899: n. pag. Print. 
to sequester $\mathrm{CO}_{2}$, in combination with technologies to reduce the use of grid energy, houses can be made to be net absorbers of $\mathrm{CO} 2$, achieving an essential feature of sustainability.' ${ }^{45}$

In 'Building with Straw Bales', Barbara Jones summarises some of the benefits of straw bale construction as:

'sustainable, energy efficient, highly insulating, acoustically insulating, low fire risk, affordable, structurally sound, healthy living environment, empowering and fun.' ${ }^{46}$

Straw will be used in bale configuration as the fundamental modular eco building blocks, and offcuts and loose straw will be added to clay plasters as reinforcement in this project.

There is a great deal of misunderstanding around timber and its preservative treatments, especially as part of the 'leaky home situation'. A knee jerk reaction has seen calls to legislate for higher levels of treatment in buildings than ever before. Rotten untreated timber was a result of, not the cause of leaky homes. By suitably cladding buildings, such as using breathable natural materials, there is no need to risk exposure to toxic chemicals through the use of treated timbers, as the breathable plaster system will contribute to the preservation of the timber framing.

Douglas fir will be the preferred framing material exhibiting excellent moisture repelling propertiesbdue to its molecular structure.

New Zealand Macrocarpa is also underrated and is known to have been used untreated as a direct substite for H3.1 pine in the past.

45 Donn, Michael. 'Life Cycle Potential of Strawbale and Timber for Carbon Sequestration in House Construction.' Academia. edu. n.d. Web. 3 Sept. 2013

46 Jones, Barbara. Building with Straw Bales: a Practical Guide for the UK and Ireland. Totnes: Green Books, 2009. Print

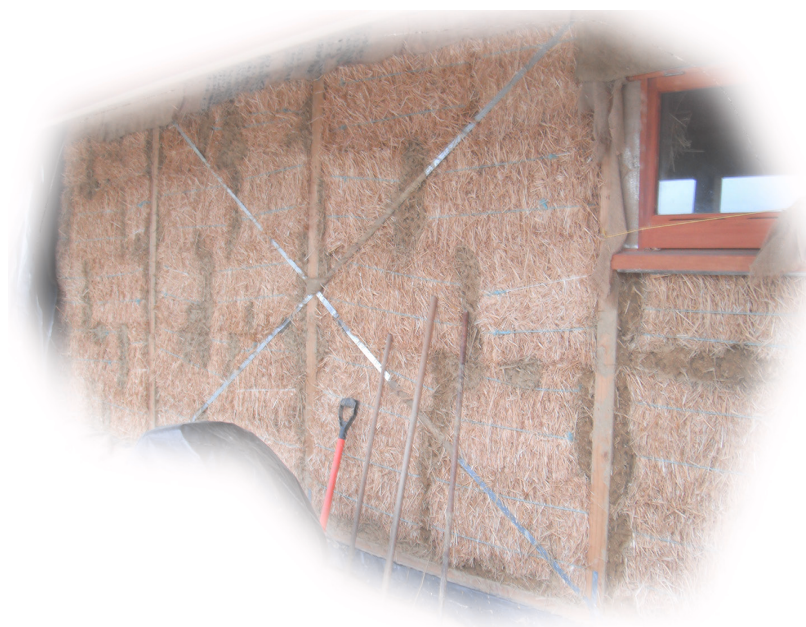

Image 29. Strawbale, timber and clay provide structure, insulation, and substrate for a new wall. This wall is ready for its initial clay slip coat. Note metal bracing will be covered in netting and clay prior to plastering.

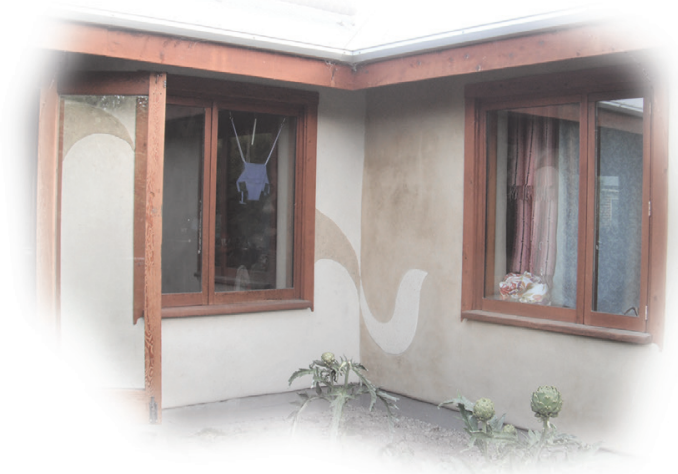

Image 30. Oxides can be used to colour wall surfaces, or as in this example the plaster itself has been coloured and varied for a decorative finish. 


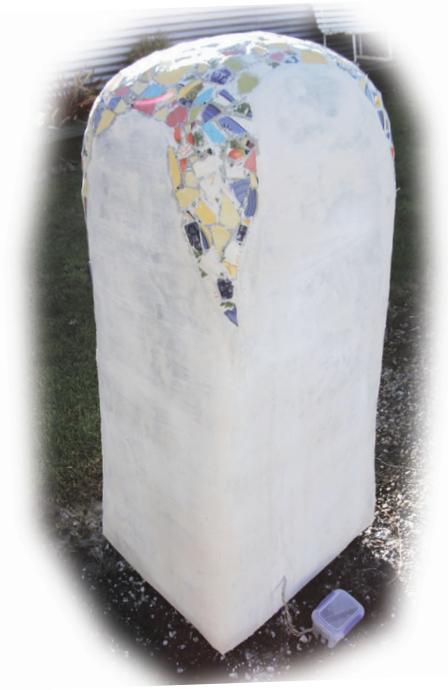

Image 31. Test bale with its first coat of lime paint, has been tested regularly for moisture migration through seven sensors that were fitted prior to plastering.

(below) 3D cutaway computer model of a typical composite straw bale wall. Timber wall elements and top box beam form the main structure and support for the roof and around windows and doors. Flat steel strapping is an effective bracing option.

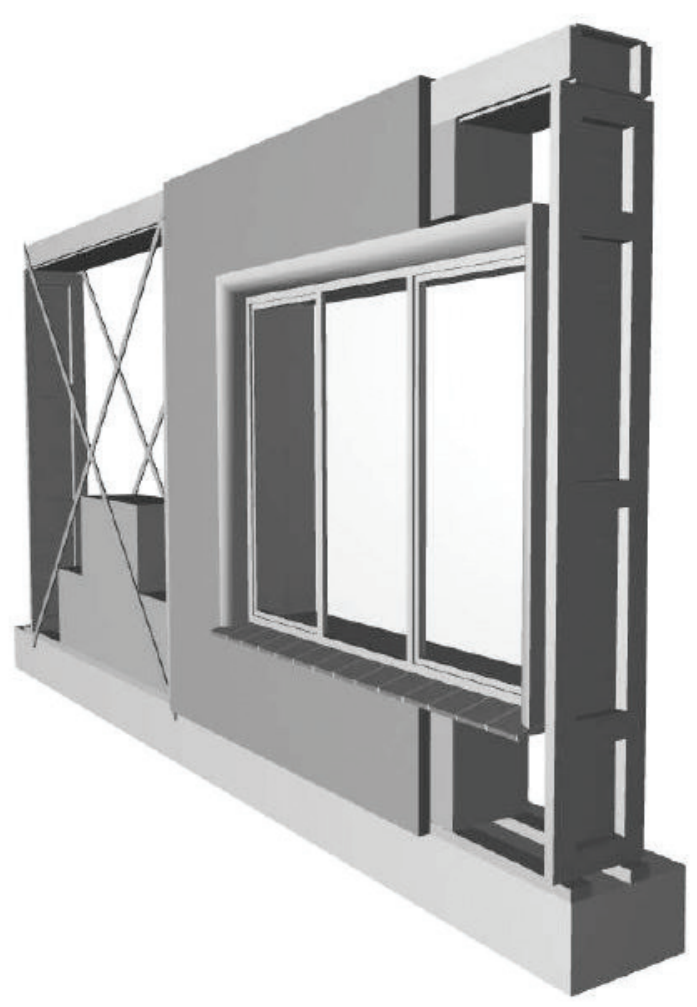

\section{Synergy In Combination}

In combination lime, clay, straw and timber are highly suited for construction. This composite system works synergistically, creating a highly resilient, moisture regulating, water proof, mould inhibiting, non combustible, superior acoustic and thermal permeable wall that has been proven over many centuries of use, as discussed earlier in chapter 4 Precedents.

In a previous study ${ }^{47}$ a single bale was finished using the aforementioned combination with seven moisture sensors fitted. The research was conducted on New Zealand's west coast, in salt laden sea air, with regular high winds and driving rain. The sensors were monitored daily for the first three months. Two years later the readings indicate the wall to be in excellent health despite being hit by a car, then being unceremoniously relocated. The resultant cracks and dents have not been repaired and it has never had the obligatory 'big hat' or wide eave roof often considered essential to straw bale walls. The tiled top is considered unsuitable for most applications and yet despite these encumbrances this local research confirms this systems suitability in New Zealand.

The composition of the proposed ecohouse wall begins with a timber frame which can be within the wall or exposed on either side of it. However in the case of exterior framing, the timber will need to be more resilient, as it is exposed to weathering and insect damage and therefore should be a hardwood. Typically the frame is imbedded into the wall itself and due to the properties of the surrounding clay and lime plaster it need not be treated with preservative or insecticide, as each of the coverings adds preservative properties to the wood. The clay acts as a wicking agent drawing moisture away from the timber. The lime plaster has several benefits providing a barrier through which insects do not penetrate, it allows moisture to migrate effectively

47 Jaycock, S. Moisture Retention and Migration Monitoring Within Straw Bale Walls. Wellington, NZ:: Victoria University, 2012. Print. 
self regulating the internal wall moisture levels. Also it provides a limestone surface which when tested using the New Zealand Earth Building Standards erosion test shows NO visible deterioration, and the alkaline properties act as a preservative to the wood, straw and fibres it encases.

When straw is left exposed it decomposes rapidly and is not suitable to use unprotected. Once it is encased in an earth and lime plaster render it becomes the most durable of wall infills. In the composite wall's structure, straw forms the shape of the wall whilst also providing extremely high acoustic and thermal insulation and is rated noncombustible (fireproof), adequately satisfying the Australian Standard (AS 3959) for building in bushfire prone areas. In some cases it is practical to construct a load bearing strawbale wall whereby most of the timber framing becomes obsolete. By encasing straw in clay and lime a beneficial synergy occurs, the bale providing support for the plaster render, whilst the clay and lime render protect the bale. The clay draws moisture away from the straw allowing it to evaporate through the lime render. The lime not only 'breathes away' the moisture, acting as a self regulating membrane, it also provides a sturdy protection for the clay, which would otherwise erode due to wind and rain. The lime is constantly setting, reverting to limestone over time, meaning its ability to resist erosion improves with age provided it is maintained.

The benefits of this composition go beyond its self preserving ability. Although it is built to last it will decompose if broken down, reverting with a minimum of fuss to its basic compostable elements. This sustainable and recyclable low impact system also provides a healthy environment for humans. The walls 'breathe', and although it is not massive volume changes of air, it does mean that the air within the building gets filtered, and doesn't get stale when closed up. The lime also acts as a fungicide, preventing mold growth, one of the major problems in current housing, particularly low cost housing.

\section{Incompatibility Issues}

Early contemporary straw bale construction often consisted of baled walls with cement based surface renders and internal structural steel elements. As with manufactured materials mentioned in chapter two it was only over time that the problems associated with moisture have become apparent. Care must be taken if it is necessary to use these materials in combination.

Cement based renders were adopted for use on strawbale structures in the 1930's and many of these homes remain problem free, although just as many have encountered problems. Cement renders on straw bale walls are waterproof whilst in good condition, preventing any moisture migration. Provided the bales were dry when fitted, and provided they stay dry, this is a satisfactory design decision. However if the bales are wet, which problematically they become when applying the render, or as water enters cracks which inevitably appear as cement based products are prone to cracking, the problem of wet and rotting bales occurs. This problem is of particular concern in New Zealand where the high instance of earthquakes makes cracking of inflexible renders over flexible bales inevitable.

Steel strapping has been found to work for bracing purposes, provided it is wrapped in fabric and imbedded in the base plaster coat. Solid steel elements within the bale wall, such as reinforcing and beams, become a dew point where the temperature differential between the cold mass and the insulative bale creates ideal conditions for condensation to form, allowing mold formation and eventually rotting of bales. 


\section{Reflection}

Prior to the rediscovery of natural material composite walls, using cement based renders and acrylic paints were unfortunately a popular finish for straw bale construction. Time has once again shown that although the idea of a hermetically sealed wall seemed good at the time, now it is understood to be detrimental to the straw and timber interior wall elements:

'Cement and acrylic based plasters should not be used on straw bale buildings because of their low vapour permeance.' 48

Walls of clay, lime and straw composite are a natural building solution highly suited to straw bale construction, and meet the criteria of this thesis. Being water permeable and having a coarse surface finish they are not suitable for wet areas like bathroom and shower walls. In chapter 6 (research) Tadelakt, an ancient Morrocan plaster technique is introduced as a sustainable environmentally healthy solution for wet areas. 
'Our skin is vital to our health and comfort. Our body temperature, moisture, and bioelectrical balance are maintained owing to its capacity to "breathe". Our second skin - our clothes - must also be able to breathe, as must our third skin - our homes - if they are to provide a healthy indoor environment for us all.'

David Pearson 


\section{Design Phase 2}

PARKING

COURTYARDS

HEXAGON IMPLIED

\section{REFLECTION}

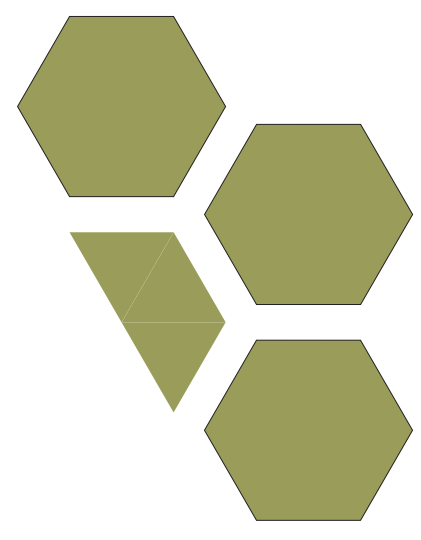

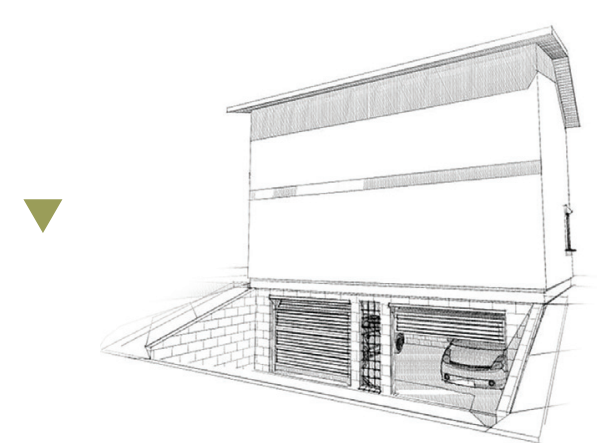

1. Subterranean garaging

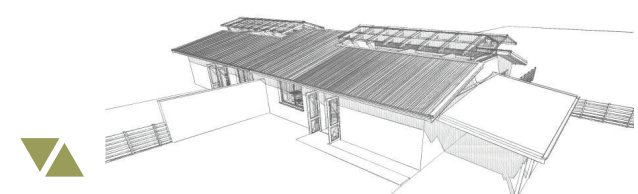

2. Semi Detached Enclosed Courtyard

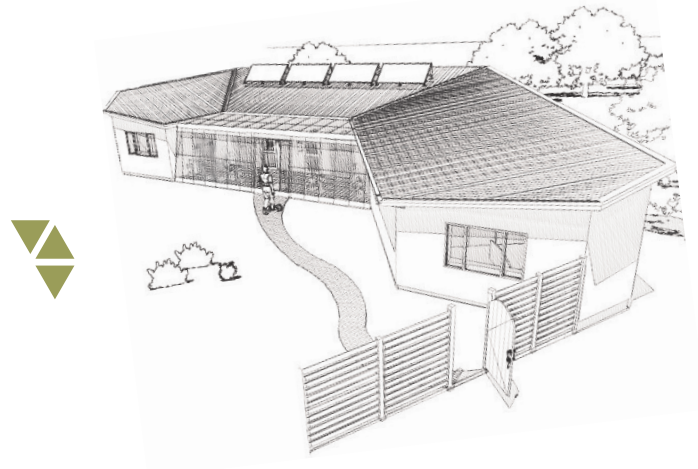

3. First Hexagon Semi Enclosed Courtyard 


\section{Parking}

Individual subterranian or partially underground storage and parking could be utilised to reduce the site area covered by housing. However this is a 'false economy', as the resultant garage access requires more paved surface than an attached or freestanding garage or carport.

Underground parking is better suited to larger developments and could be carried forward into a multistorey design at a later date but will not feature in this thesis final design.

\section{Courtyards}

Covered courtyards provide private semi outdoor spaces with good light and solar access, but the surrounding walls limit sunlight for much of the day, especially in winter.

Opening the north of the courtyard, with sufficient open space in front of the building, allows good solar access for most of the day and if oriented correctly in relation to other houses can maintain a high level of privacy. Swinging the 'wings' of the house outwards opens the design up for greater light and solar access, and suggested the hexagon as a potential site configuration.
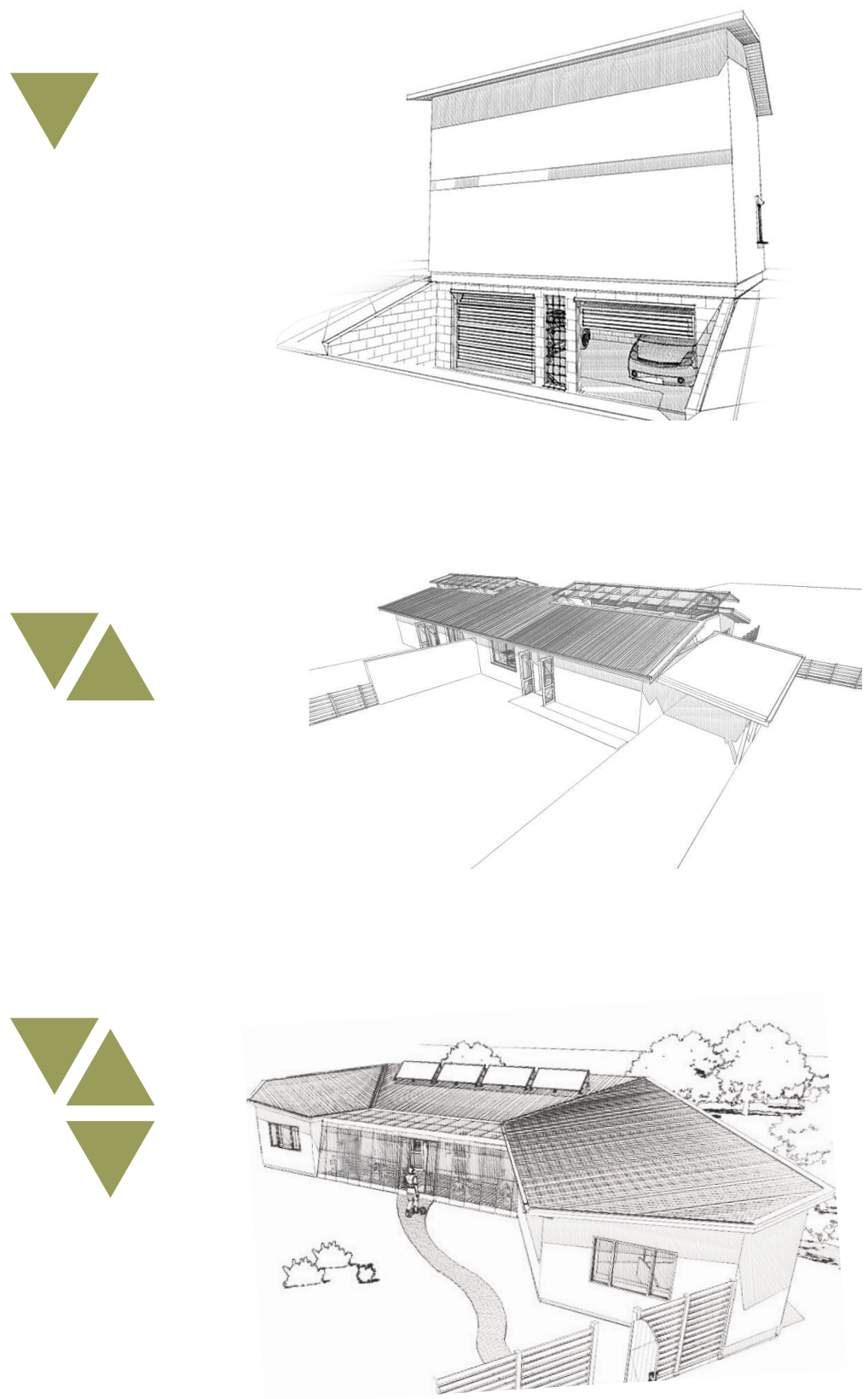

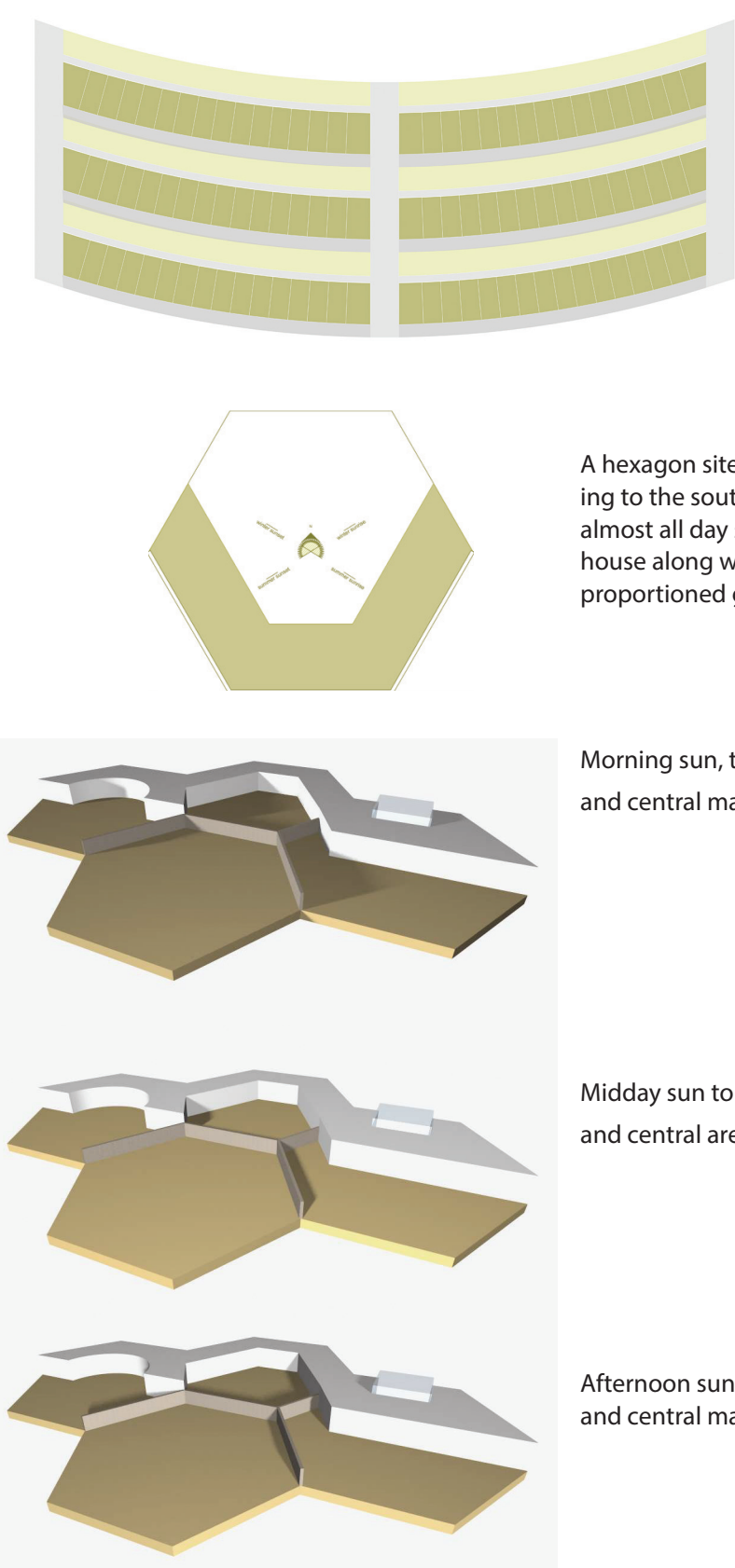

Modifying the fish scale with a row house concept does not increase density and still required significant roading for individual access. The monotonous regularity does little to the desirability of this format.

By designing the house along 'boomerang' or winged styles and fitting to a hexagonal site geometry, new housing typography is developed. By building to the southern side of the site the sun remains on the north face of the house all day, and on the front of the west and east wings for most of the day.
Morning sun, to west wing and central mass of house.

Midday sun to east, west, and central area of house.

Afternoon sun to east wing and central mass of house.

\section{Reflection}

Subterranean garaging will not be incorporated in this thesis design but will be considered at a future time, as it is better suited for high density and multistorey use.

Hexagonal sites show potential for increased density eco housing and are researched next in the following chapter six (research).

Traditional courtyards require larger land allocations than other typologies. An open north side or glass sided north courtyard or sunroom offers many of the benefits without increasing land requirements. This aspect will be developed in chapter seven (design phase three). 

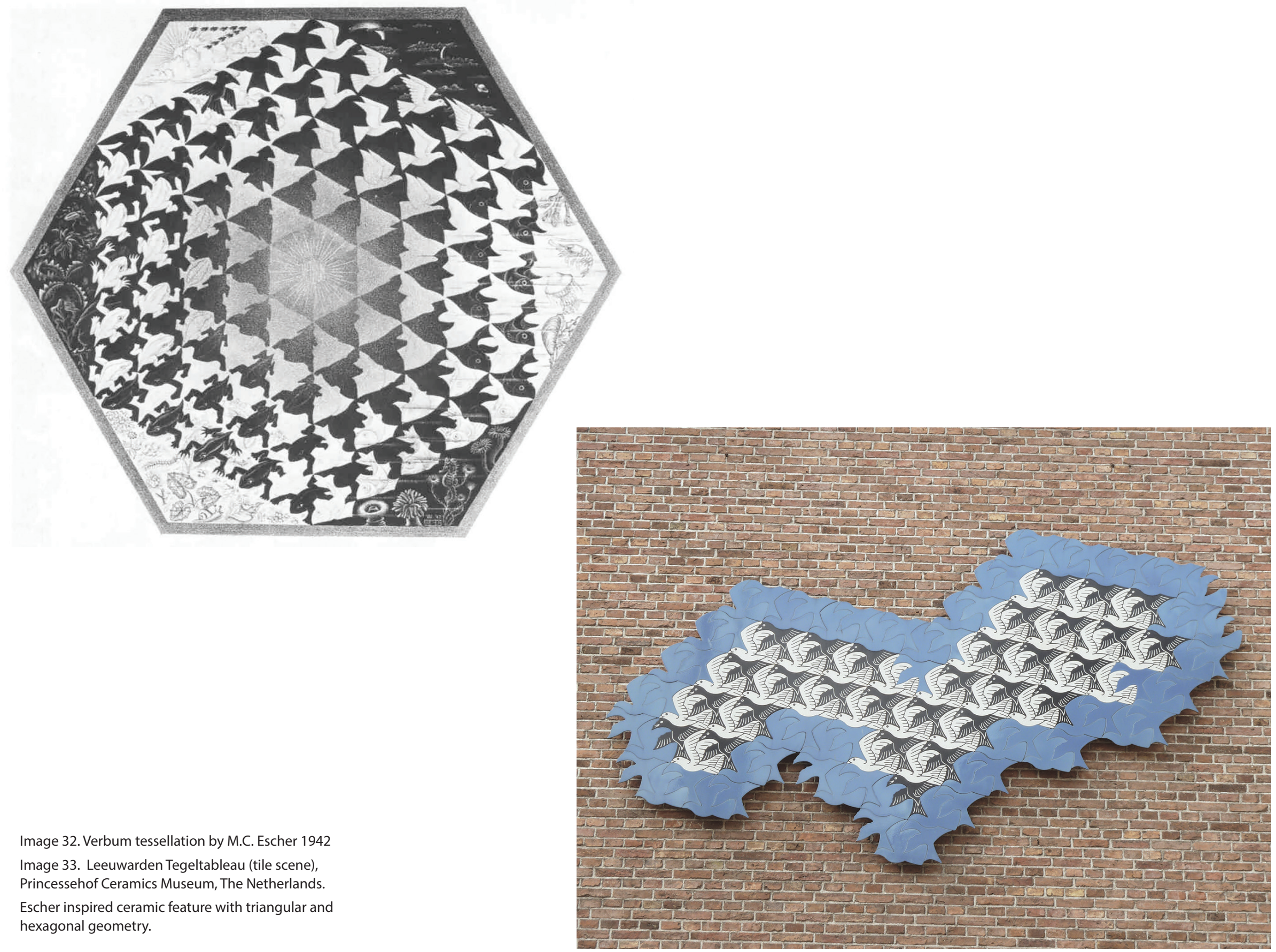
Image 33, Leeuwarden Tegeltableau (tile scene),

Princessehof Ceramics Museum, The Netherlands.

Escher inspired ceramic feature with triangular and hexagonal geometry. 


\section{Research}

\section{HEXAGON}

\section{TADELAKT}

\section{REFLECTION}

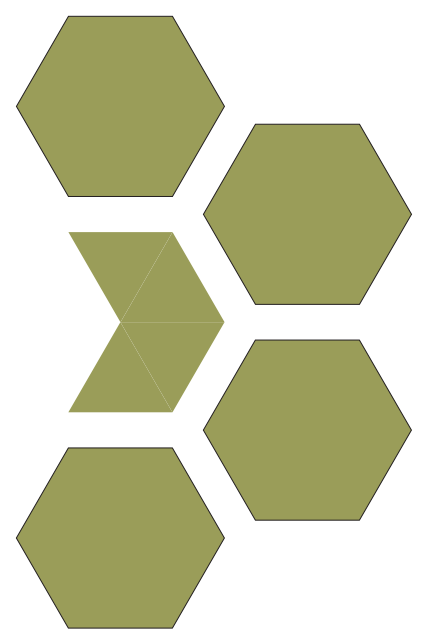

\section{The Hexagon}

Scientists have recently discovered hexagonal geometry in the molecular configuration of graphene. Graphene is referred to as a 'two dimensional miracle material', hexagonal in shape, at a molecular level. Graphene is expected to take humanity into a new and exciting material age, with speculation that this carbon based material is the basic building block of earth and all that is on it, and will soon be readily available in many forms. This vitually infinite resource is 200 times stronger than steel, and transparent. ${ }^{49}$ The opportunities for this material in architecture will be truly exciting.

In 'Utopia or Oblivion' ${ }^{50}$ and elsewhere in his writings, Buckminster Fuller presents the hexagon as part of his research into geodesic dome structures and discusses the efficiency of this geometric shape:

'Constructed of a complex framework of self-bracing triangles, the geodesic dome is the strongest and most economical structure ever designed. No other form of enclosure covers so much area without internal supports. The larger it is, the stronger it becomes. Geodesic domes have proven durable in hurricanes that have flattened traditional homes.' ${ }^{51}$ 
One development of the geodesic dome, the monolithic dome is sometimes referred to as an 'EcoShell'52, an economical structure resistant to wind, storm, earthquake, fire, rot or insect damage. The unfamiliar interior shape and structural complexity are probably why dome houses have not become mainstream, despite their superior strength and potential cost savings. Modern CAD design and CNC manufacturing methods may justify revisiting this building typology as the design and construction methods have now caught up with Buckminster's futuristic endeavours.

As a chronological review of hexagonal planning schemes, 'Hexagonal Planning in Theory and Practice', published in 'The Journal of Urban Design' reveals why the hexagon as a town plan is not in use today, and is a key reference for this part of this research. In the opening paragraph Ben-Joseph and Gordon state that:

'Residential neighbourhood designs with street patterns based upon hexagonal blocks were proposed by several planners in the early 20th century. Urban designers such as Charles Lamb, Noulan Cauchon and Barry Parker demonstrated the economic advantages and efficient land use generated by hexagonal plans. By 1930, hexagonal planning was a leading theoretical alternative to the rectangular grid for residential subdivisions but it was displaced by the loop and cul-de-sac model developed in Radburn, New Jersey, by Clarence Stein and Henry Wright...'and goes on to say... 'The incorporation of the cul-de-sacs and loops design as the alternative to gridirons in federal regulatory documents in the 1930s eventually ensured that the US private building industry adopted this design concept.' 53

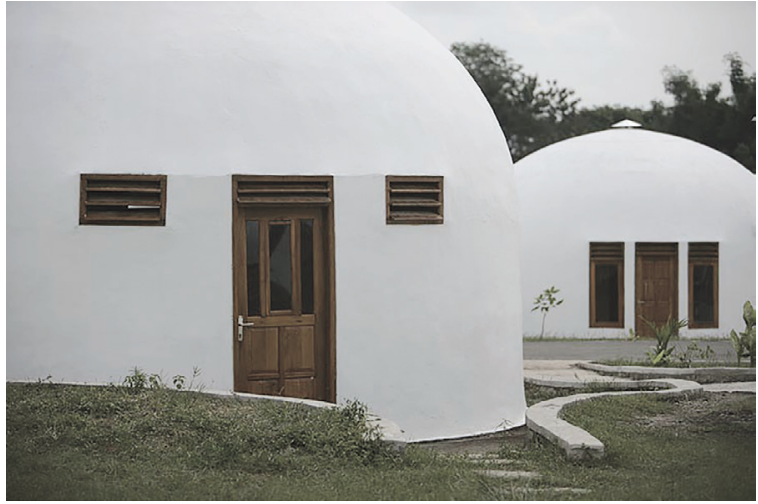

Image 34 .

Ecoshells are highly resilient structures based on geodesic geometry.

52 Craven, Jackie. 'Monolithic Dome Homes'. N.p., n.d. Web. 19 Oct. 2014

53 Ben-Joseph, Eran, and Gordon, David. 'Hexagonal Planning in Theory and Practice'. Journal of Urban Design 5.3 (2000): 29. Print.

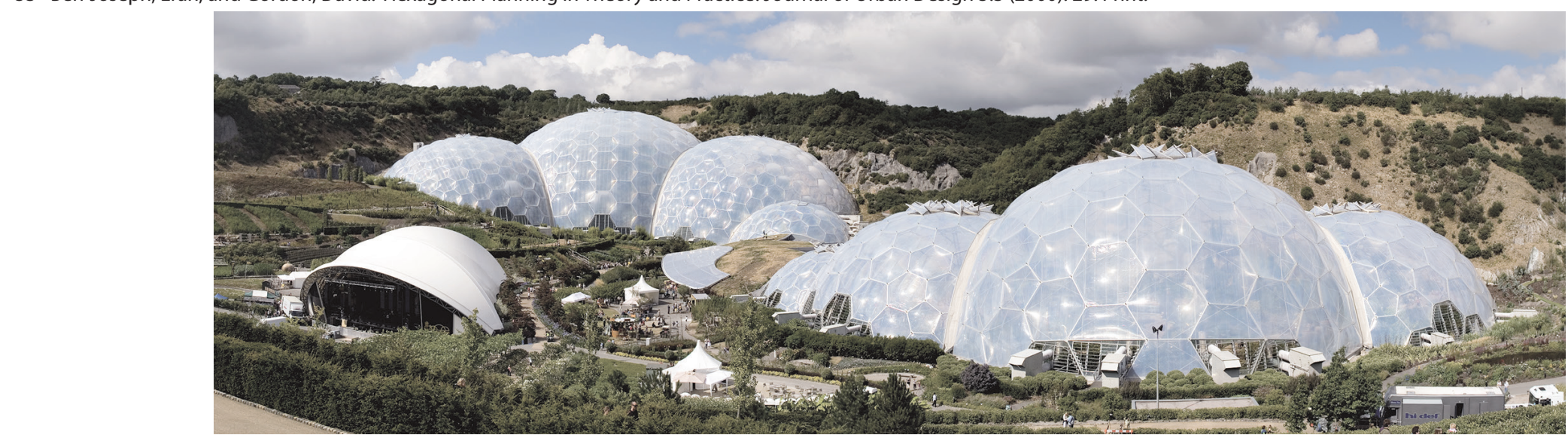




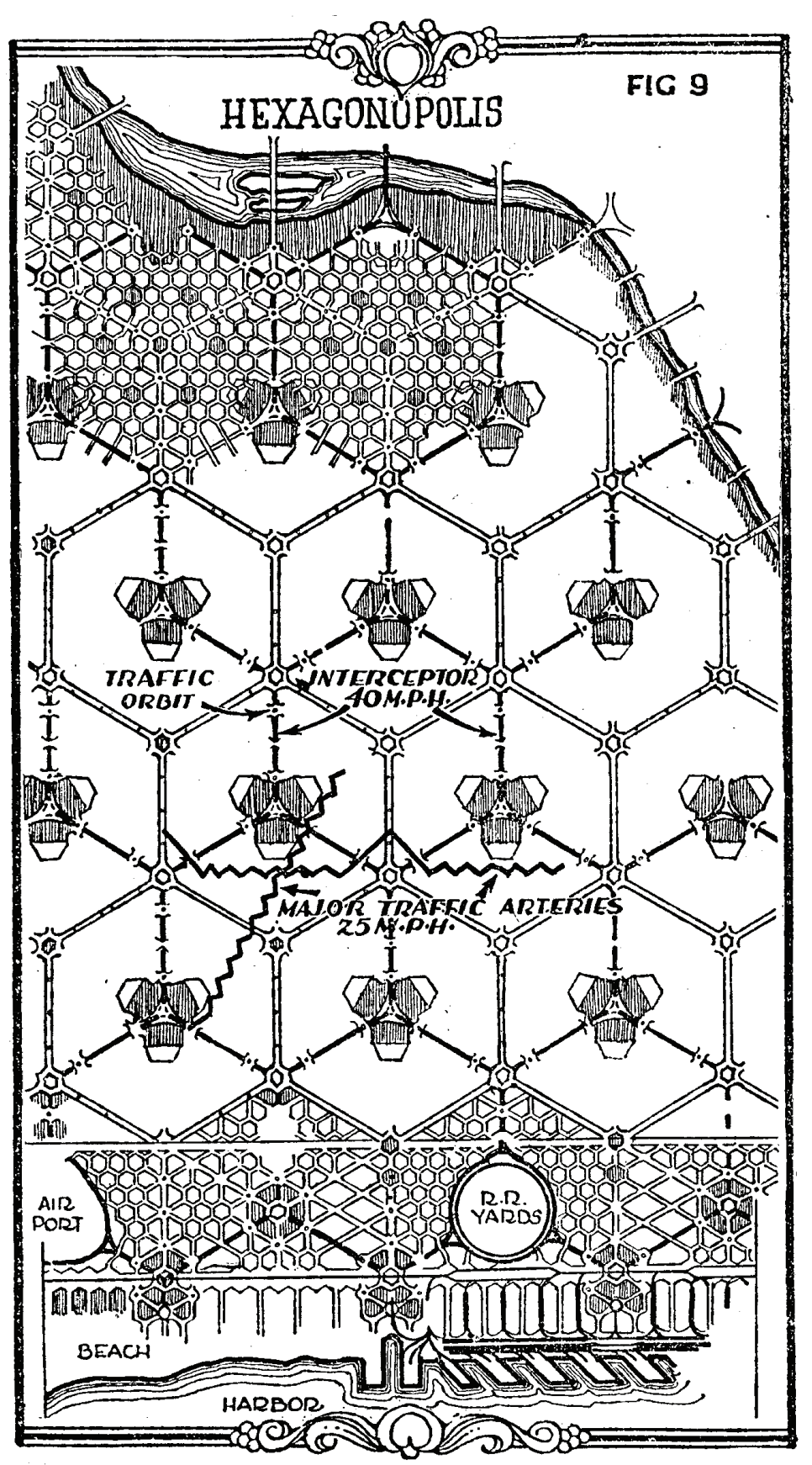

Early designs such as Hexagonopolis designed in 1927 (left) were of a larger scale that which is proposed within this thesis. Although shorter roads and smaller sites suggested that hexagonal based design should be an economical solution for town planning, the concept never gained popularity and eventually fell into obscurity. The hexagon as a design proposition was tested on both the micro and macro scale and is explained in Joseph and Gordon's work. This thesis considers the hexagon at a meso scale as the basis of a medium density ecohousing subdivision. The meso scale falls between the macro of town planning as tested by urban designers of the early 1900's and the micro scale of Frank Lloyd Wright and many others who have utilised the hexagon as a matrix or overlay within individual building designs.
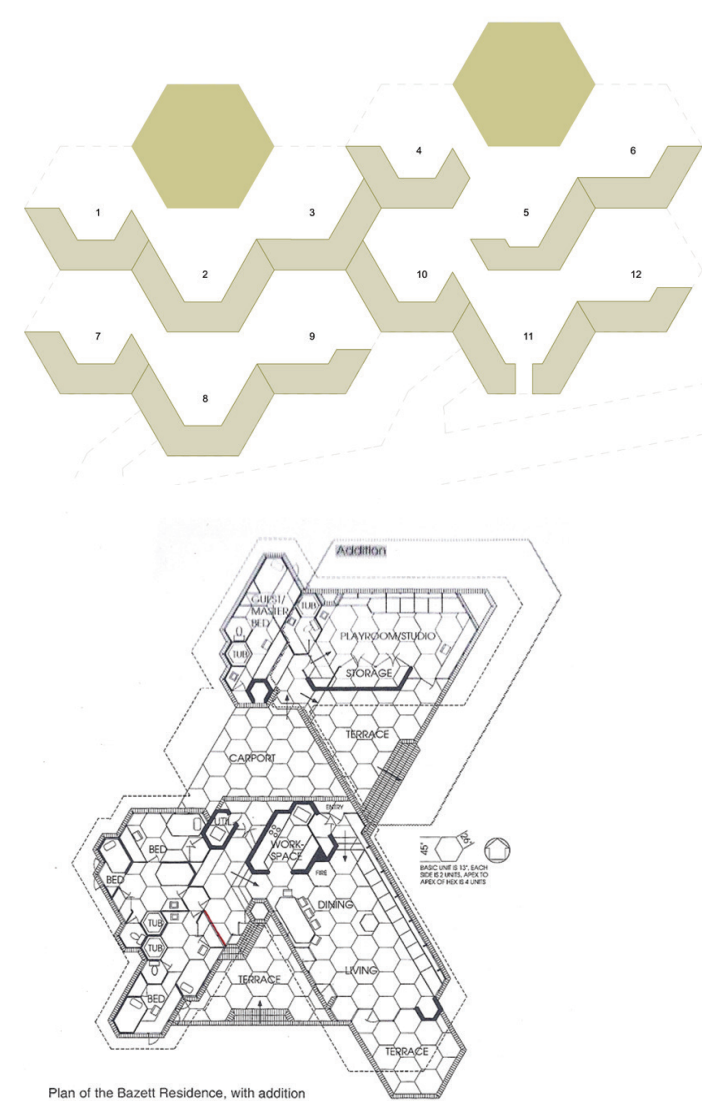

Image 35A. (far left this page) Hexagonopolis Utopian city design is of macro scale and is rigidly hexagonal in formation.

Left

Meso scale housing proposal utilising hexagonal geometry for defining sites. It is less rigidly confined to the hexagon. Houses adopt part of the hexagon and reinforce the dominant angles and dimensions and can vary in shape within the hexagonal site boundary.

Image 35B.

By comparison Frank Lloyd Wright's micro scale hexagonal house plan configuration is less literal still, allowing two of the three dominant axis to inform his design. 


\section{Tadelakt}

Tadelakt is an ancient Morrocan very beautiful and water proof lime plaster treatment. Tadelakt was originally used to finish the interiors of water cisterns keeping water fresh and hygienic, then later, when the beauty and versatility of this material became evident, developed as an art form decorating North African palaces, hammams, oriental steam baths, and homes.

Very little has been written about Tadelakt, as traditionally the process passed from artisan to apprentice over a time of training. There are only two books ${ }^{54,55}$ available devoted exclusively to tadelakt, neither of which provide sufficient information to enable readers to replicate the process.

Research for this part of the thesis involved attending an intensive Tadelakt training course in Colorado USA. Theory, material evaluation and composition were taught, then applied in practice, constructing a circle of three cob outdoor garden seats, which were lime coated and finished using the tadelakt process.

Images on these pages illustrate the diversity of design possible with tadelakt.

\section{Image 36-40 Top to bottom}

36. Cob outdoor couch ready sculptured and ready for plastering

37. Lime plaster oxide coloured coat being applied.

38. Stone polishing, compressing soft plaster

39. Colorado 2014 Tadelakt Class memebers

40. Tadelakt bathroom vanity created by the course tutor

54 Michael Johannes Ochs. Tadelakt. W. W. Norton \& Company, 2009. Print

55 Ziesemann, Gerd, and Martin Krampfer. Tadelakt. Sehlem: Kreidezeit-Eigenverl., 2007. Print.
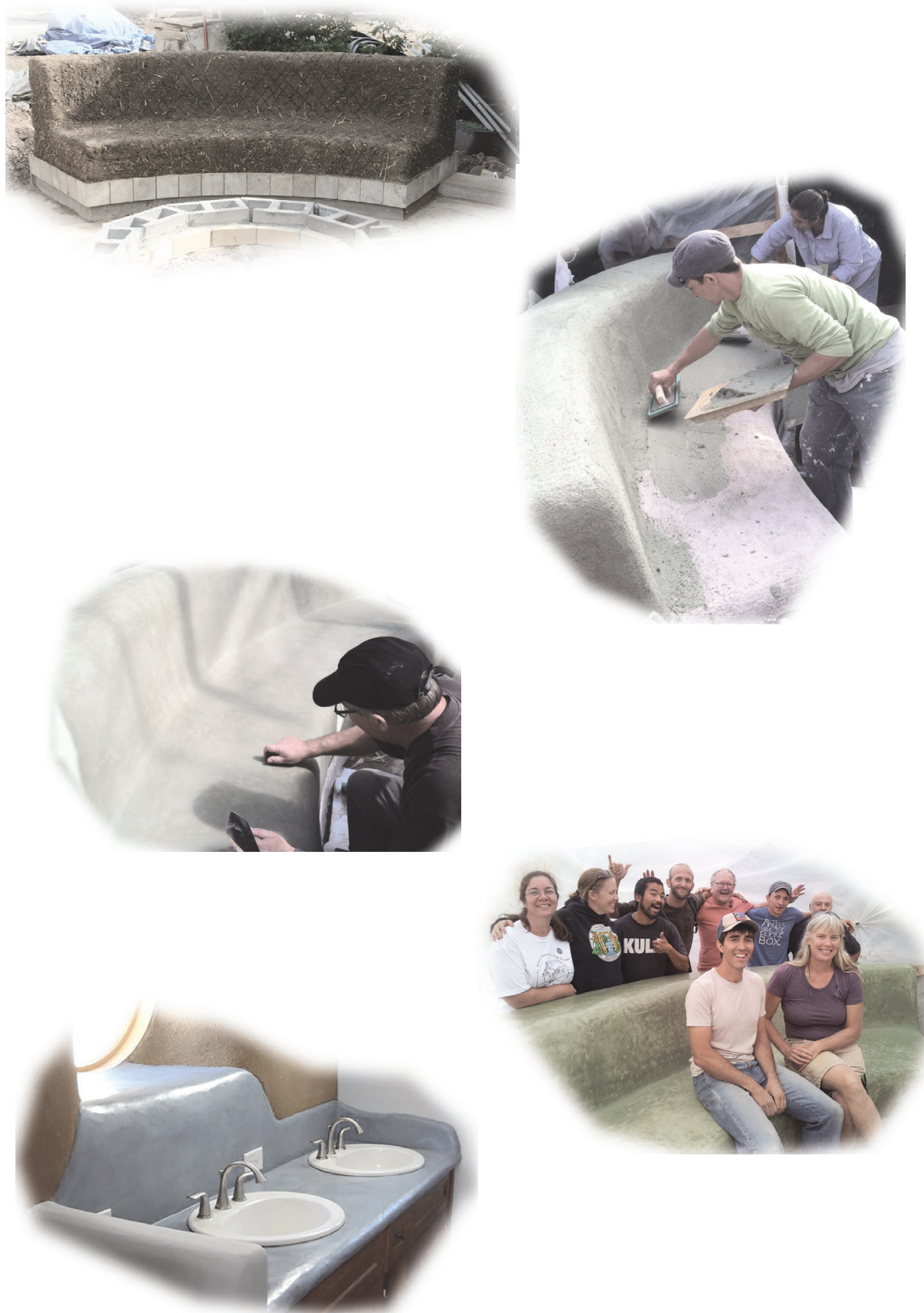


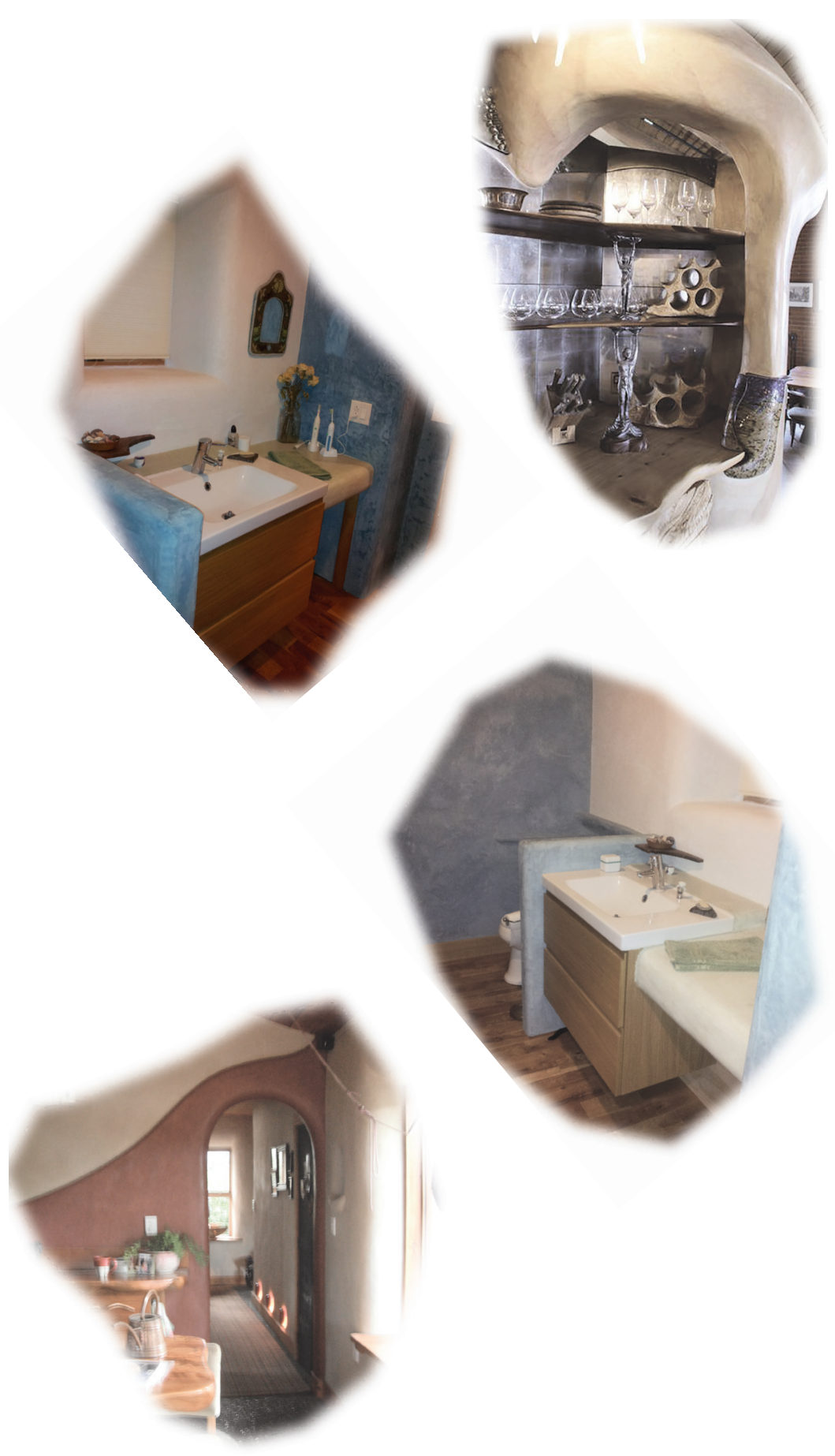

\section{Reflection}

The hexagon as a meso site layout is carried forward for development for both final designs in this thesis as it offers opportunities for new site and house configurations that allow for good view shafts and solar access whilst retaining a high level of privacy.

Tadelakt provides a solution for wet areas in natural homes where previously less sustainable, highly processed products were necessary. The need for a natural wet wall solution is resolved in Chapter 7 (design phase three) with the use of tadelakt.

Image 41-44 Left Top to bottom

41. Tadelakt sculptured bar feature.

42. Bathroom tadelakt 1

43. Bathroom tadelakt 2

44. Sculptured kitchen 'splashback' extends over door as tadelakt feature.

45. Below: Sculptured tadelakt garden wall and seating.

46. Right: Construction of ornamental tadelakt globes is often used as a first project training technique when learning the tadelakt process.
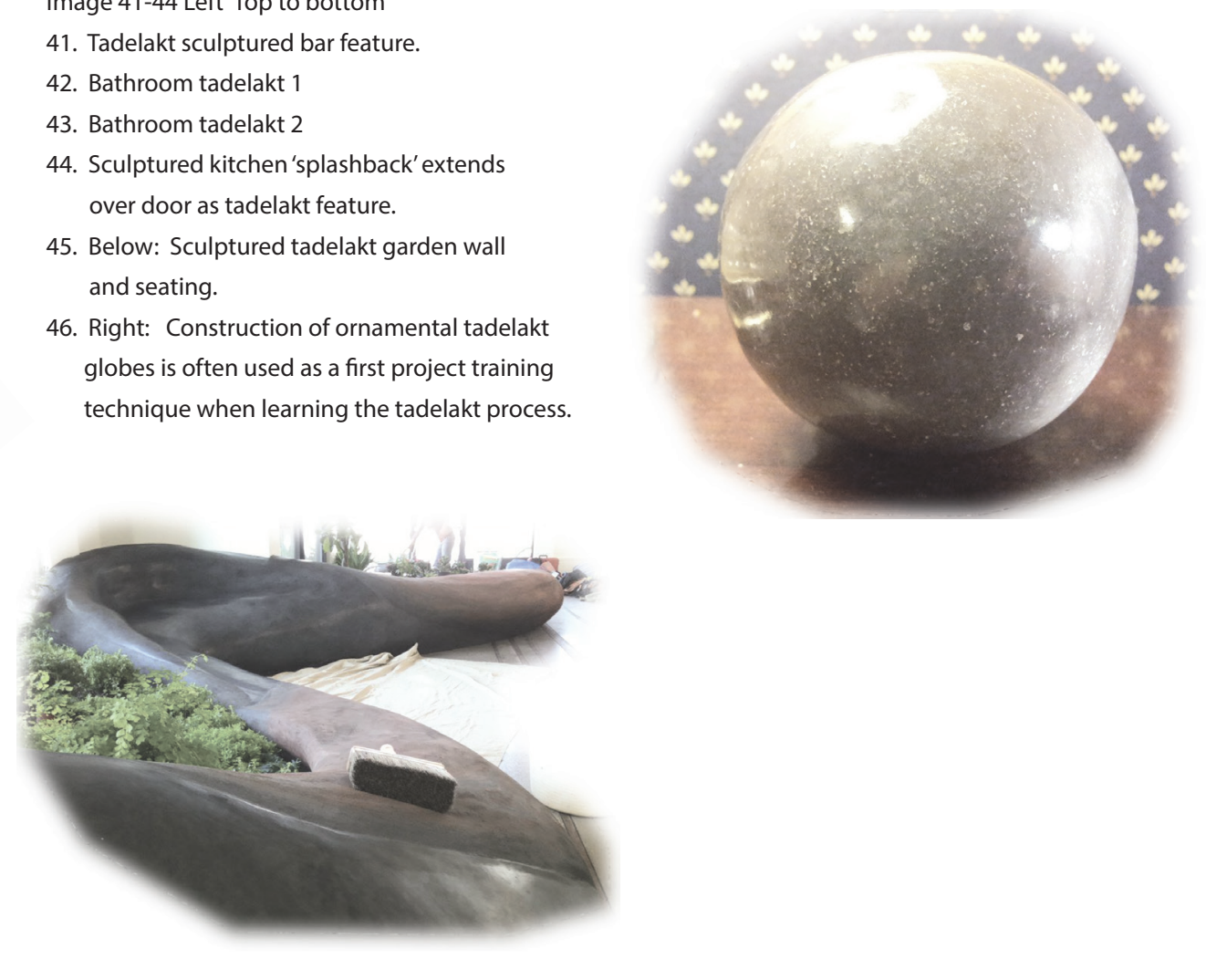
'People should think things out fresh and not just accept conventional terms and the conventional way of doing things.'

\author{
R. Buckminster Fuller
}




\section{Design Phase 3}

\section{TYPOLOGY}

DESIGN ELEMENTS

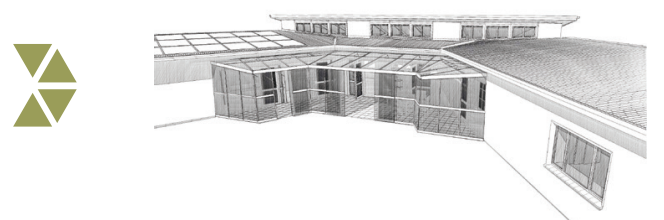

Four Bedroom Single Storey Unit.
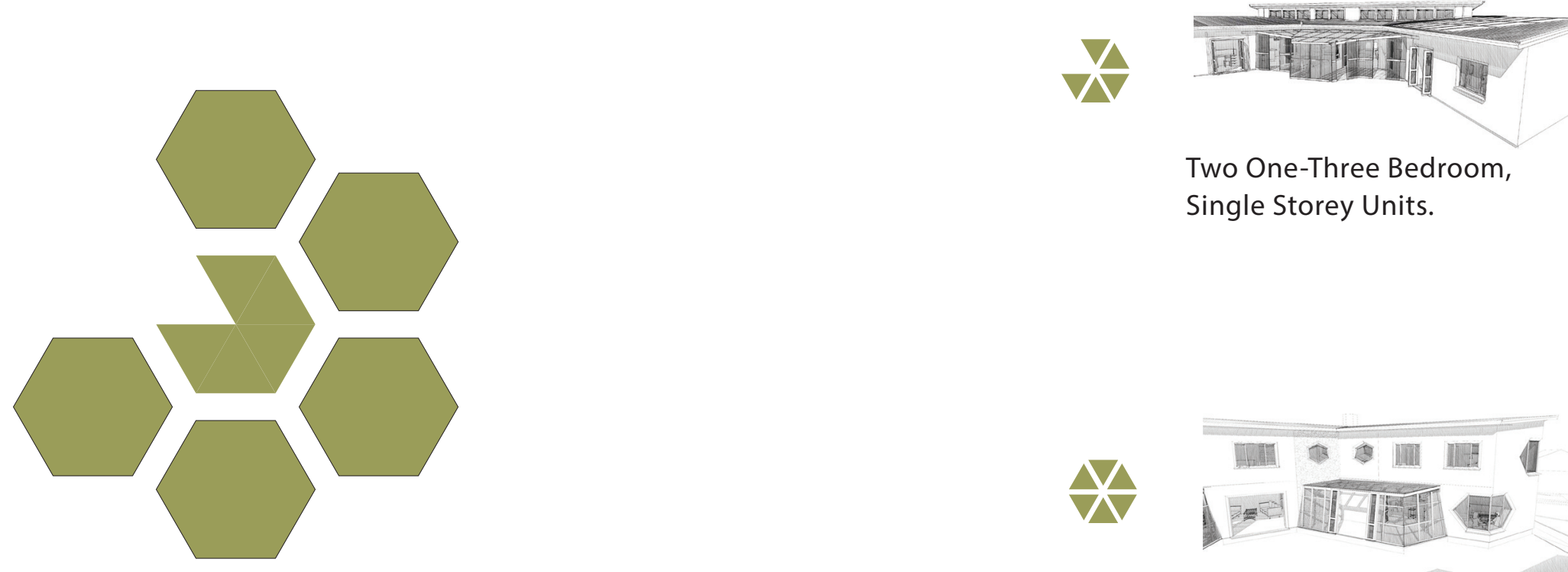

Single Storey Units.

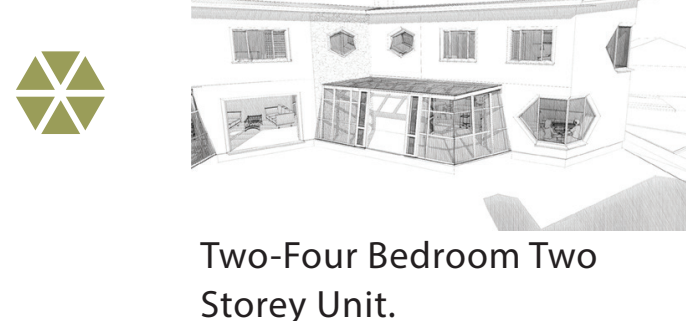


Hexagonal shaped site geometry at meso scale facilitate a wide variety of building configurations.

Through the design-led-research process used in this thesis, hexagon geometry has been tested. The first design iteration, (right) chained hexagons as a long thread. This is suitable when following existing roads, particularly when applied to roads running in an east to west direction by improving solar access which in turn is beneficial for natural lighting and passive solar heating. This format was taken forward for use in the solution for the Forbes Road Development which is design solution one of this thesis.

The five or six hexagon perimeter enclosing a central hexagonal site is an economical use of land, giving a site density of $24 \mathrm{dph}$ single storey and up to to $50 \mathrm{dph}$ as a two storey design, whilst using less land per dwelling and the central common area is accessible to all. In these designs the centre hexagon can be stretched a little and serve as a communal, enclosed garden space. After evaluating this variation, it was applied to the Awatea Road Development.
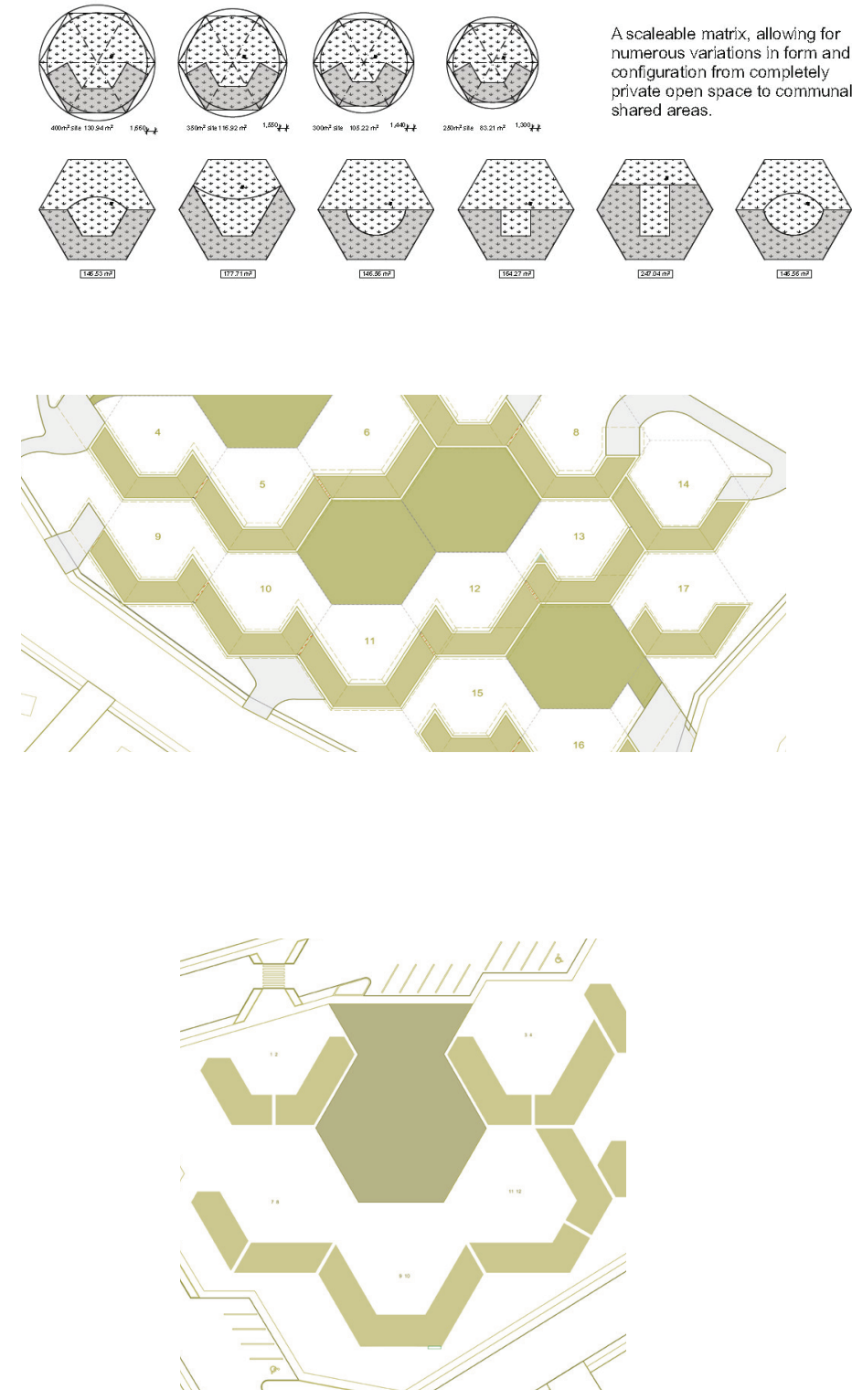


\section{Typology}
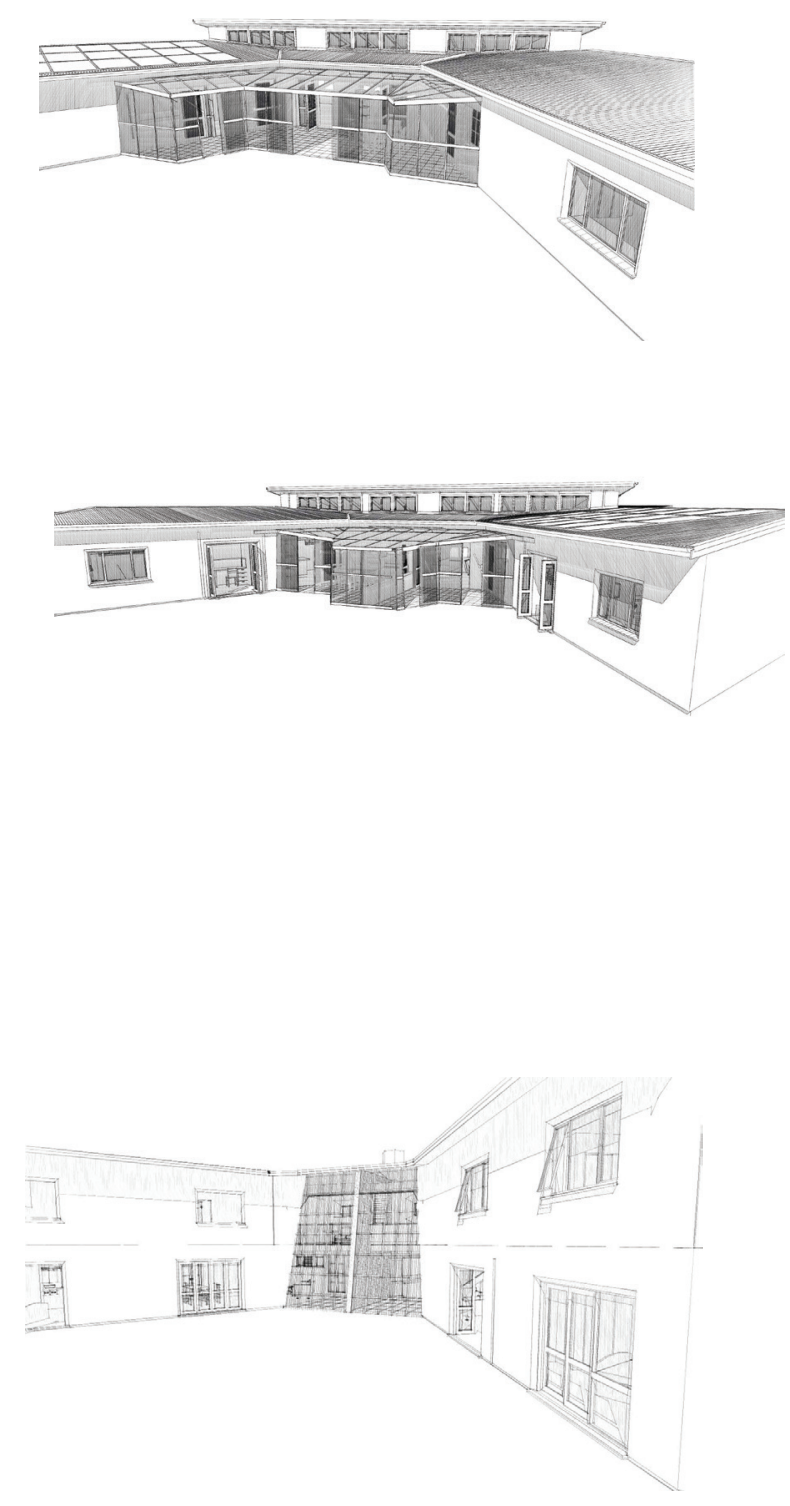

Basic home on a hexagon site.

A four bedroom home designed to fit to the rear of a hexagon site, with three walls on boundaries and two party walls. All site space is concentrated as a north outdoor area enjoying high levels of exposure to daylight and passive solar gain. This forms part of the basis of the finished designs.

Two homes on one hexagon site.

Two adjoining two-bedroom apartments easily share a $400 \mathrm{~m}^{2}$ site, effectively doubling site density along with the associated cost savings. The yard area could be shared or fenced and/or planted according to individual requirements. The single typology shall form the basis for the Forbes Road design solution one (chapter 8).

Two family homes on one hexagon site.

Two two-storey apartments to one hexagon site doubles the building occupancy potential. These units can have up to four bedrooms each. The two storey typology forms the basis for the Awatea Subdivision design solution two (chapter 9).
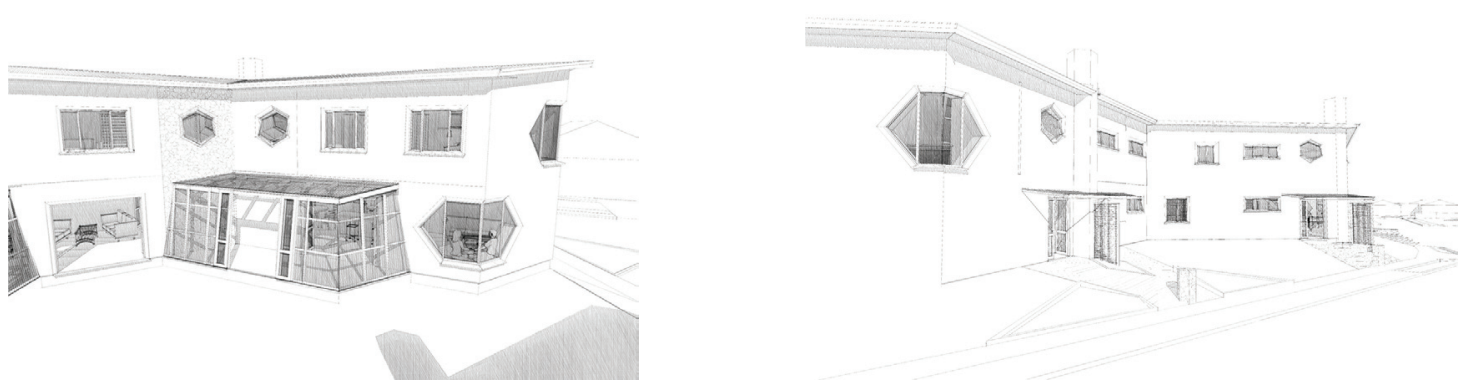
The 'hexagon flower' (right) is reminiscent of early 1900's town planning and Eschers drawings mentioned in earlier research chapters.

This geometry can be expanded infinitely, whilst retaining accessibility through the inclusion of east-west park access and north south service roads, on a square or larger diamond hexagon grid.

This iteration could suit a fully developed multi storey complex with interior parkland and underground parking and services. As the final iteration in this chapter it presents an opportunity for future higher density development beyond the scope of this thesis.
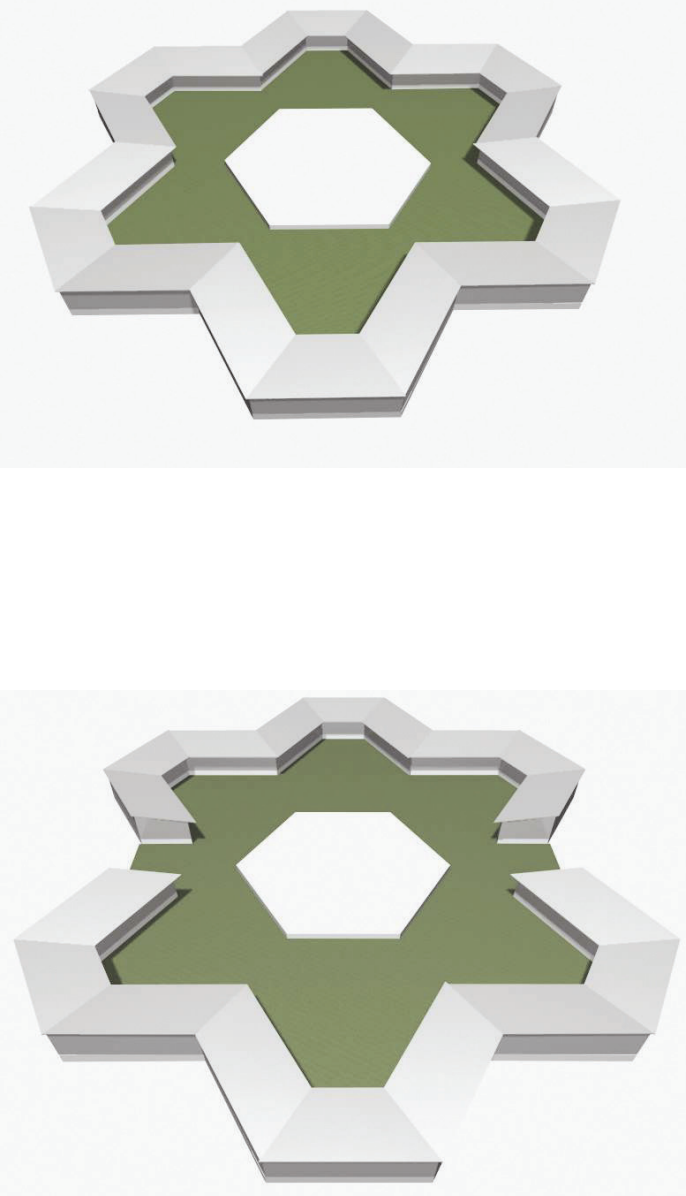


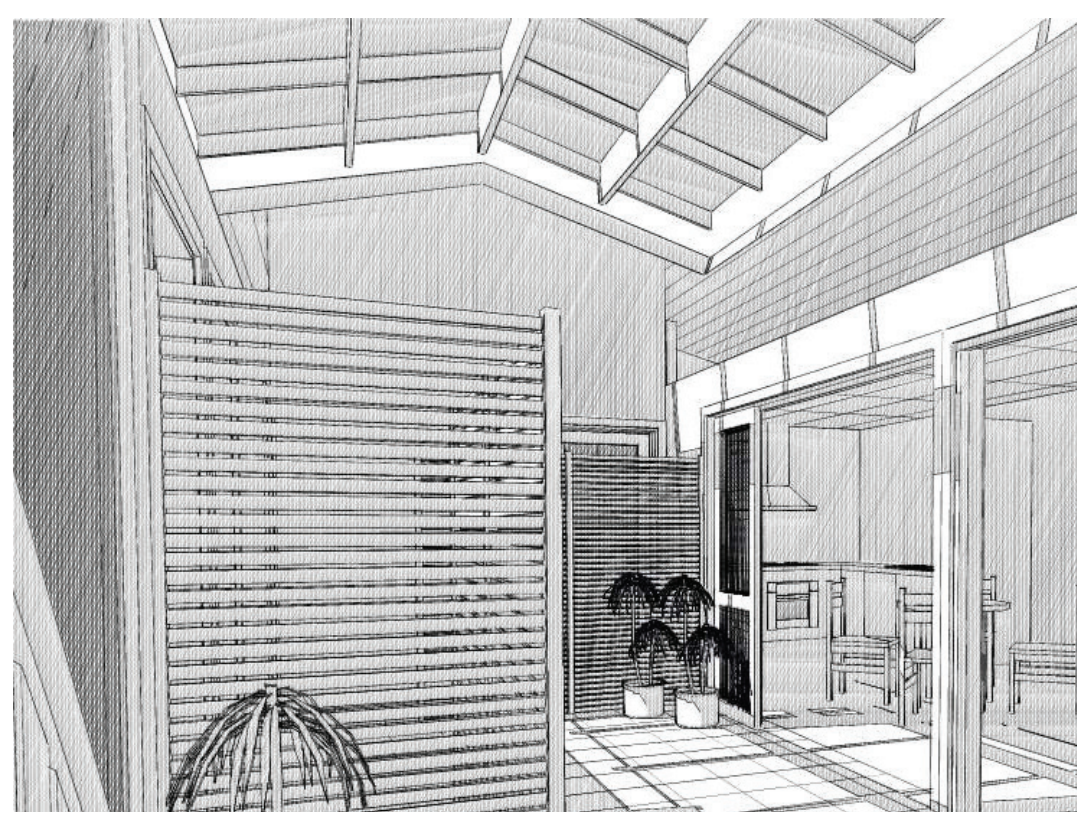

\section{Illustration Left}

An early fully enclosed courtyard design which developed into a clear walled north face design.

Illustration Below.

An early study of hexagonal interaction and the shapes that can be generated within the matrix.
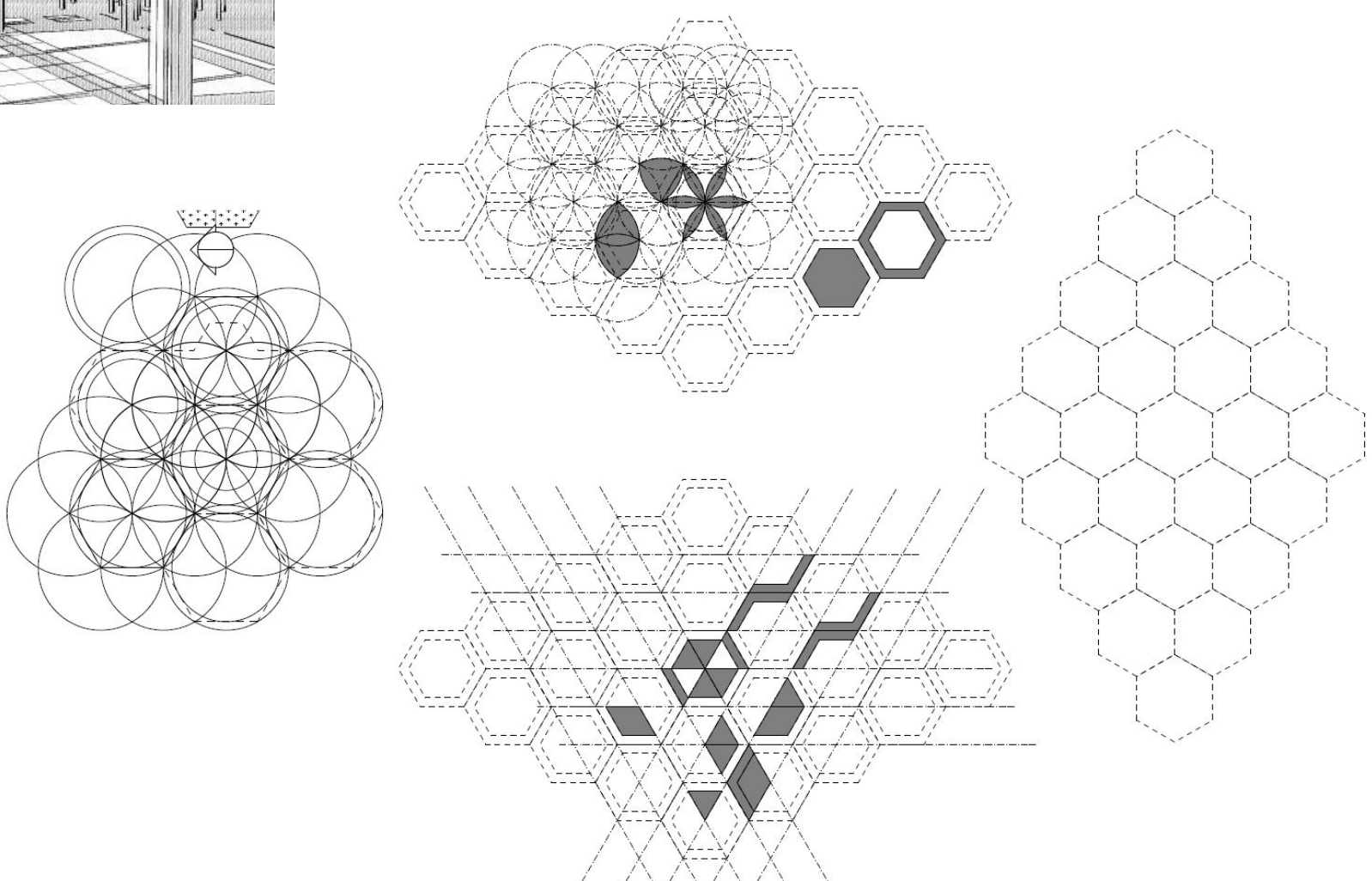


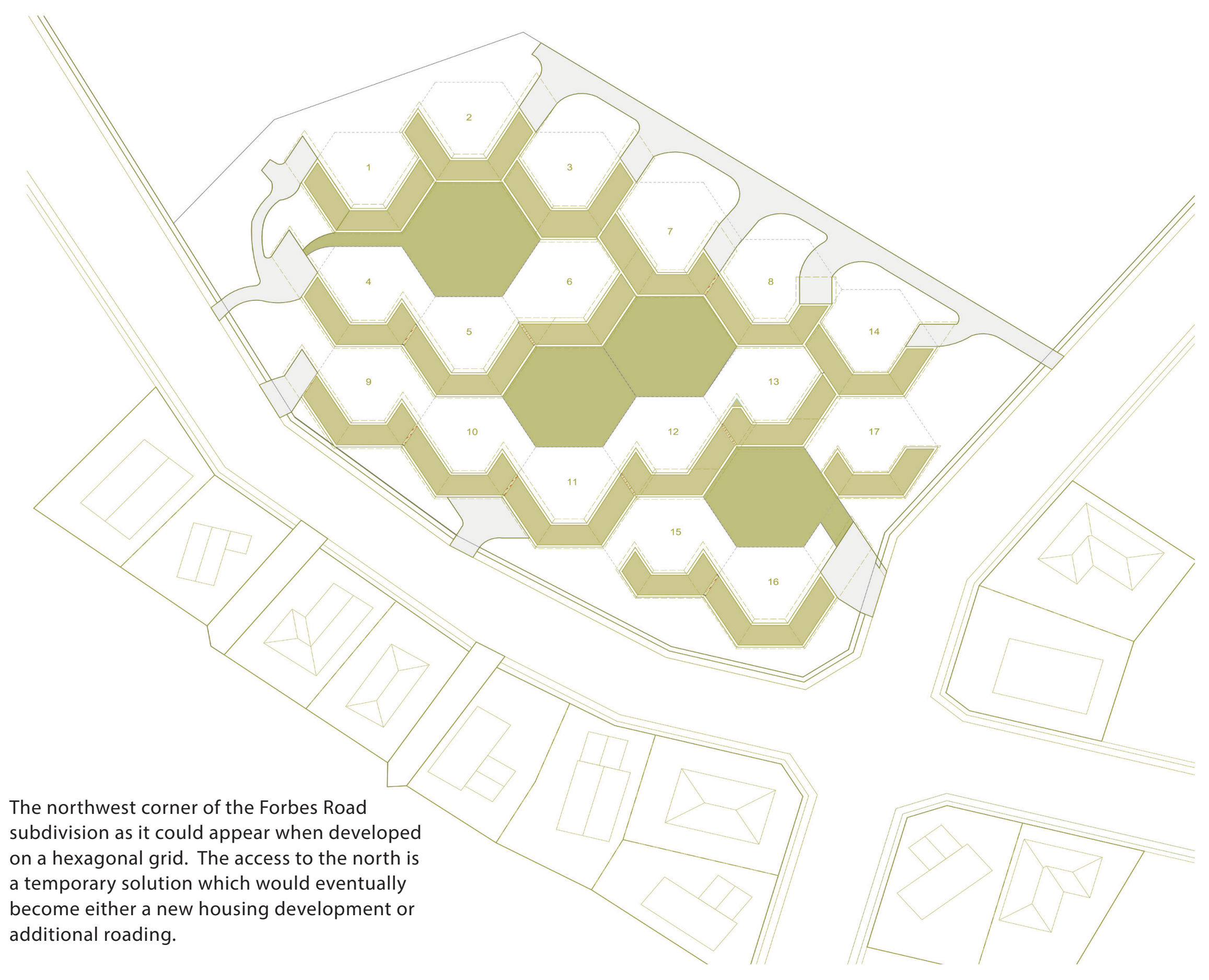




\section{Solution 1}

\section{FORBES ROAD}

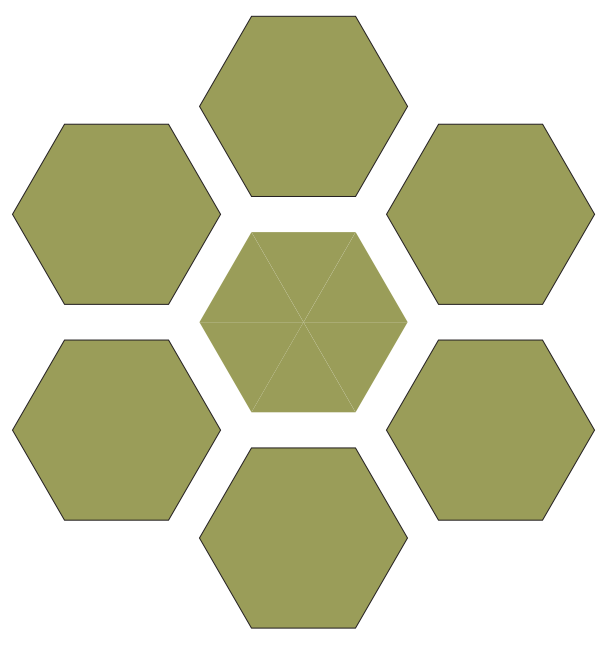

Forbes Road is typical of areas where land is available at reasonable cost. In these situations, chaining of single storey semi detached zero lot designs can be accommodated easily, with garaging and storage either at the rear and periphery of the sites or as is often preferred in New Zealand residential developments, integrated with the house.

Introducing a hexagon base development to an existing greenfield development is quite straightforward. The main site location consideration is the integration into the existing rectangular and cul-de-sac site configuration, and how to treat the transitional zones. The road edge adjoining the building development acquires new interest, with spaces suited to development for parking, gardening and socialising. The northwest corner of the subdivision is one hectare and has thirteen sites zoned for single dwellings and cannot be subdivided. The resultant $13 \mathrm{dph}$ is low even for suburban residential where 20 dph is typical.

The facing page illustrates a chained hexagon with three shared common areas. All homes have a good northerly aspect and most have direct access to a commons. The access road to the north is only a temporary solution which would in time be resolved as additional hegaxon sites and roads were added.

This design for Forbes Road, incorporates chained hexagons with an expanded cluster. Although higher densities could be achieved it would be at the expense of outdoor shared space, privacy and compromising solar access. Densities of 16-20 dph single storey can be achieved comfortably, improving on the $13 \mathrm{dph}$ site formation cul-de-sac approach. The individual blocks of land for each unit should prove useful as recreation or garden areas with the shared outdoor space allowing residents a significantly improved outlook and outdoor living experience on these smaller privately owned sites. 

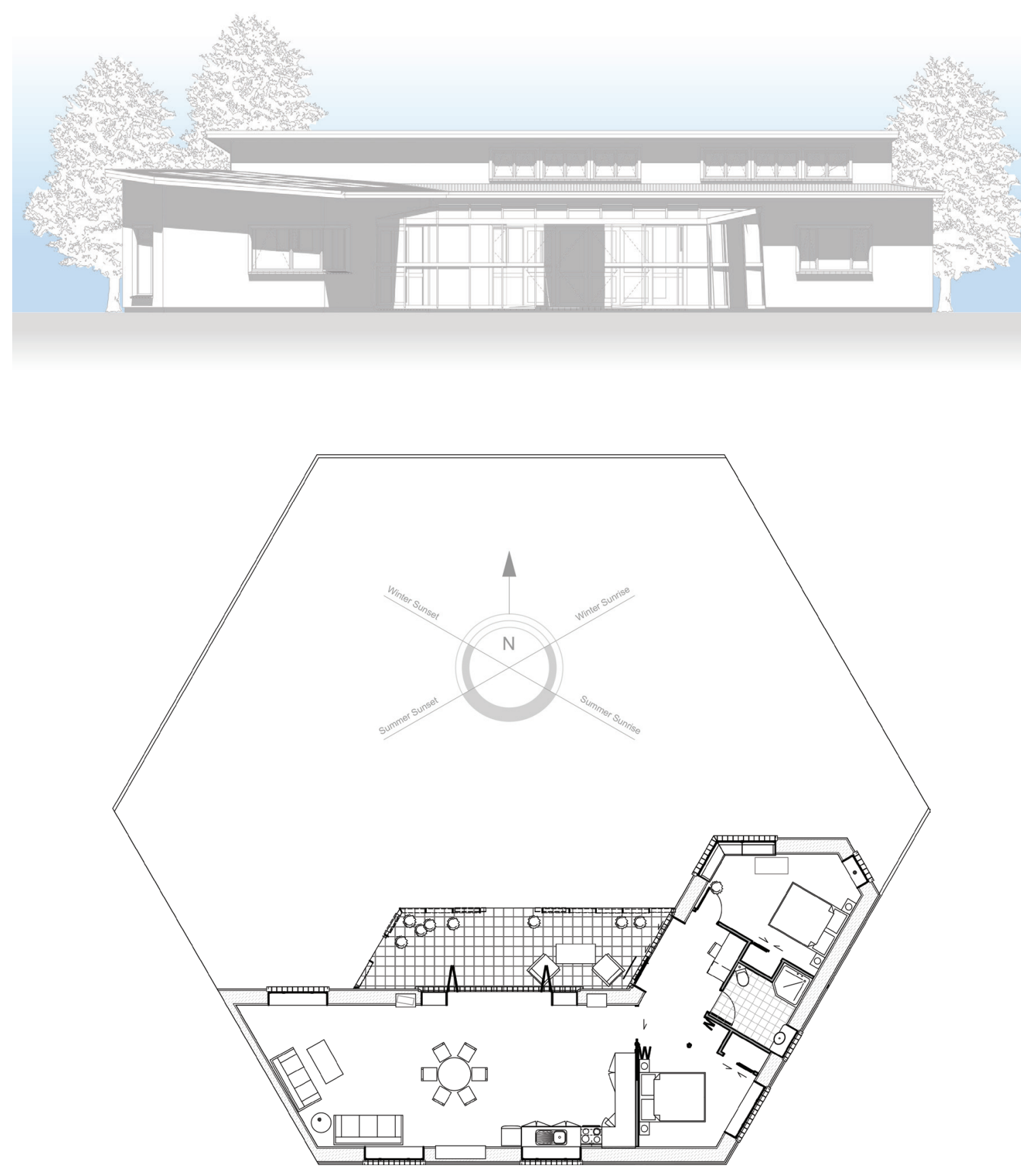

Two bedroom unit.

Site Area $\quad 400 \mathrm{~m}^{2}$ Unit Area $\quad 107 \mathrm{~m}^{2}$

Site Coverage $\quad 27 \%$

Dph 25

Sunroom $\quad 21 \mathrm{~m}^{2}$

Bathroom 1

Toilet combined

Bedrooms 2

Sleeps 4

Living Area $\quad 1$

Study Alcove 1 


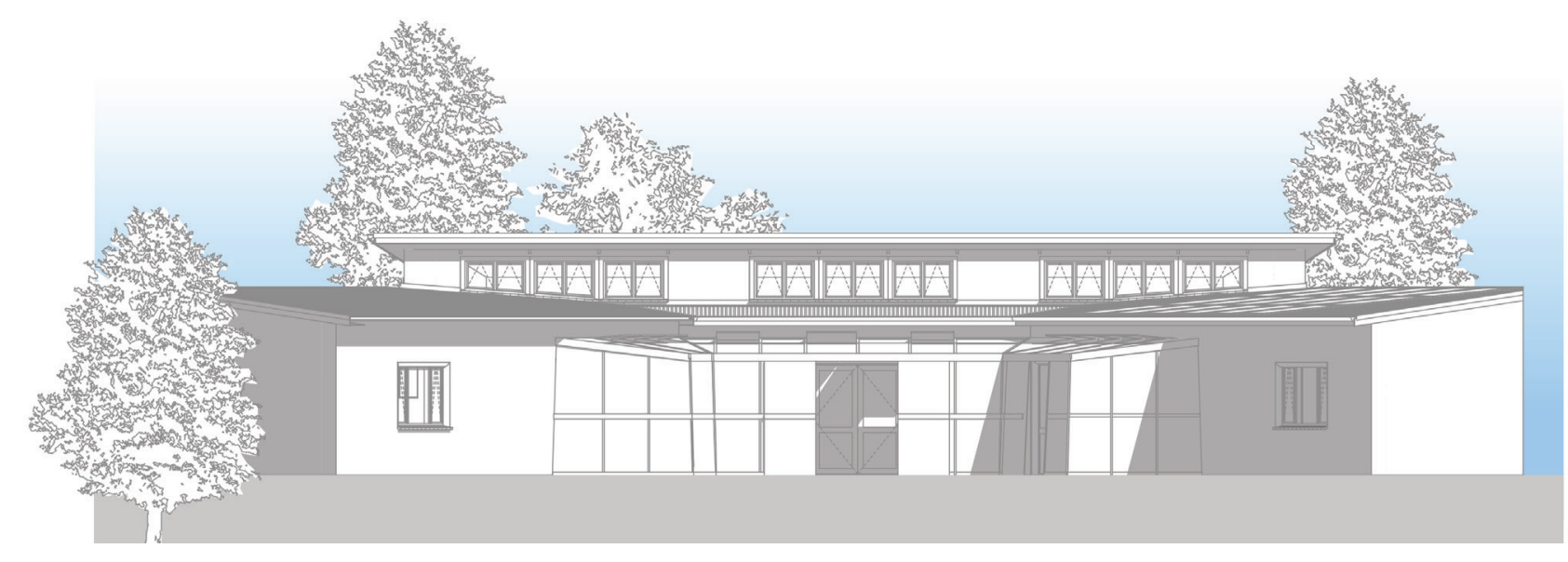

Three bedroom unit.

$\begin{array}{ll}\text { Site Area } & 400 \mathrm{~m}^{2} \\ \text { Unit Area } & 133 \mathrm{~m}^{2} \\ \text { Site Coverage } & 33 \% \\ \text { Dph } & 25 \\ \text { Sunroom } & 18 \mathrm{~m}^{2} \\ \text { Bathroom } & 1 \\ \text { Toilet } & \text { combined } \\ \text { Bedrooms } & 3 \\ \text { Sleeps } & 6 \\ \text { Living Area } & 1 \\ \text { Study Alcove } & 1\end{array}$

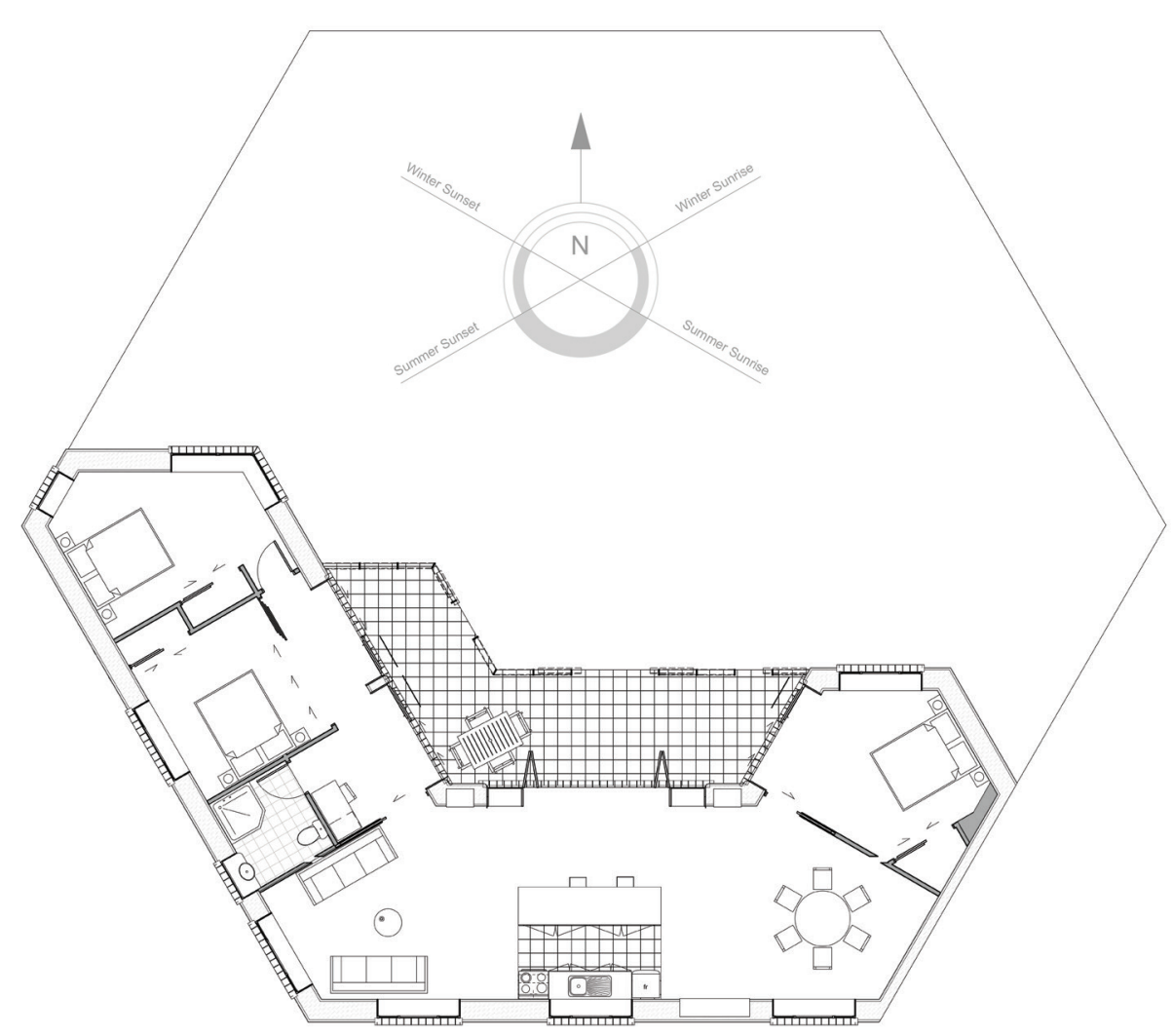



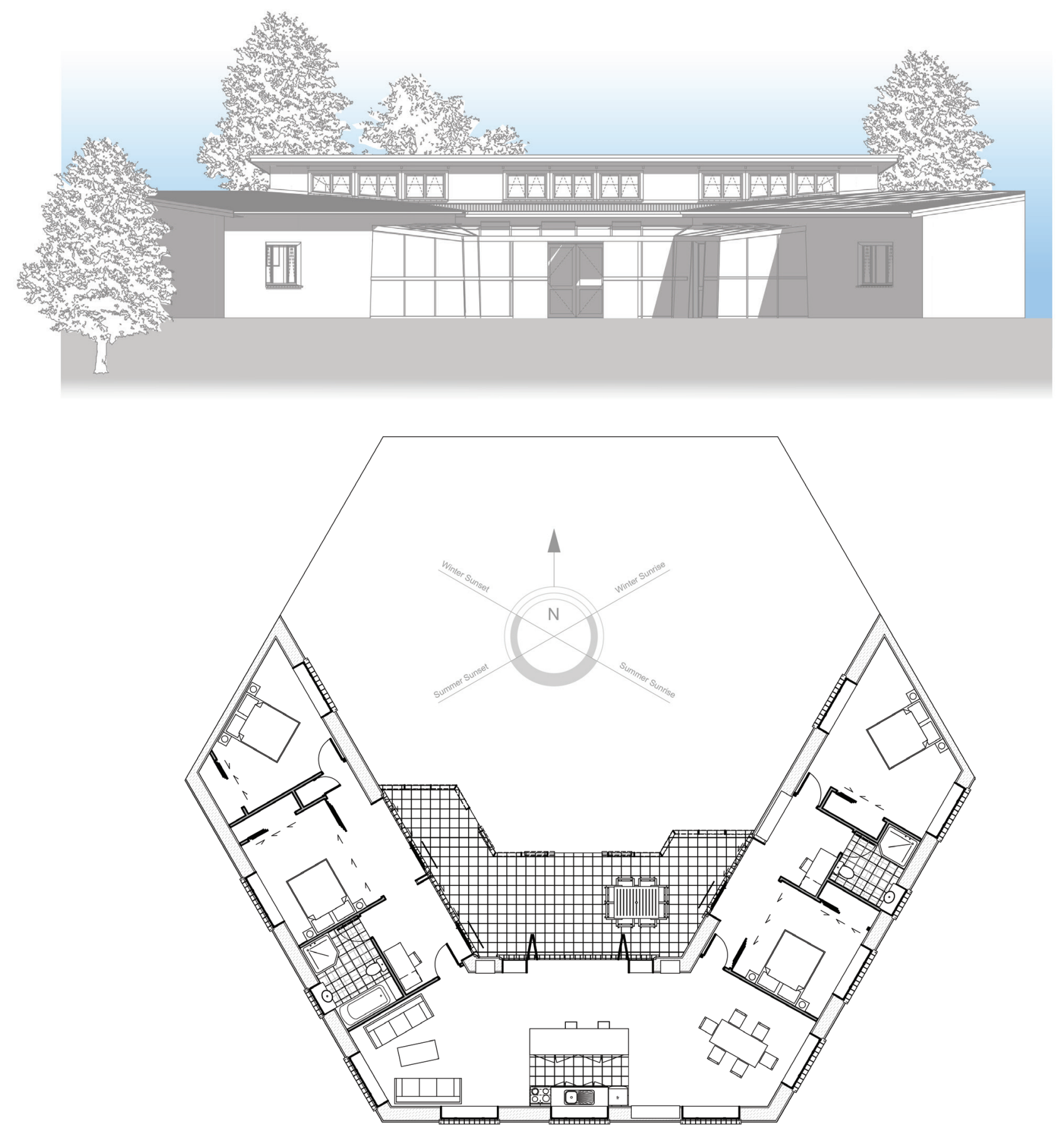

Four bedroom unit.

Site Area $\quad 400 \mathrm{~m}^{2}$

Unit Area $\quad 174 \mathrm{~m}^{2}$

Site Coverage $\quad 44 \%$

Dph 25

Sunroom $38 \mathrm{~m}^{2}$

Bathroom 2

Toilet 2 combined

Bedrooms 4

Sleeps 8

Living Area 1

Study Alcove 1 
Two by one-bedroom units provide higher density, up to $50 \mathrm{dph}$, but as only one bedroom units could be improved upon with a two storey design.

\section{Two one bedroom units.}

$\begin{array}{ll}\text { Site Area } & 400 \mathrm{~m}^{2} \\ \text { Unit Area } & 85 \mathrm{~m}^{2} \text { each } \\ \text { Site Coverage } & 43 \% \\ \text { Dph } & 50 \\ \text { Sunroom } & 22.5 \mathrm{~m}^{2} \text { each } \\ \text { Bathroom } & 1 \\ \text { Toilet } & 1 \text { combined } \\ \text { Bedrooms } & 1 \\ \text { Sleeps } & 2 \\ \text { Living Area } & 1 \\ \text { Study Alcove } & 1\end{array}$

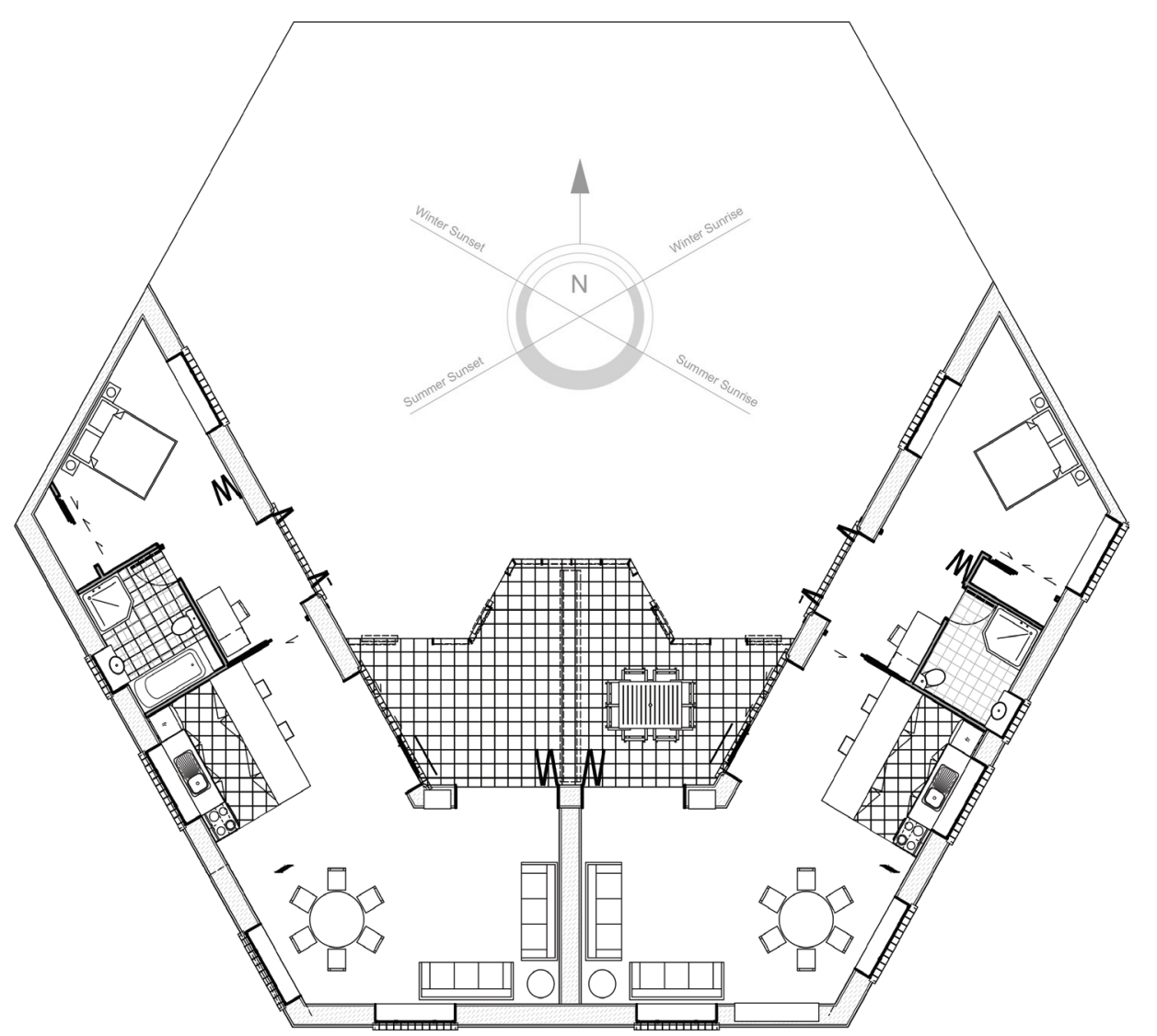




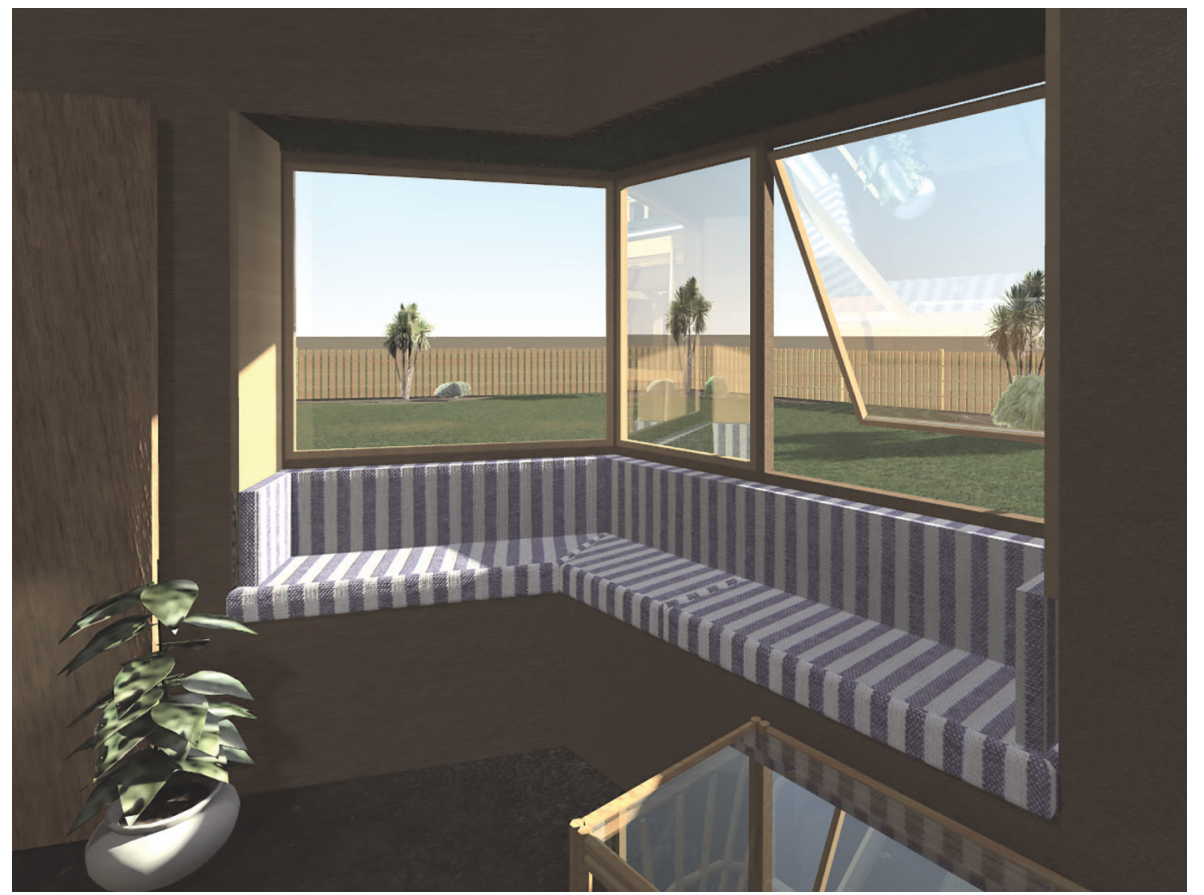

The thickness of strawbale walls allows for unique design features. Above, in the bedroom of the two bedroom unit, a bay window seat is incorporated, facing north for all day sun and a full view of the garden, without imposing into the room.

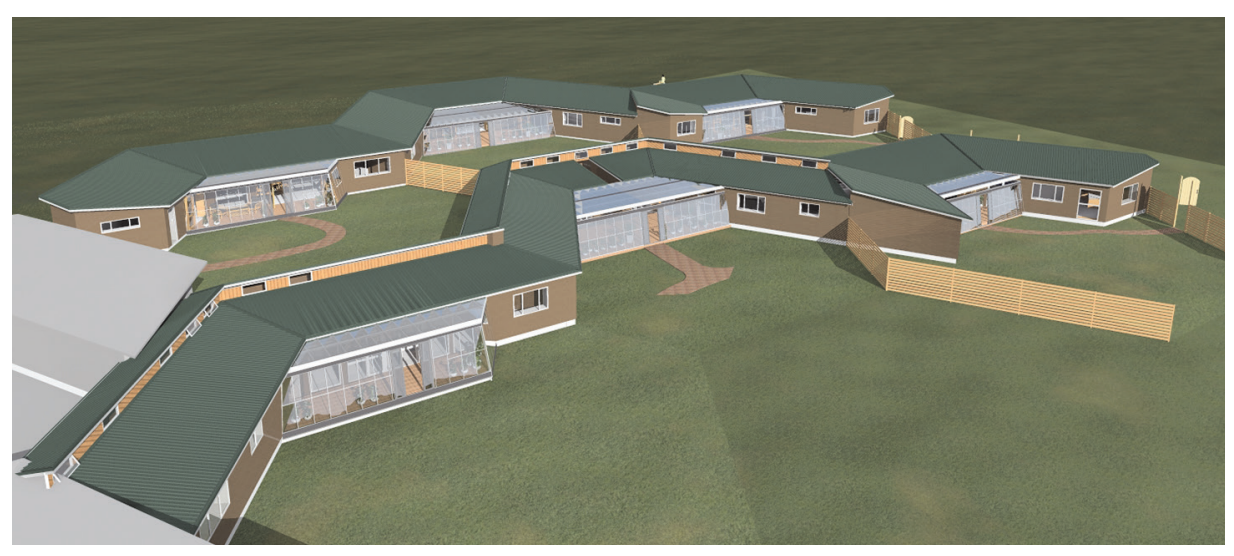

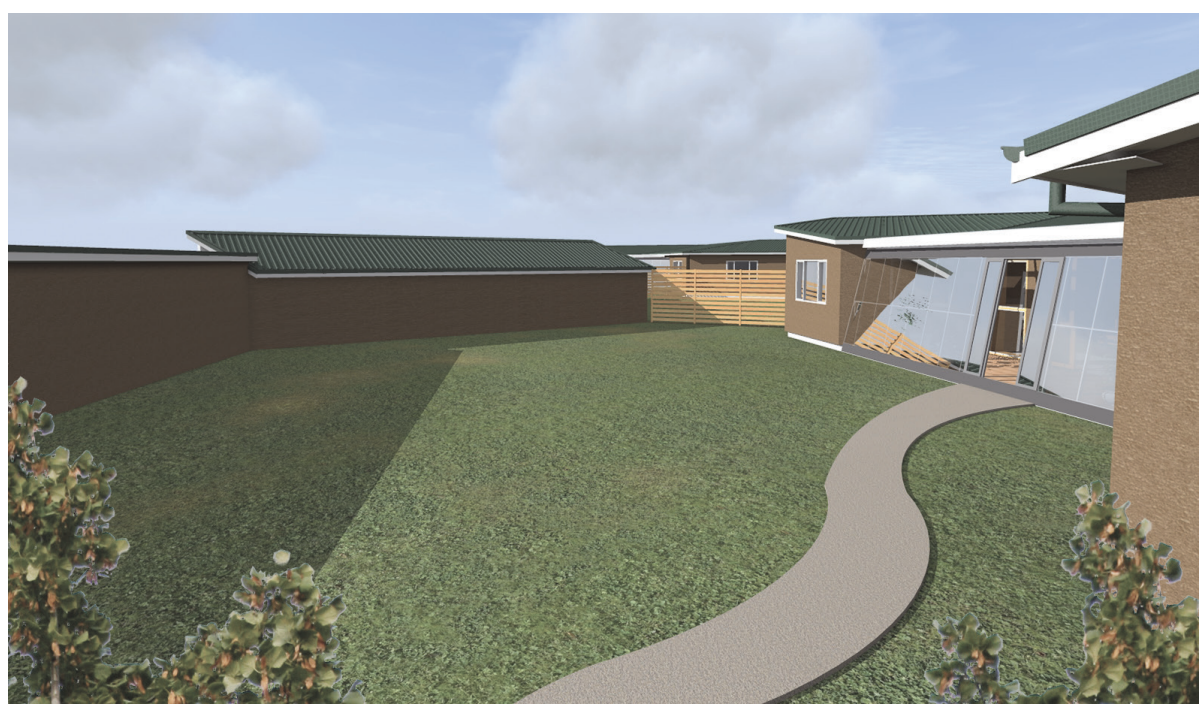

During the design process it became apparent that the south facing windows on northern units, (left in the above illustration) would either compromise the privacy of the southern units (right) or suffer from lack of light to the rear of the homes. Clerestory windows are introduced to alleviate the loss of light without compromising the rear unit's privacy.

Below are two images of early design stages. Of particular note is the 'greyed' buildings to the left in the image demonstrating the ease by which expansion is possible.

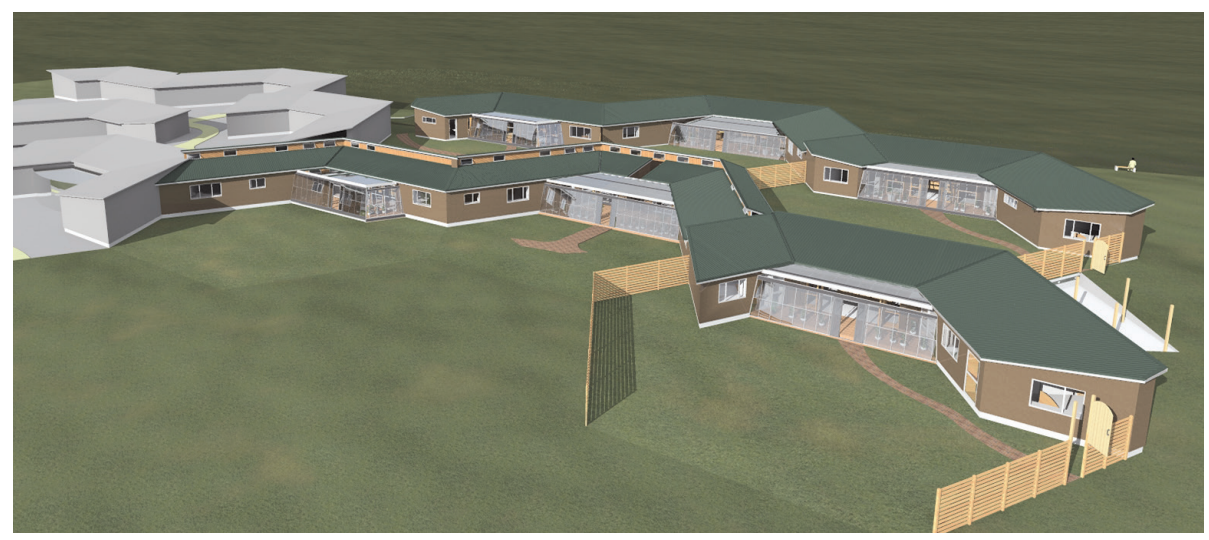




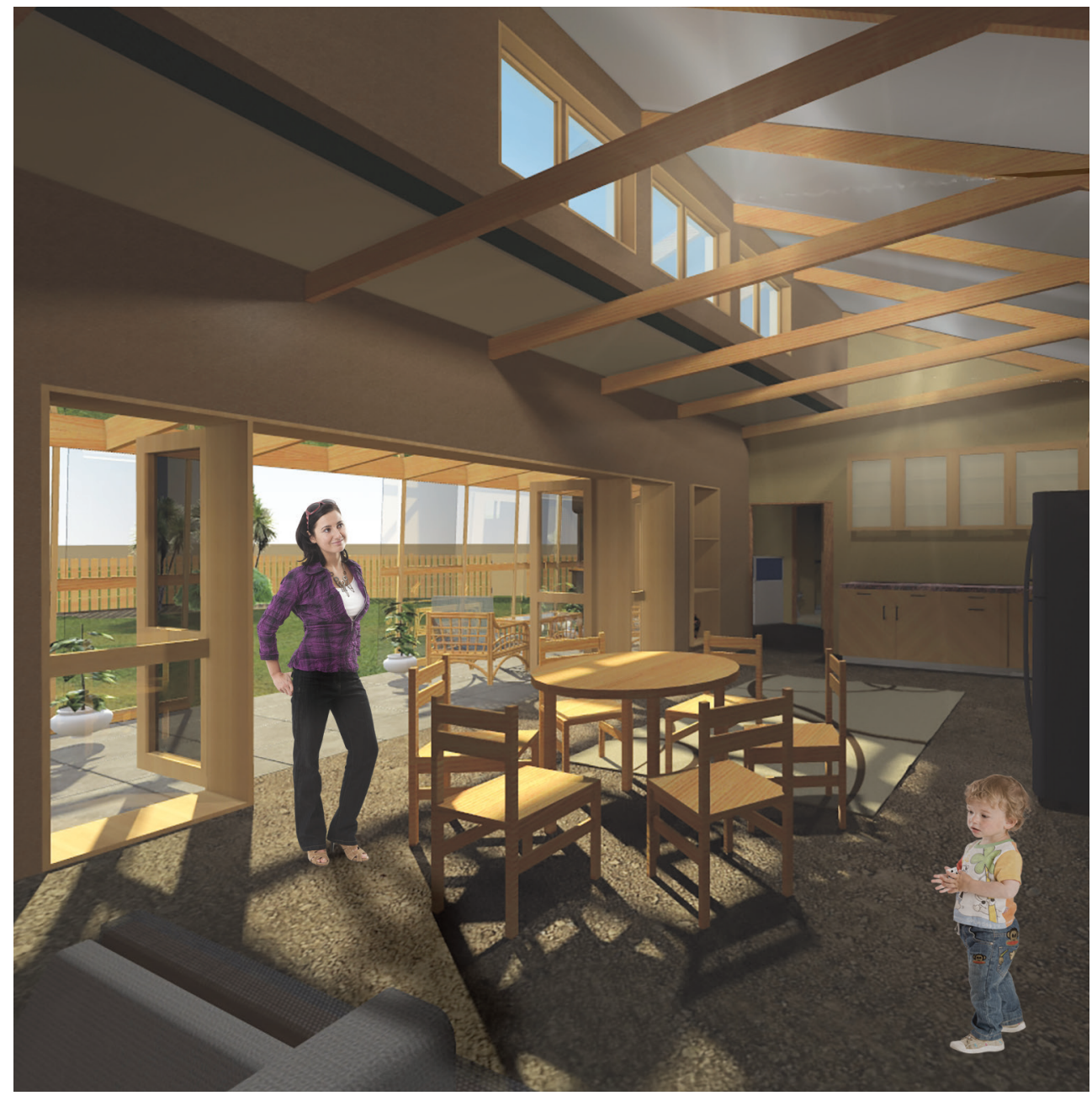

Wide bifold doors open the interior to increase living space by integrating the sunporch. The thermal mass of the porch and house floor act as a heatsink stabilising the house temperatures.

Clerestory windows allow light to penetrate the rear of the house and also work as passive ventilation which can be manually or automatically regulated.

Clerestories are ideal for single or upper storeys of homes where rear (south facing) windows would reduce privacy when houses are clustered.

Pictured below viewed from above the clerestory and ample roof space for solar panels are clearly visible.

Integral garaging can be incorporated either between or behind houses or on the end (as modelled below) when the unit is last in a row.

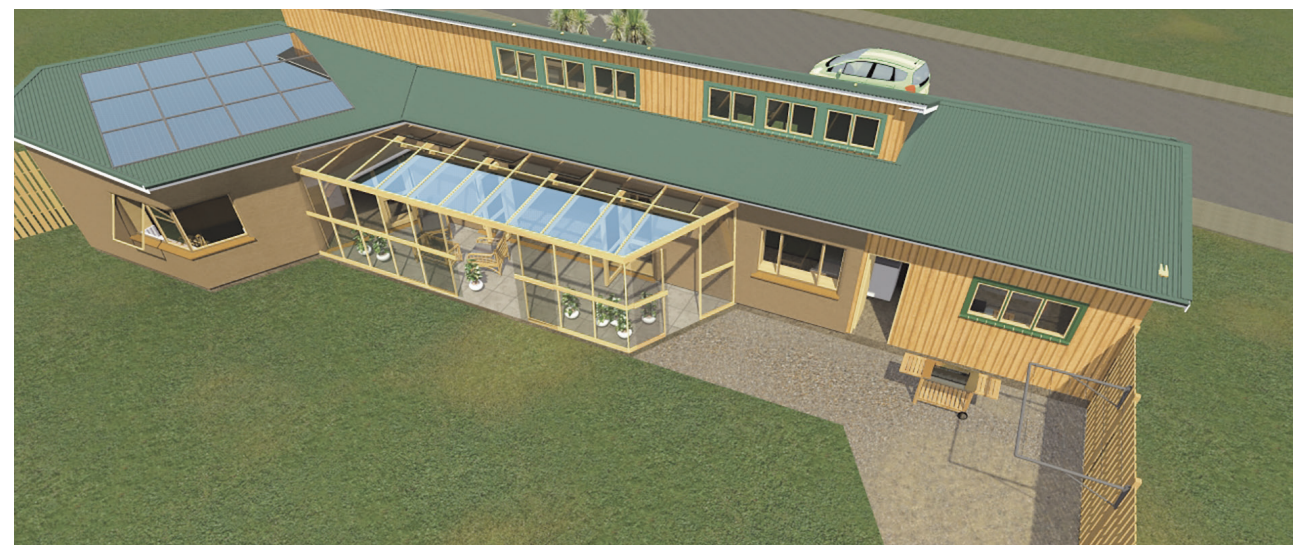




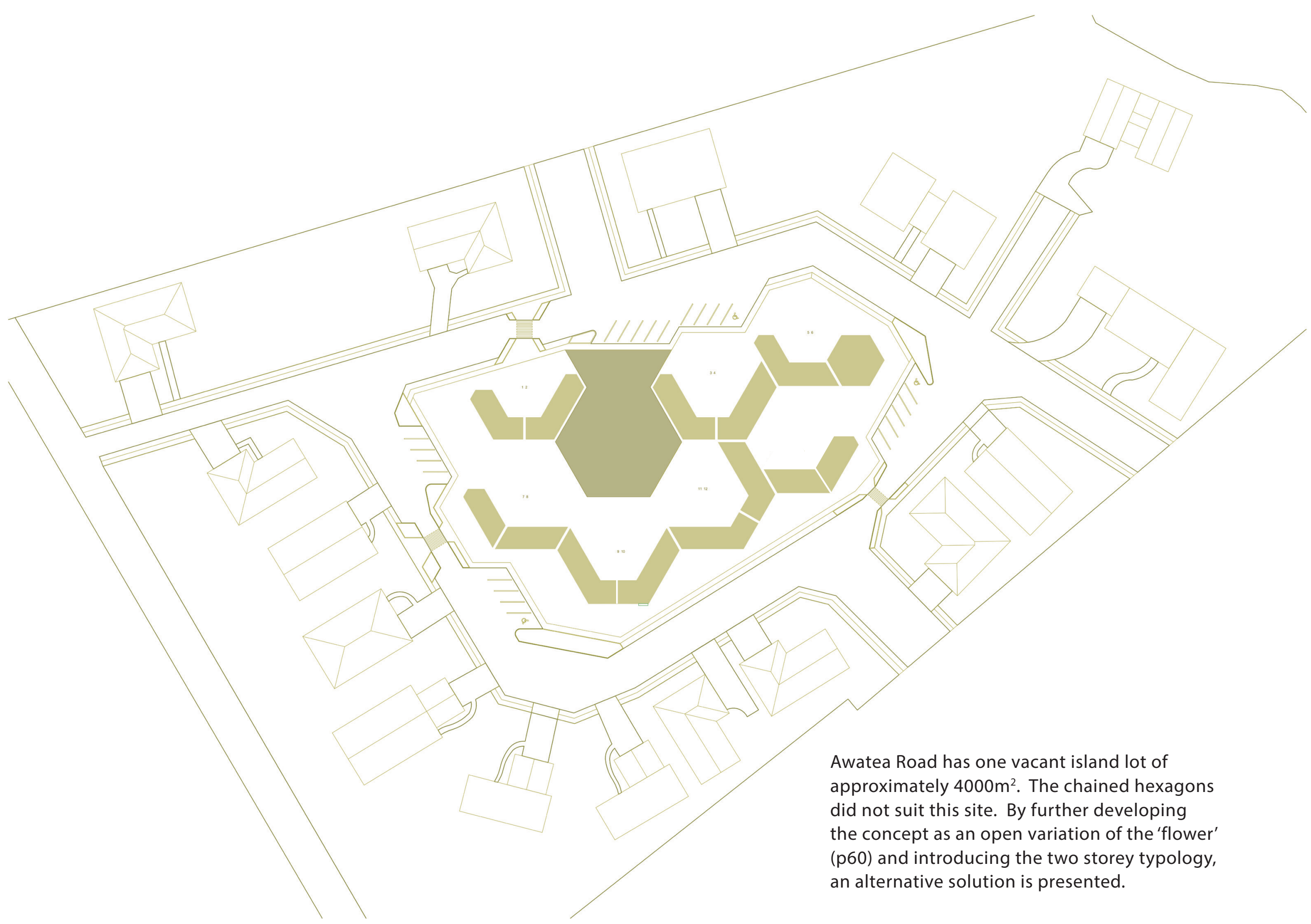




\section{Solution 2}

\section{AWATEA ROAD}

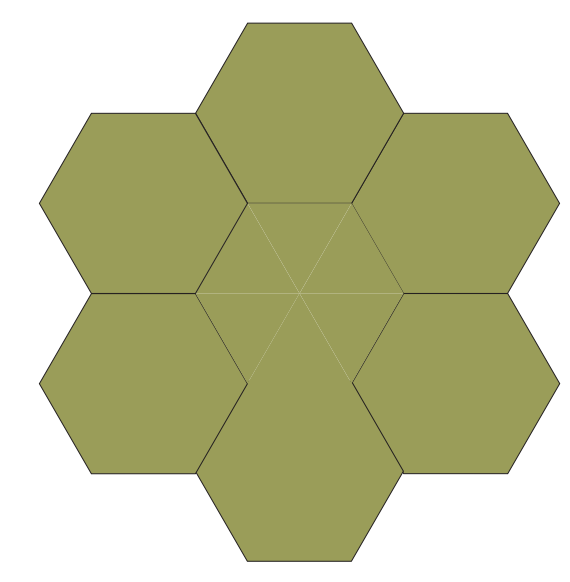

Awatea Road (Lot16) is an 'island' where a development can stand alone adjacent to and contributing to the surrounding cul-de-sac of traditional houses, and as such suits a higher density development within a suburban context.

The island style configuration of the available site was not suited to the chaining of sites which forms the basis for the Forbes Road development. The chained format, being long and narrow, required adjustment for the Awatea site. Without changing the format, homes built at the extremities would suffer from loss of privacy, road proximity associated issues, and disassociation from the development. Introducing two two-storey dwellings on a shared $400 \mathrm{~m}^{2}$ hexagonal site allows for construction of larger family homes. The density is increased to $50 \mathrm{dph}$ and the occupancy potential is doubled as each unit can be designed for up to four double bedrooms. This is a desirable scenario when land is scarce.

This also provides a higher density core to the surrounding houses and a common area accessible to the wider community, improving amenity and desirability to the whole area.

To create identity the hexagonal theme was further developed allowing the rigid geometry to direct the formation of paths, gardens and greenspaces, then taking full hexagonal elements into window and façade designs. Although a cheaper option for multi house developments is to duplicate floor and exterior designs, floor plans and facades were developed to create individual identity and visual interest for the occupants and observers. This also demonstrates the flexibility of the hexgonal site and resultant home designs. It is interesting to note the similarity between some units and the 'boomerang' home popular in the sixties and seventies here in New Zealand. 


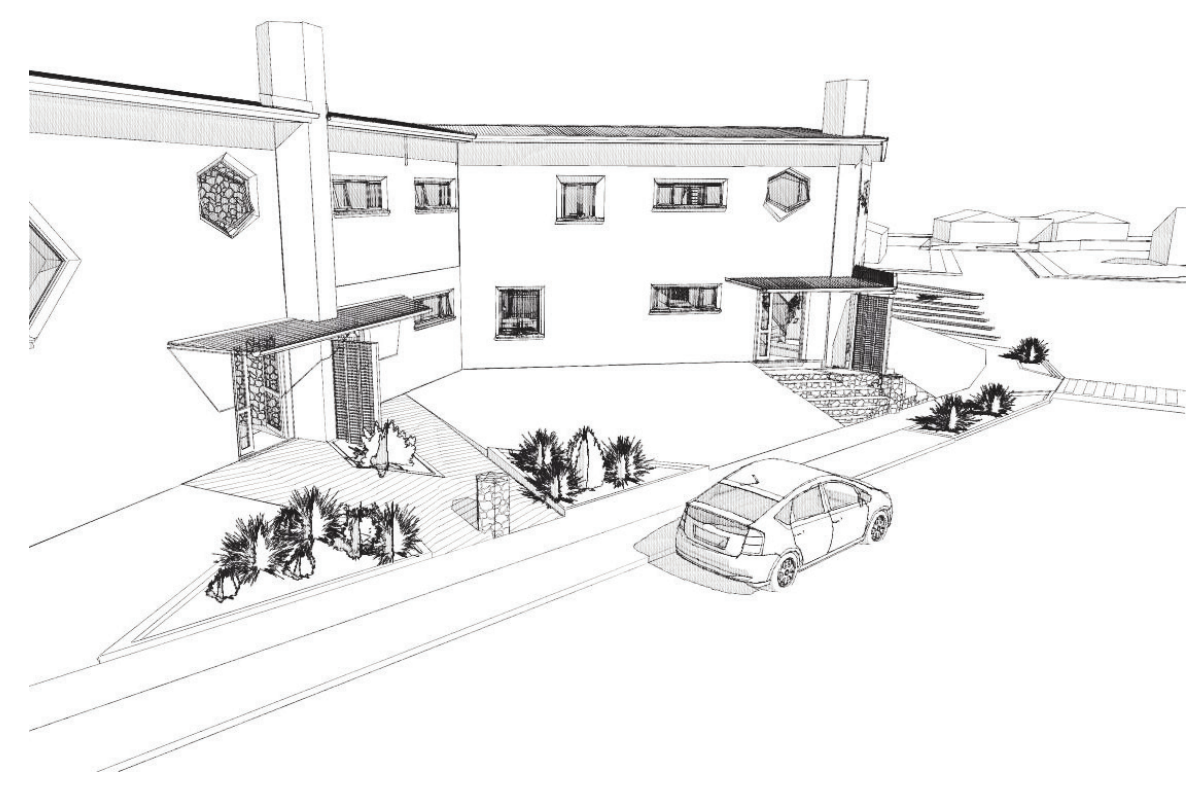

South facing walls have less window area, enhancing privacy from the road and reducing heat loss from glazing.

North facing walls favour increased glazing, thermal mass floors, sunrooms and trombe walls, all of which benefit from increased exposure to sunlight and enhances this area for use by the occupants. 


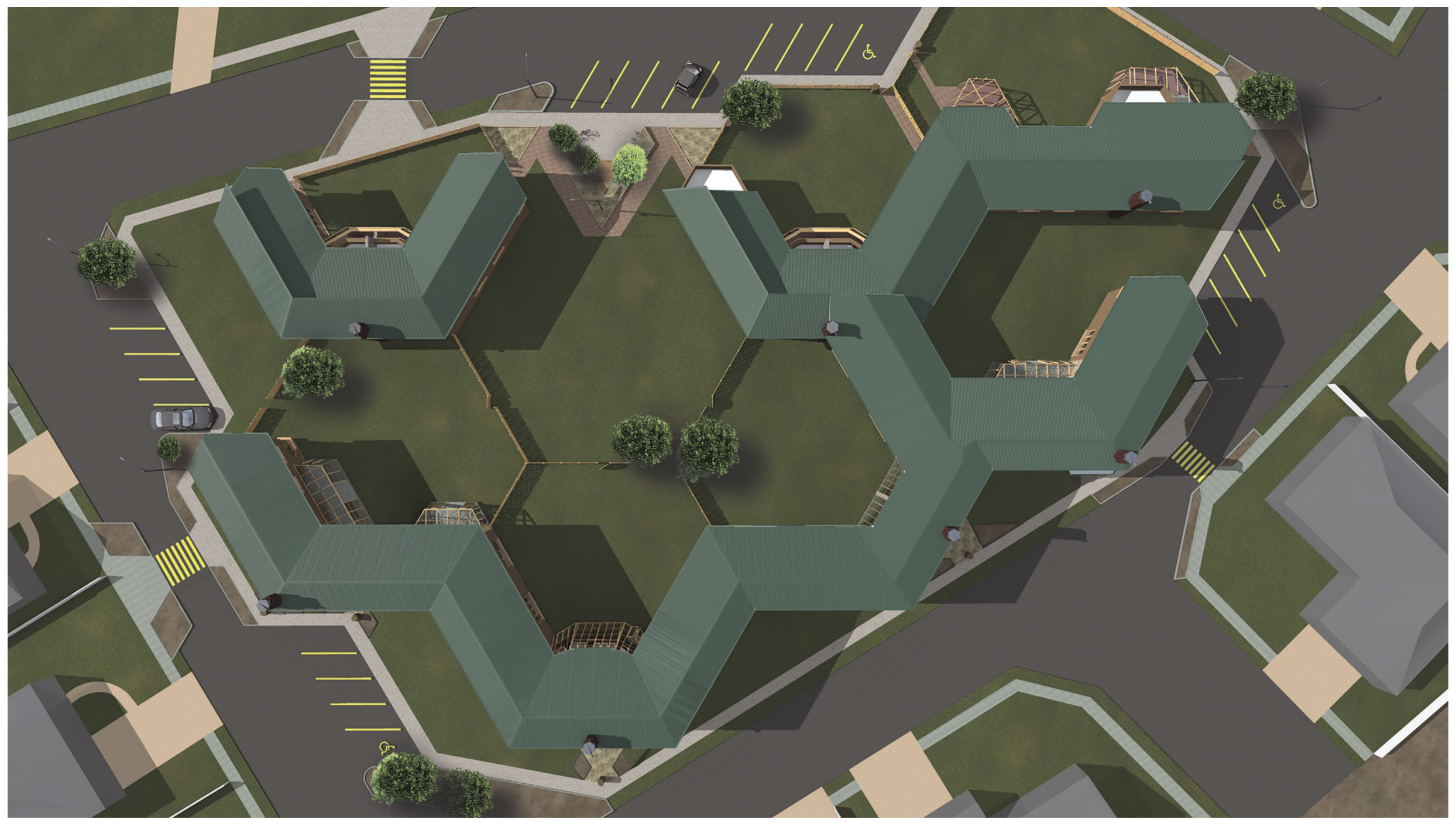

Awatea road's vacant island lot could be transformed into a medium density focal point for the local community. The public space with its northerly access is overlooked from all sides, and with limited access to the road provides a safe play ground environment. In this version, fences separate private space from public. 


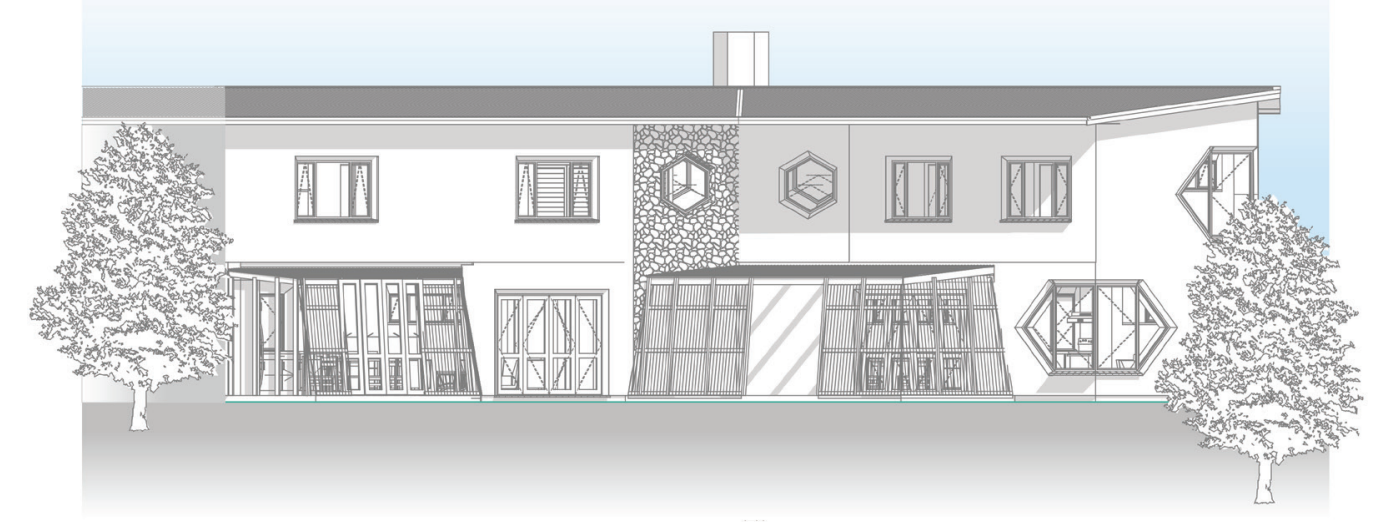

Two two bedroom units.

$\begin{array}{llll}\text { Site Area } & 400 \mathrm{~m}^{2} & \text { Unit Area } & 105 \mathrm{~m}^{2} \text { each } \\ \text { Site Coverage } & 26 \% & \text { Dph } & 50 \\ \text { Sunroom } & 15 \& 11 \mathrm{~m}^{2} & \text { Bathroom } & 1 \\ \text { Toilet } & 1 \text { combined } & \text { Bedrooms } & 2 \\ \text { Sleeps } & 4 & \text { Living Area } & 1 \\ \text { Study Alcove } & 1 & \text { Entrance } & 1 \text { double height }(\mathrm{dh}) \\ \text { First Floor Deck } & 6 \mathrm{~m}^{2} \text { each } & & \end{array}$

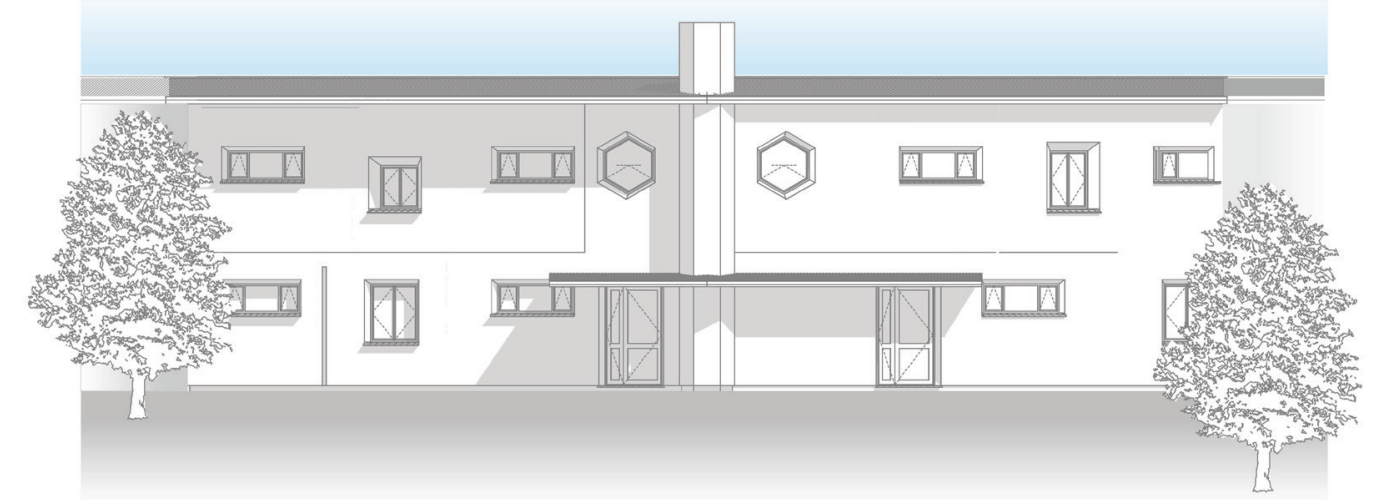

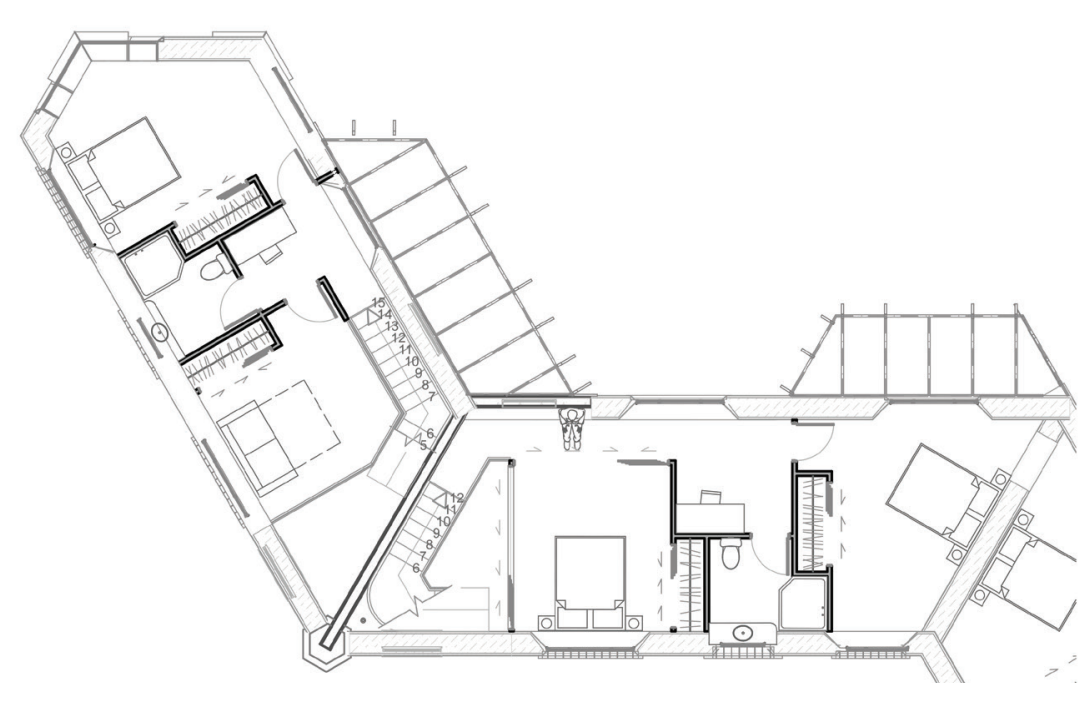

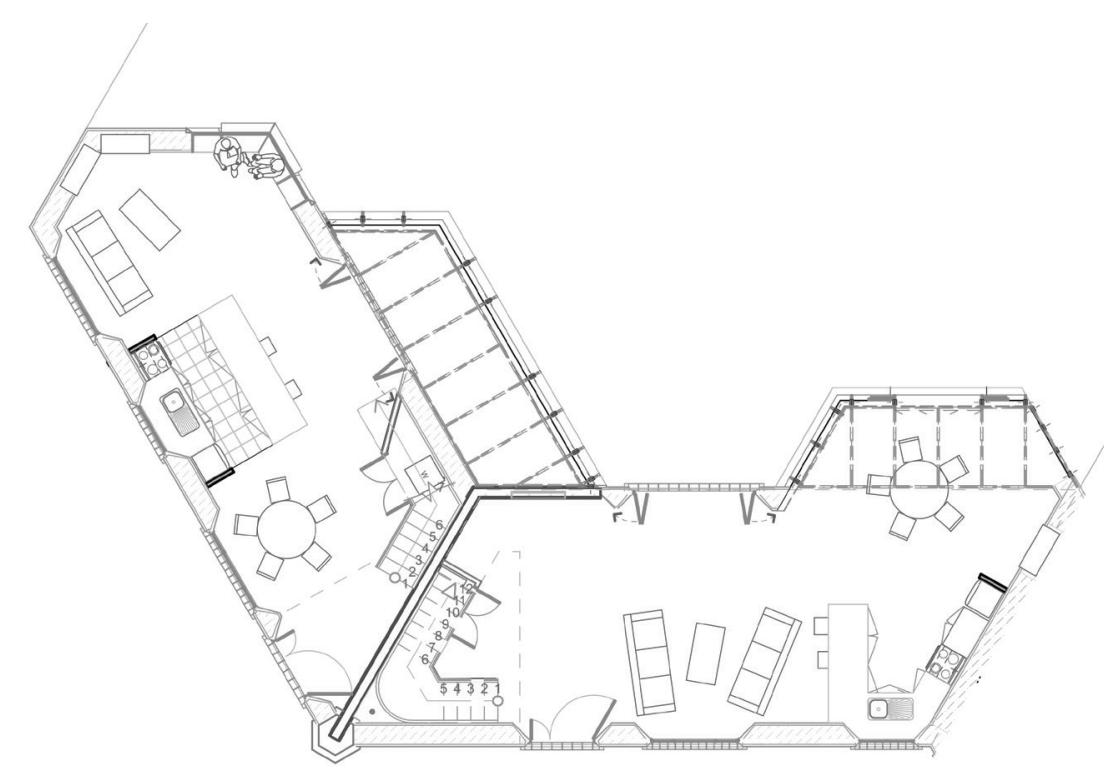




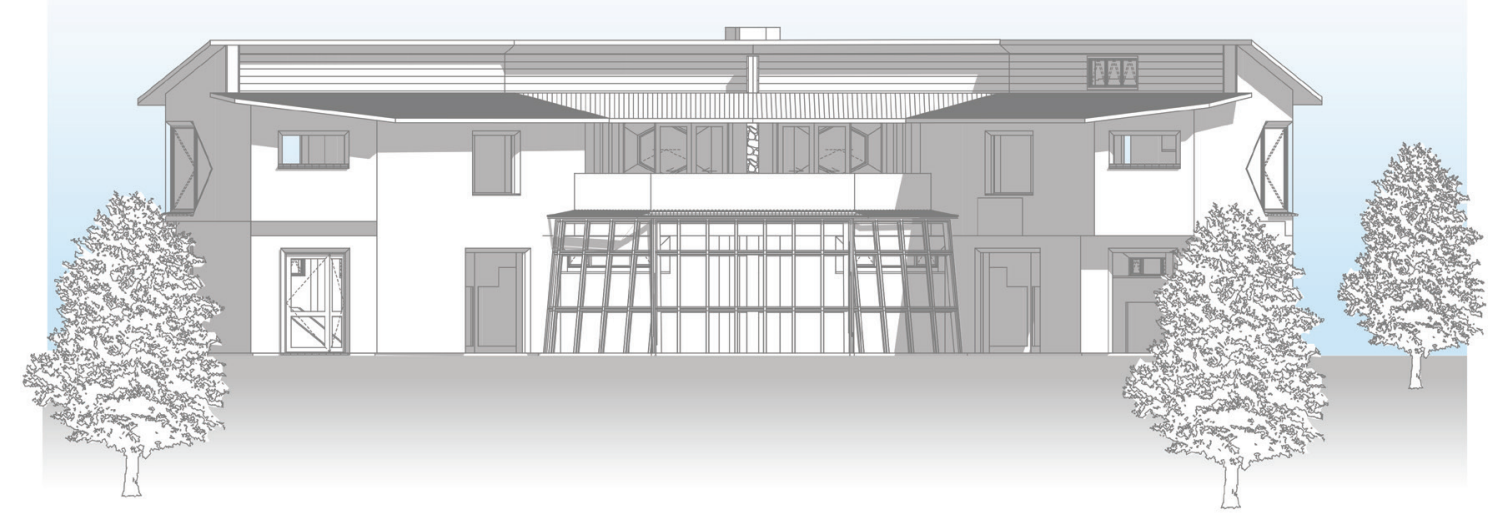

Two two bedroom units.

$\begin{array}{lllc}\text { Site Area } & 400 \mathrm{~m}^{2} & \text { Unit Area } & 160 \& 180 \mathrm{~m}^{2} \mathrm{~m} \\ \text { Site Coverage } & 45 \% & \text { Dph } & 50 \\ \text { Sunroom } & 12.5 \mathrm{~m}^{2} \text { each } & \text { Bathroom } & 1 \\ \text { Toilet } & 1 \text { combined } & \text { Bedrooms } & 3 \\ \text { Sleeps } & 6 & \text { Living Area } & 1 \\ \text { Study Alcove } & 1 & \text { Entrance } & 1 \mathrm{dh}\end{array}$

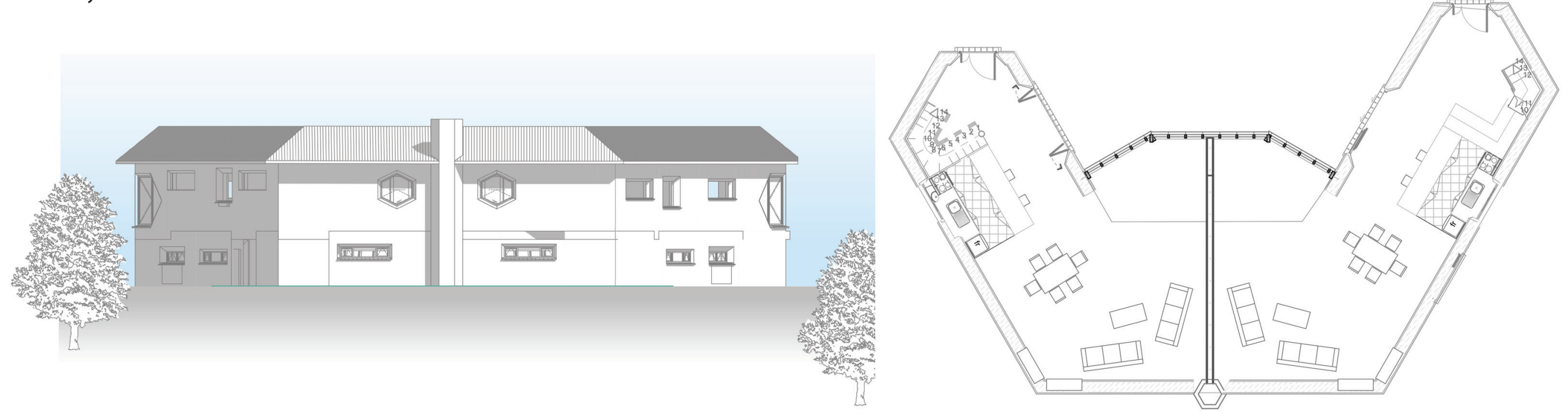



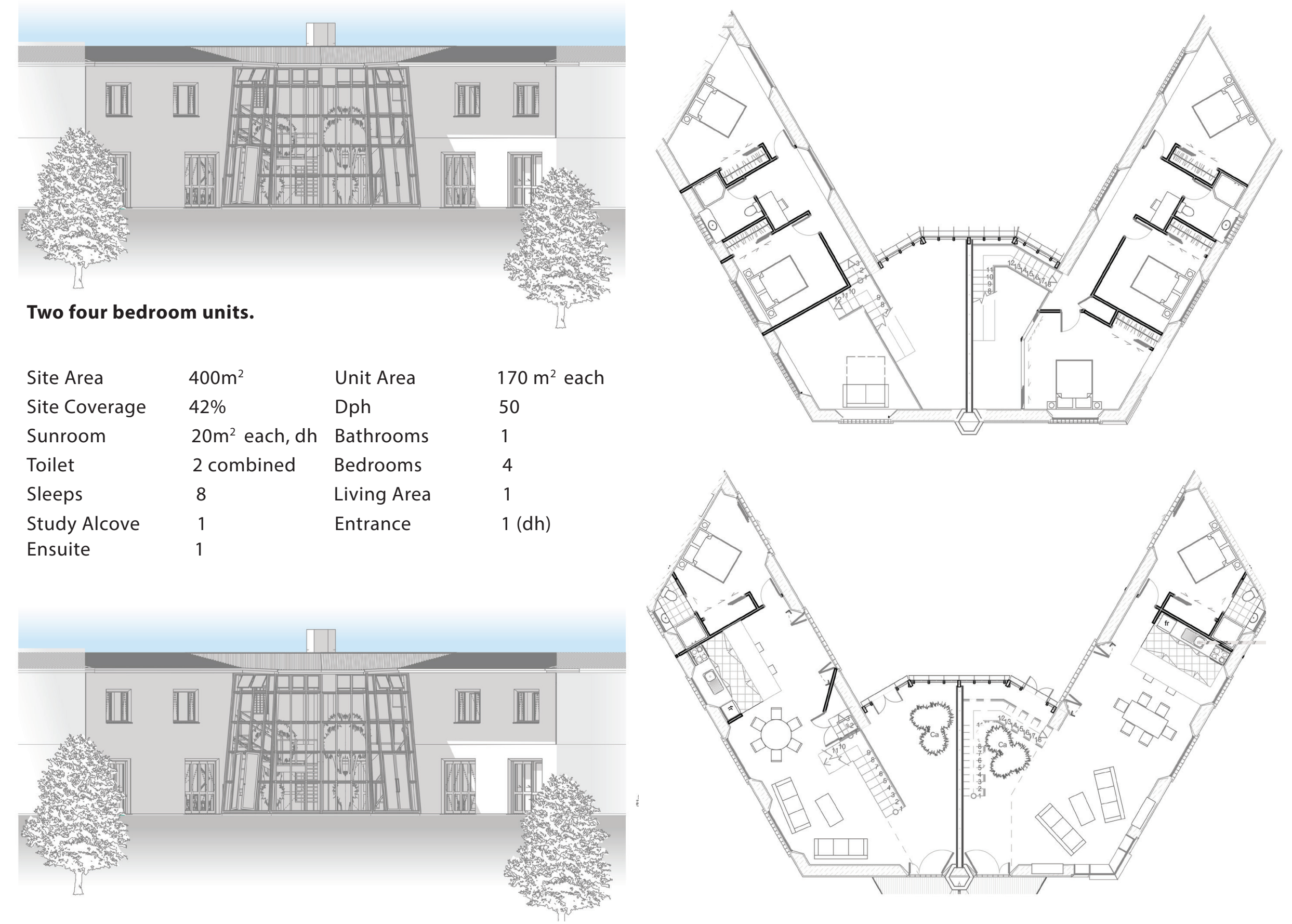


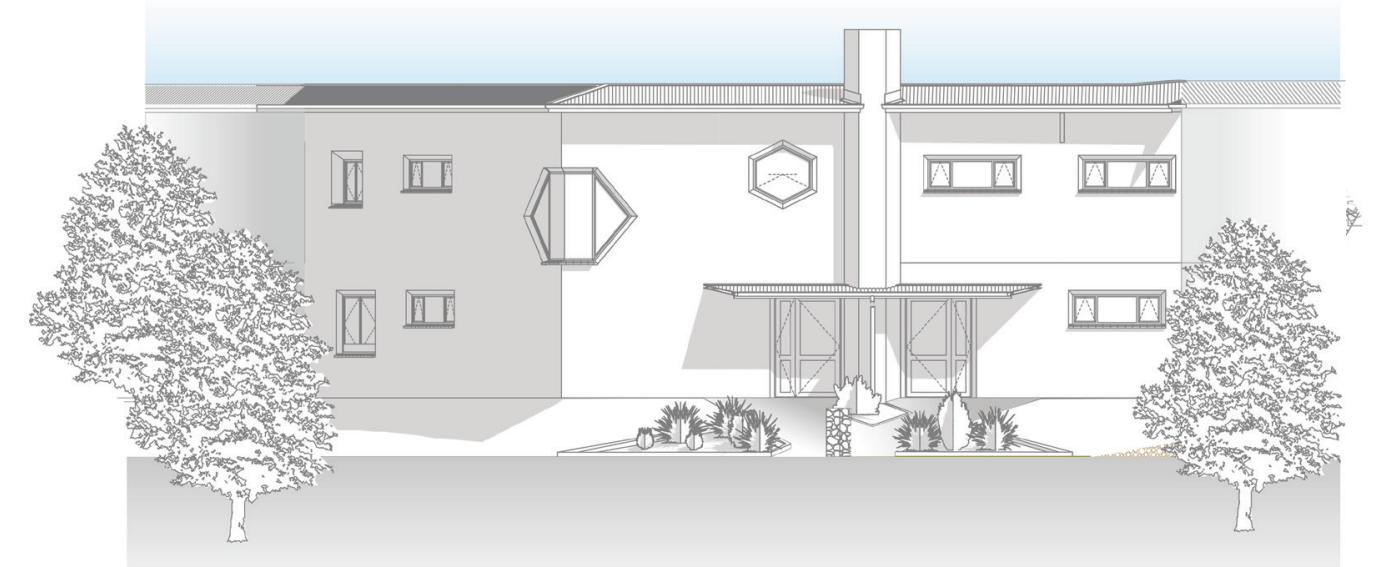

Two four bedroom units.

$\begin{array}{llll}\text { Site Area } & 400 \mathrm{~m}^{2} & \text { Unit Area } & 165 \mathrm{~m}^{2} \text { each } \\ \text { Site Coverage } & 41 \% & \text { Dph } & 50 \\ \text { Sunroom } & 8 \mathrm{~m}^{2} \text { each, dh } & \text { Bathrooms } & 1 \\ \text { Toilet } & 2 \text { combined } & \text { Bedrooms } & 4 \\ \text { Sleeps } & 8 & \text { Living Area } & 1 \\ \text { Study Alcove } & 1 & \text { Entrance } & 1 \\ \text { Ensuite } & 1 & & \end{array}$

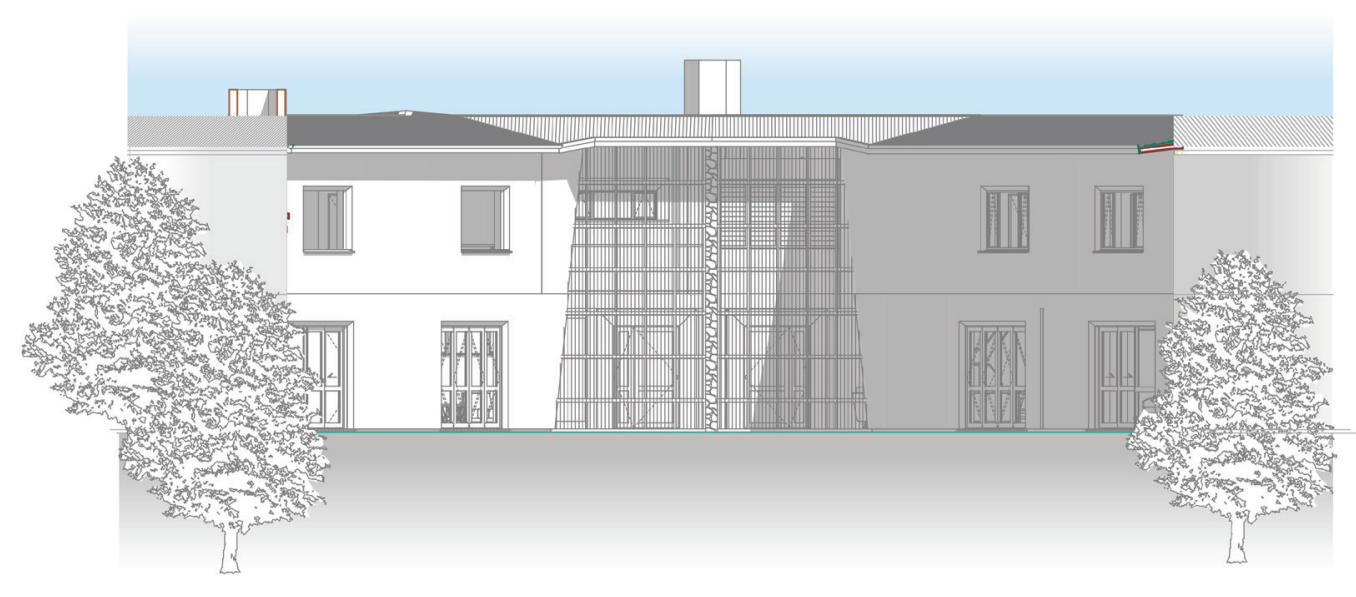

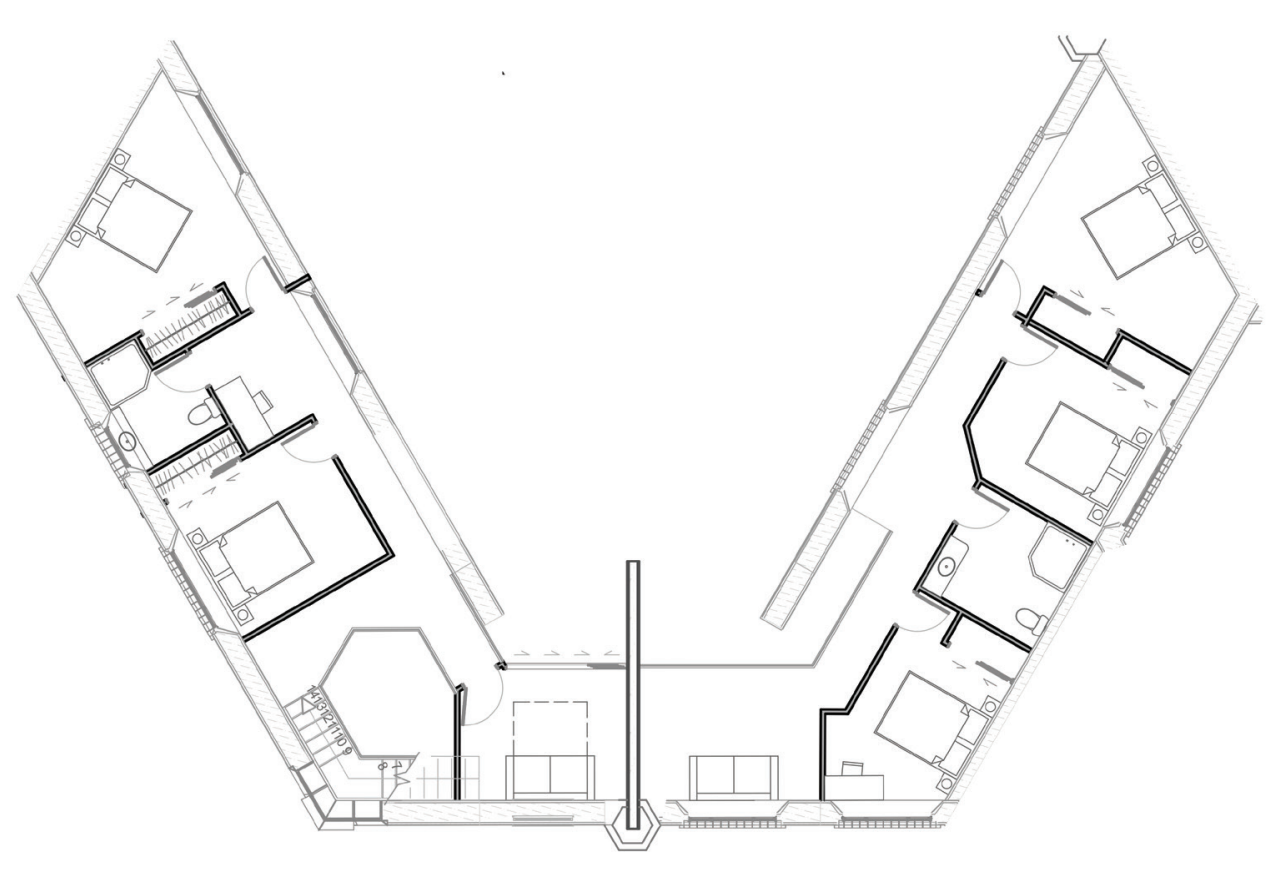

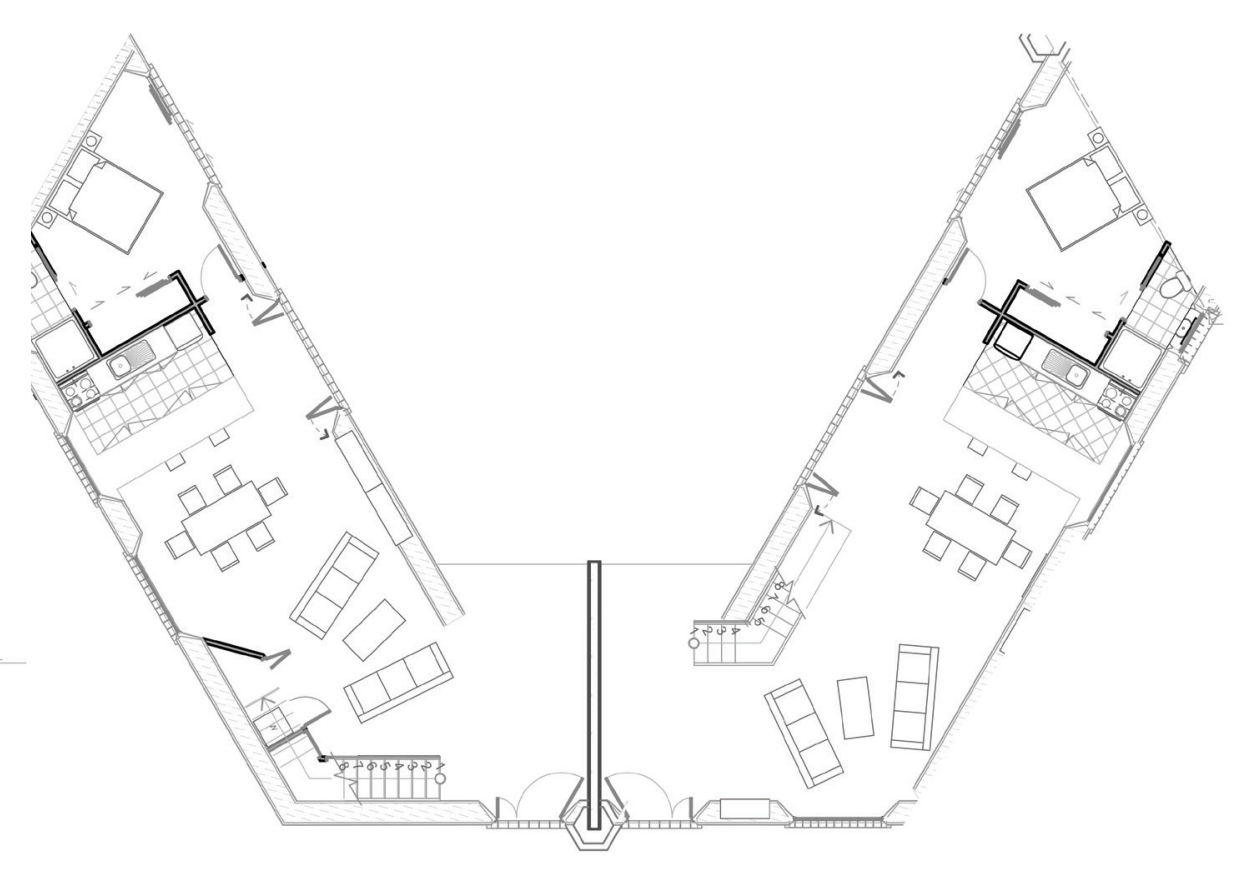


Awatea medium density development.

Right. The hexagonal format allows sunlight to access the north face of every home for up to six hours per day. The stepped configuration also means easy access to the central park area and long viewshafts provide feelings of spaciousness. Refer appendix - site analysis P112 for more information.

Below. Perimeter paths, parking and planting enhance the development.
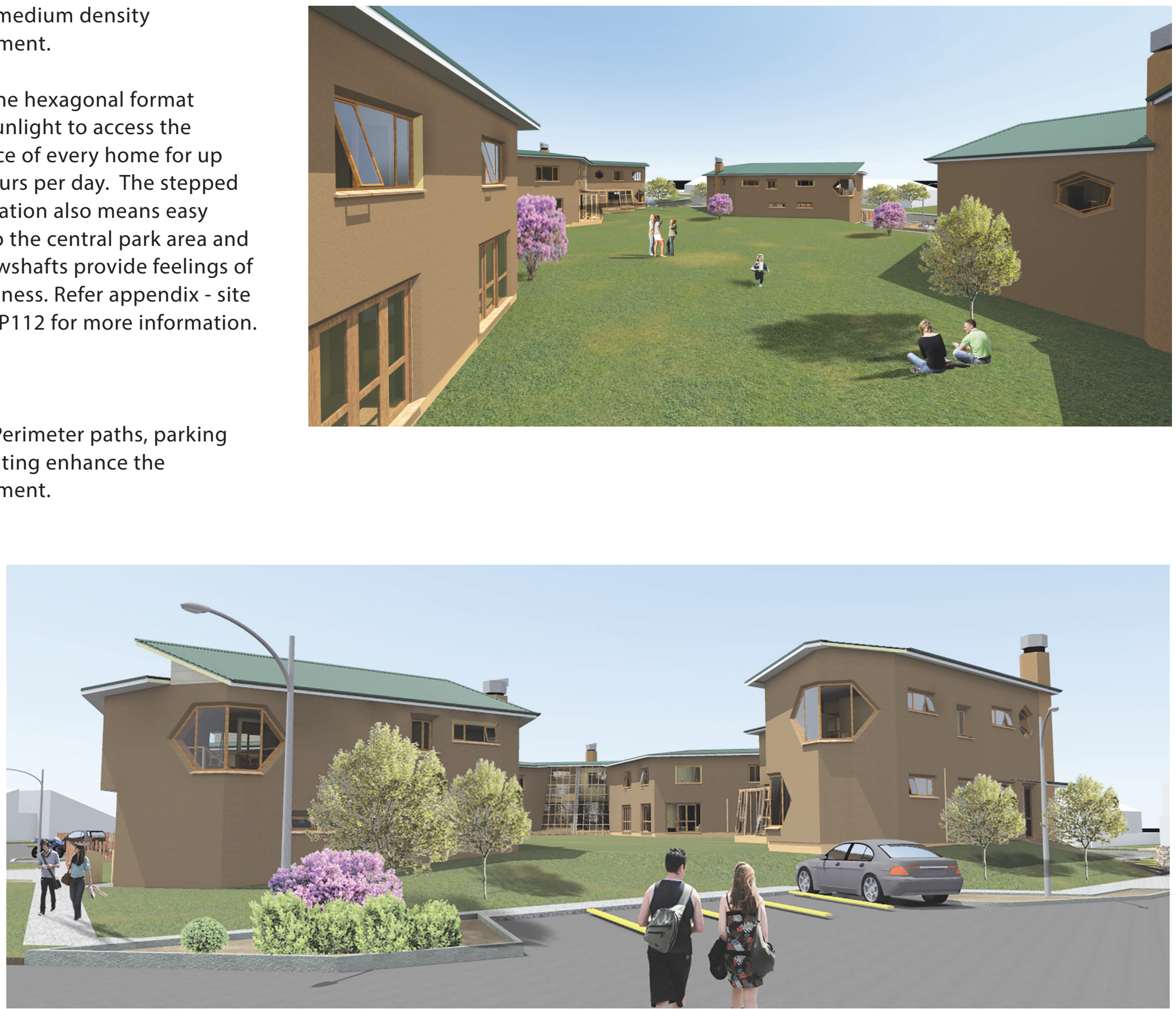


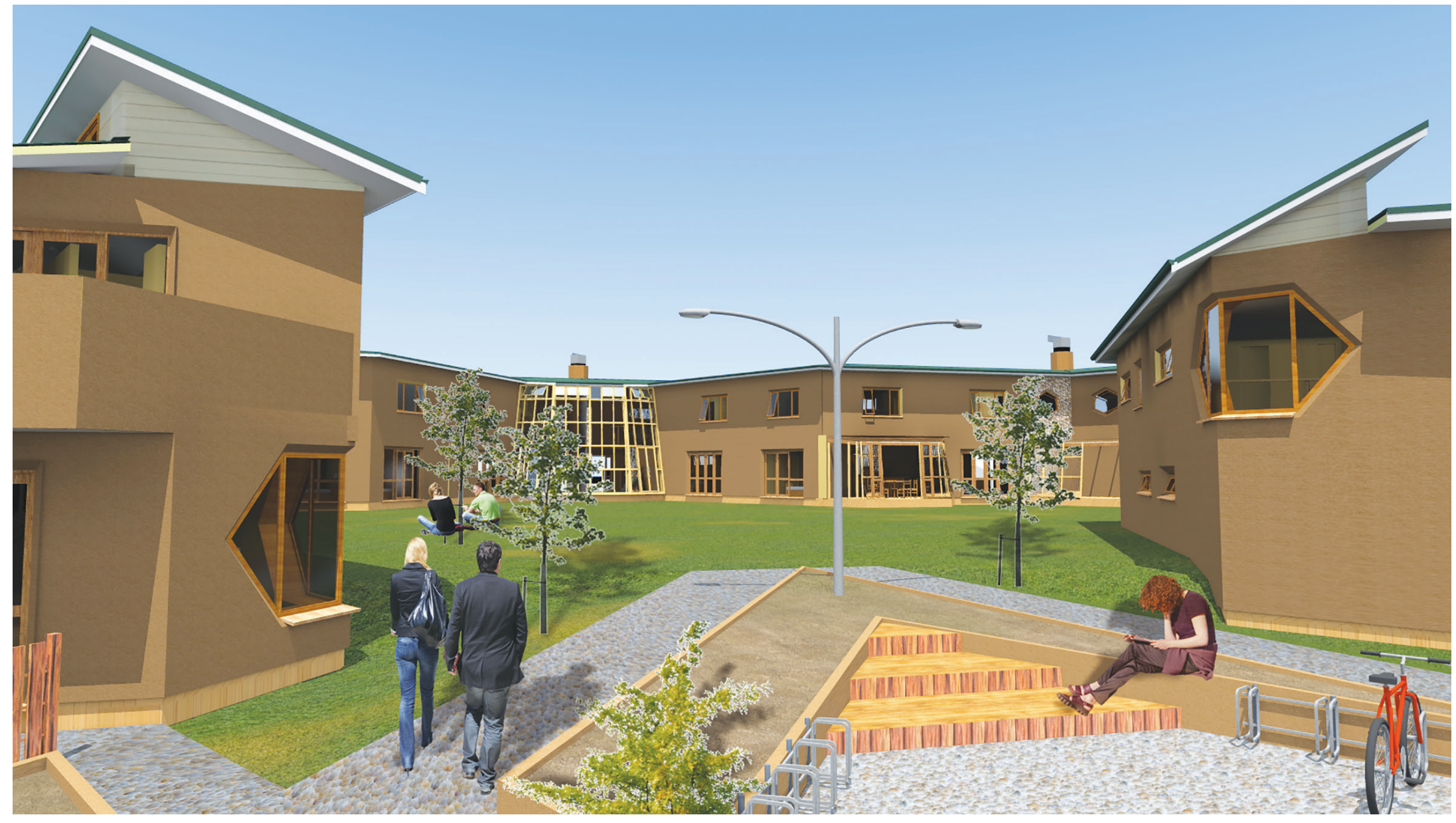

The northern entrance to the park also allows access to

the front entrance of most homes. The park and entrance security is enhanced by the overlooking homes. 


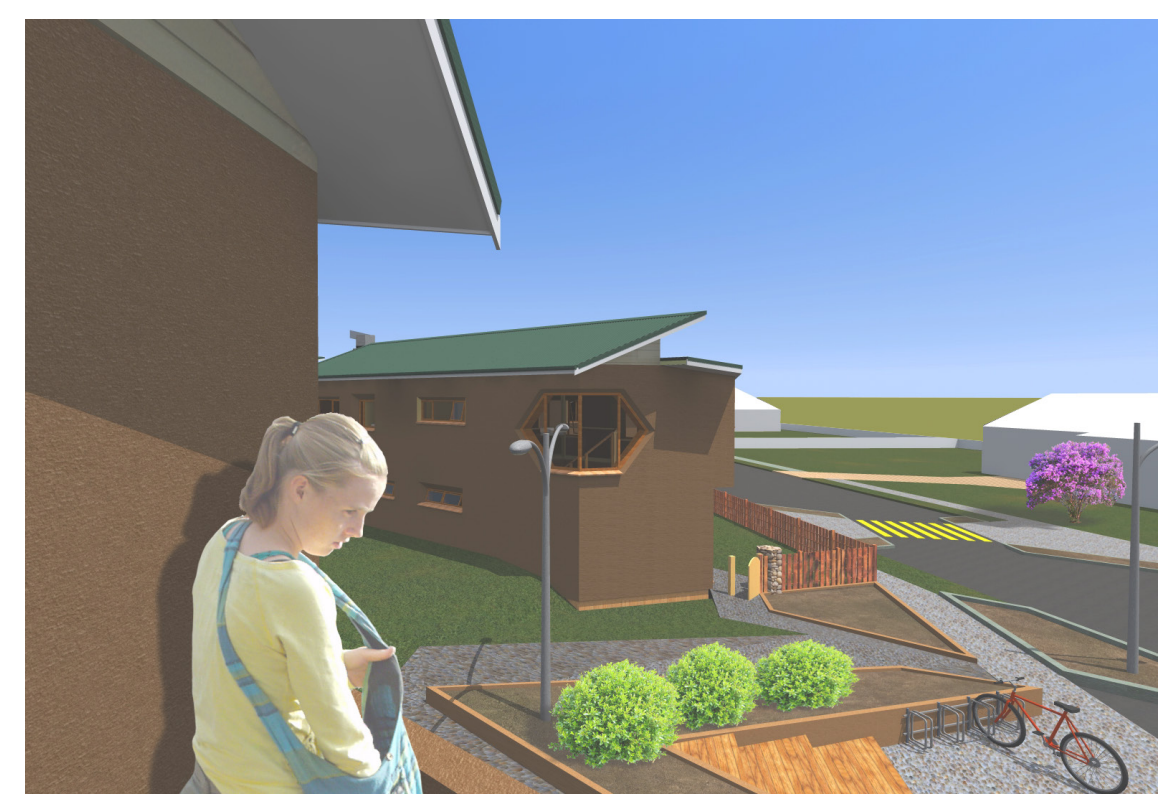

Left

First floor decks enhance outdoor living and increase security for the shared parkland. When carefully positioned they need not compromise the privacy of other homes.

Below

Glass fronted lobby and lounge area provides light and passive solar gain heating to interior thermal mass walls and floors.

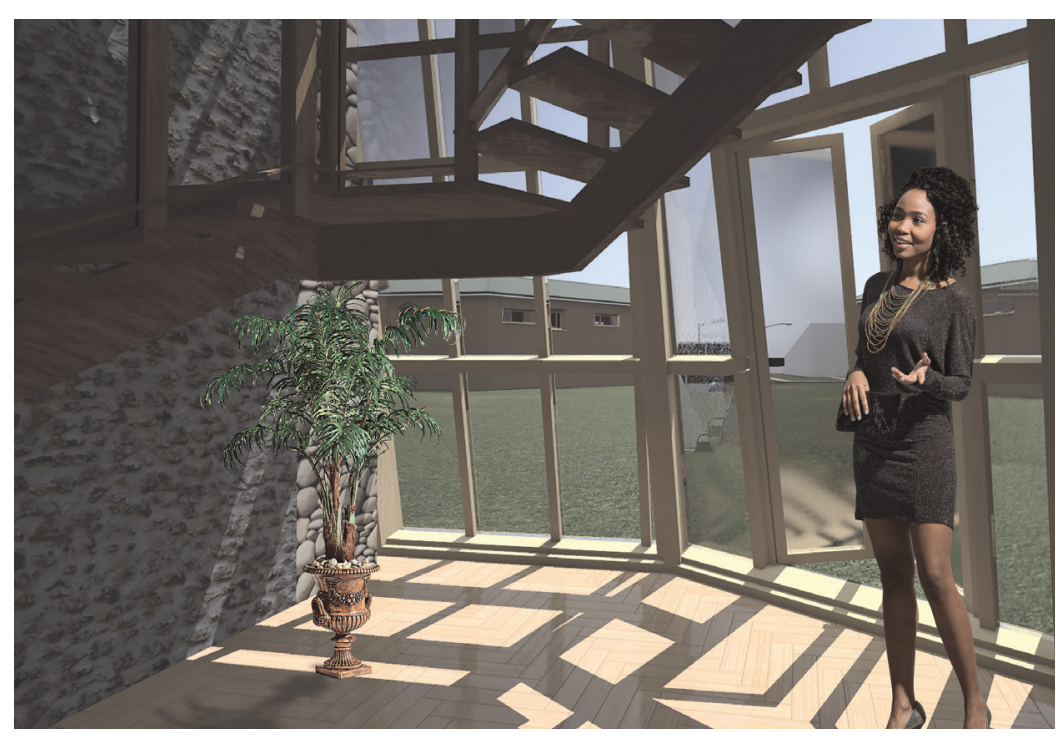




\section{Right.}

The hexagonal corner window seat is developed from the square version in the Forbes Road design solution. This later iteration draws from the hexagonal influence to add identity to the houses.

\section{Below.}

Tadelakt finished walls provide a healthy bathroom finish for walls. The recessed vanity unit does not encroach on the floor space.

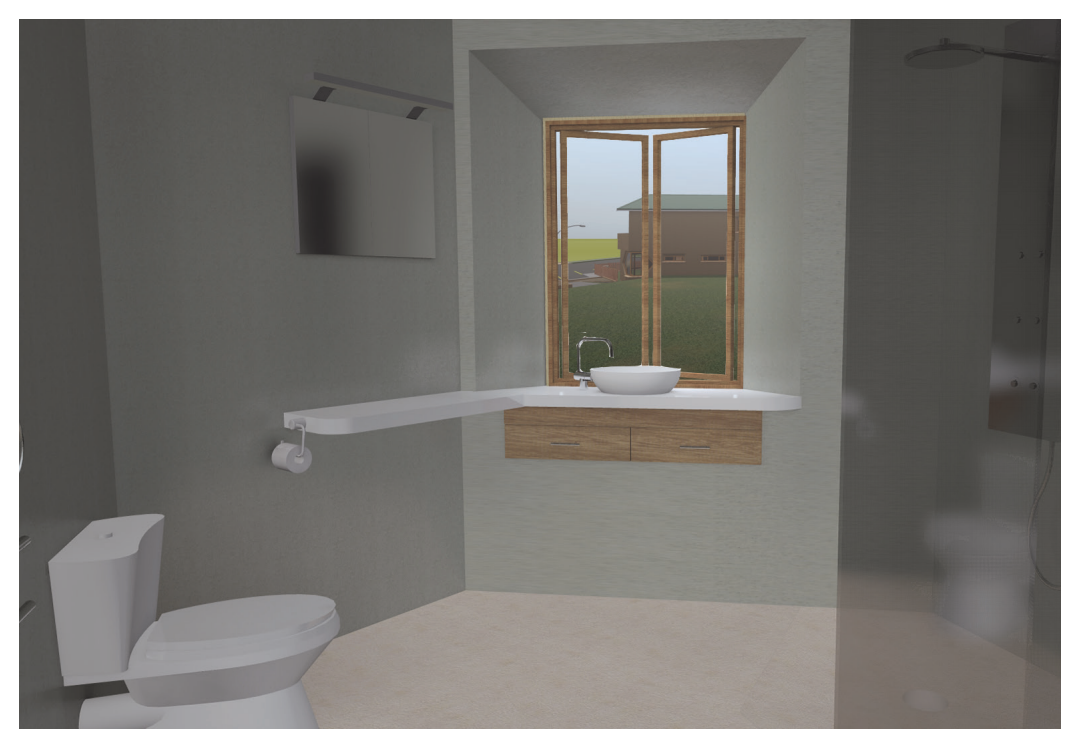

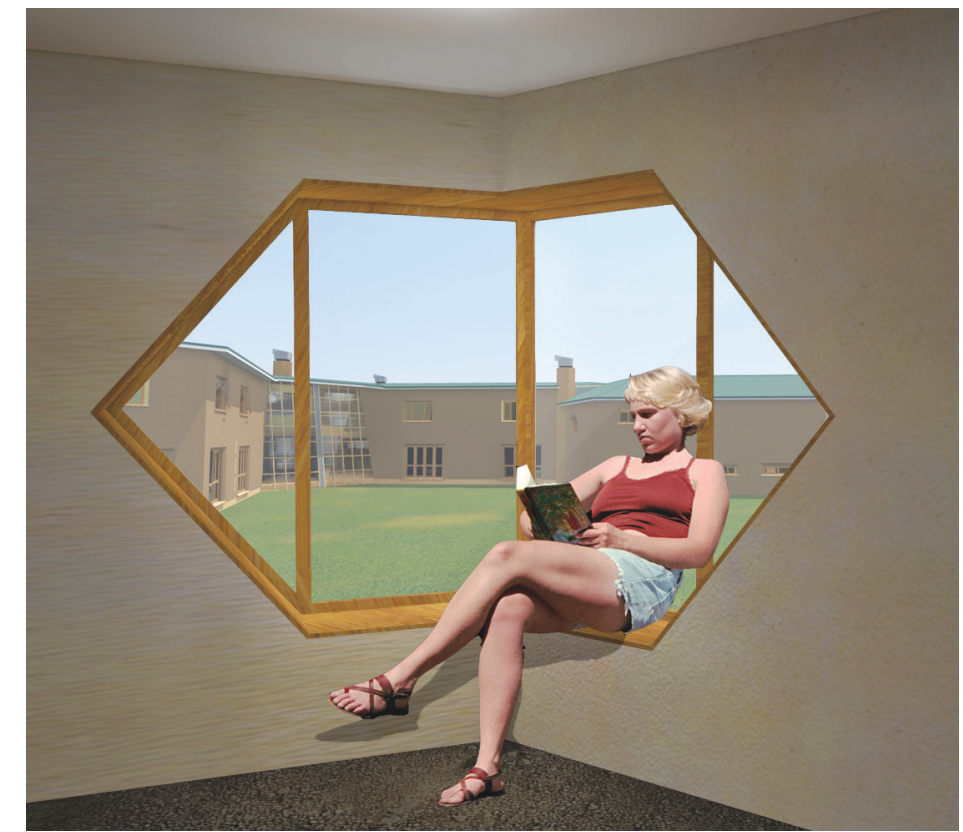




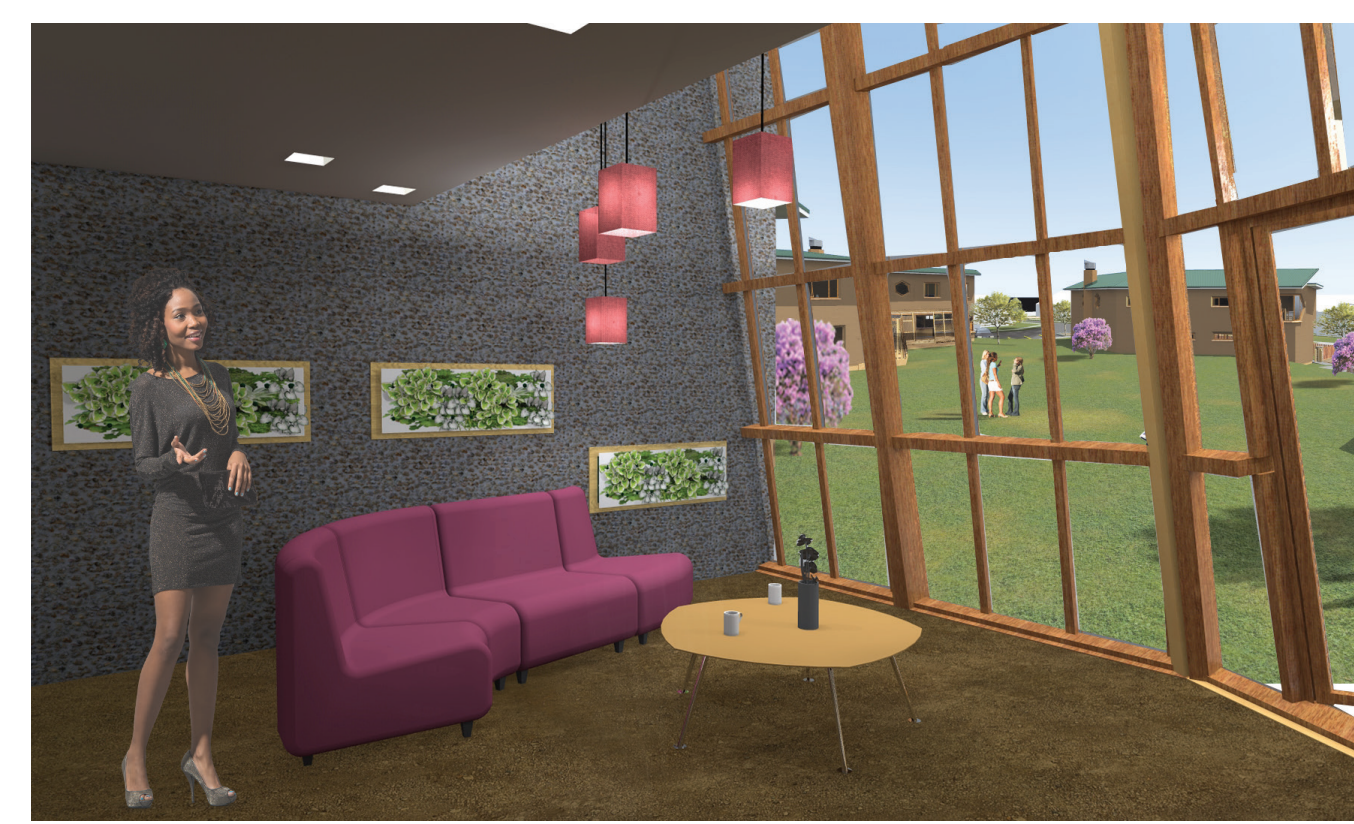

Left

Trombe wall and polished earth floors provied thermal mass, storing heat absorbed the expanisve north facing windows, stabilising room temperatures.

Right.

Recessed led lighting reduces power requirement. Recessed shelving provides non invasive storage.

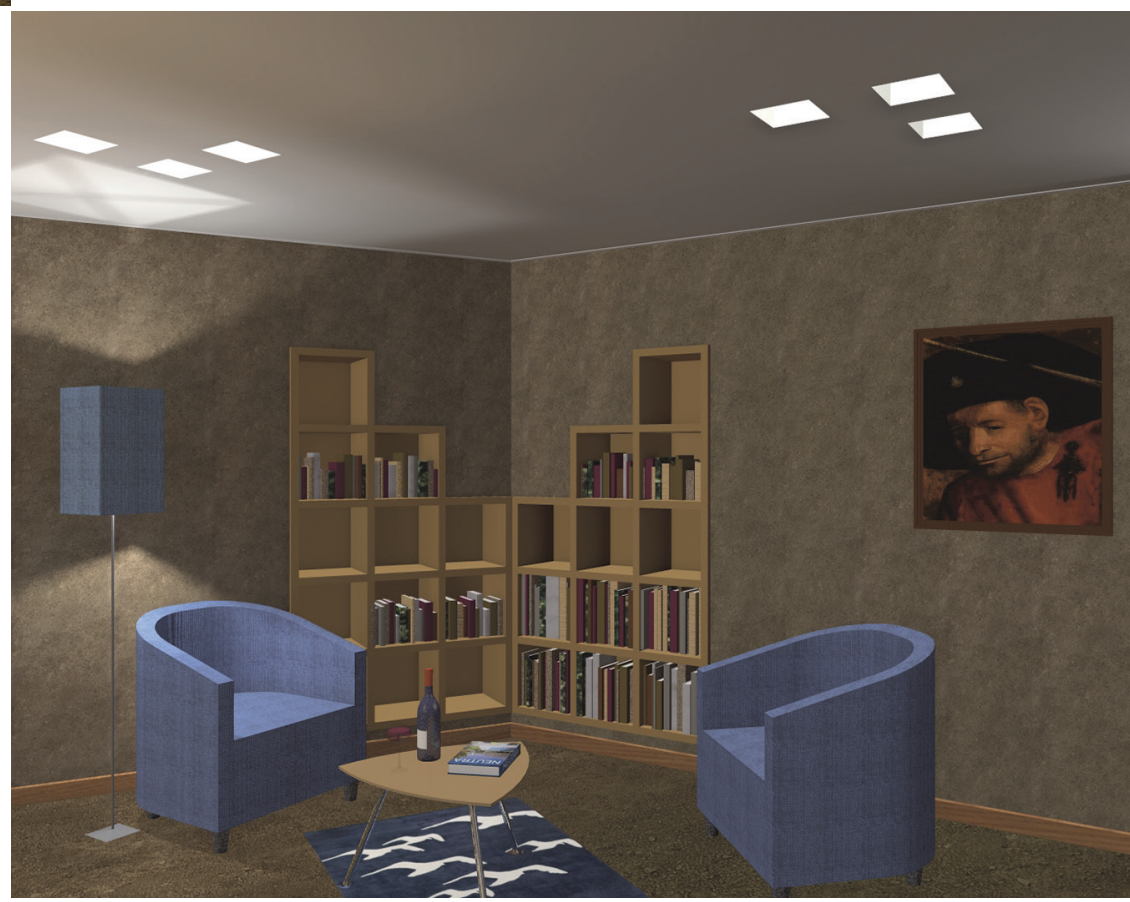




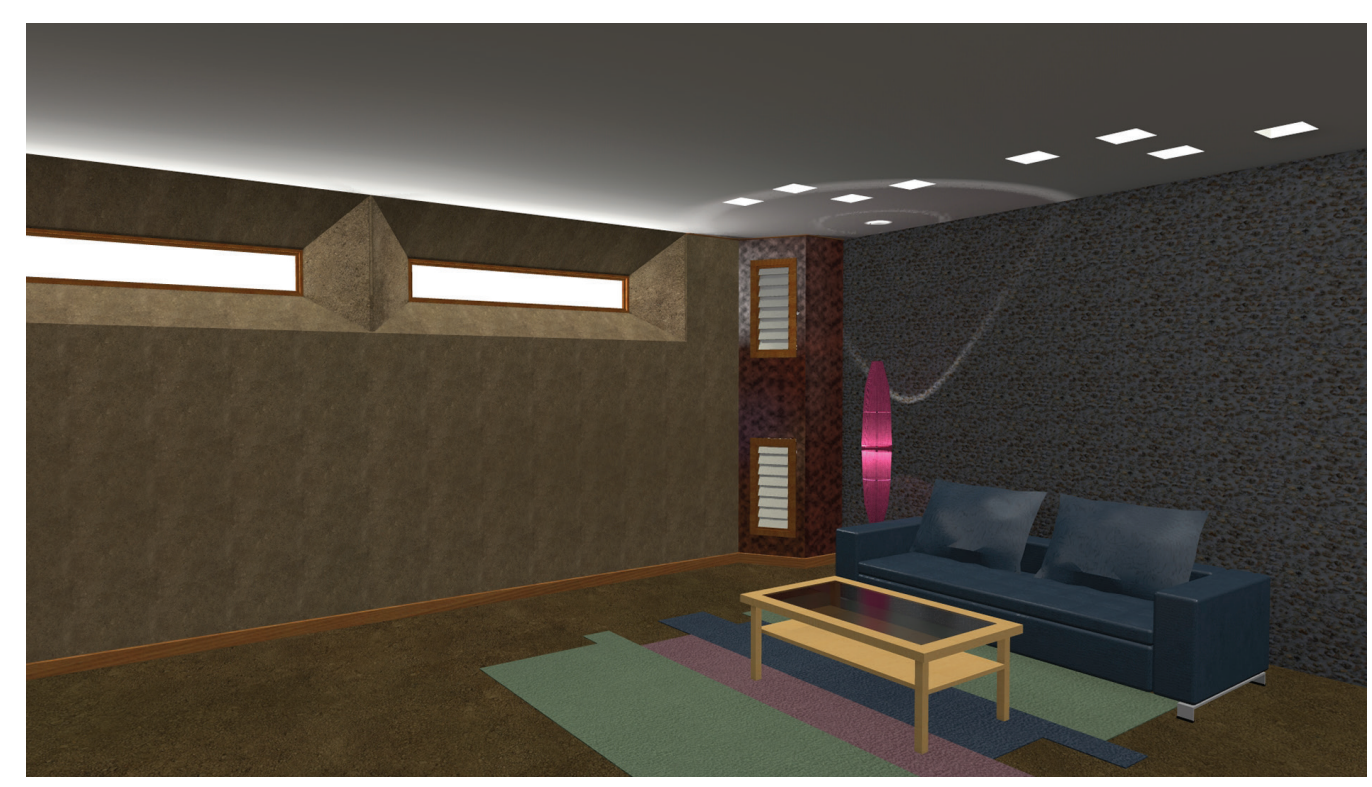

Opaque glazing in recessed 'light shelves' provides southern light to lower levels without compromising privacy.

Vents to the centre of the image induce circulation through the thermal chimney (bottom left) providing cross ventilation for the ground floor of two storey houses. The thermal chimney also provides vertical access for solar water heating and electrical services.

Below

Recessed cabintetry and kitchen benches reduce demand for floor space whilst providing storage space.
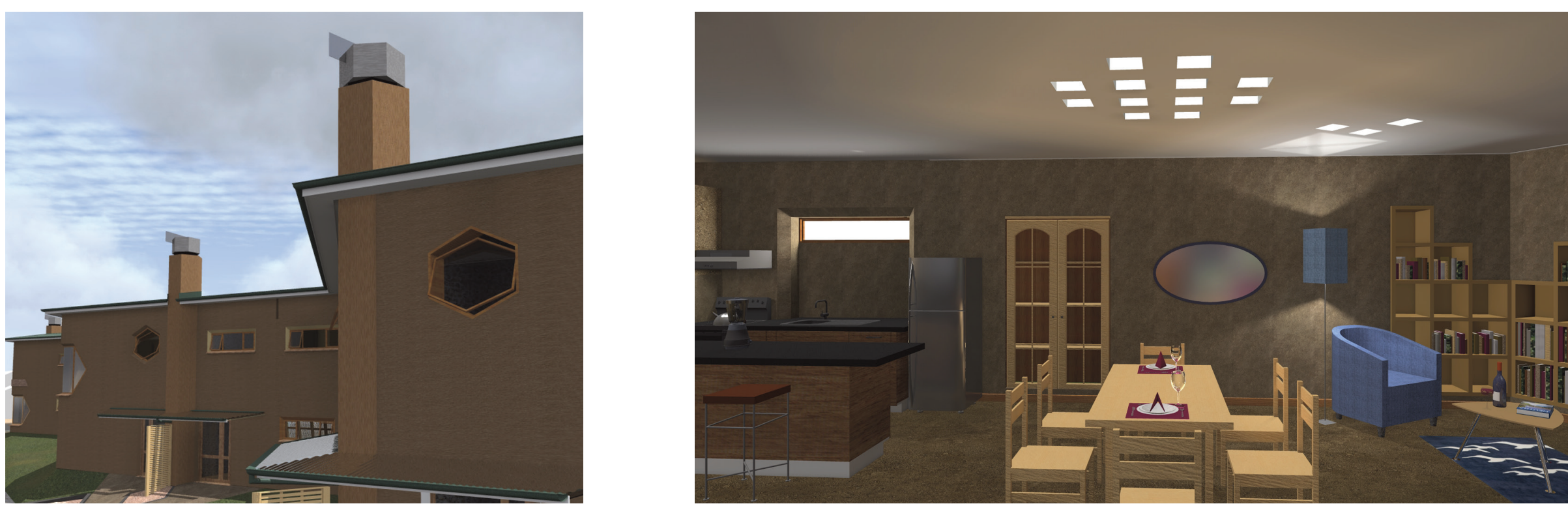
'The house should not keep us isolated from the outside world. It should select and filter, keeping out and expelling what is bad, and welcoming in and storing what is good. This is possible through the selection of the right location, appropriate materials and shape of construction, and the right technical installations.'

Dr. Anton Schneider - Bau Biologie 


\section{Conclusion}

RESEARCH SUMMARY

REFLECTION

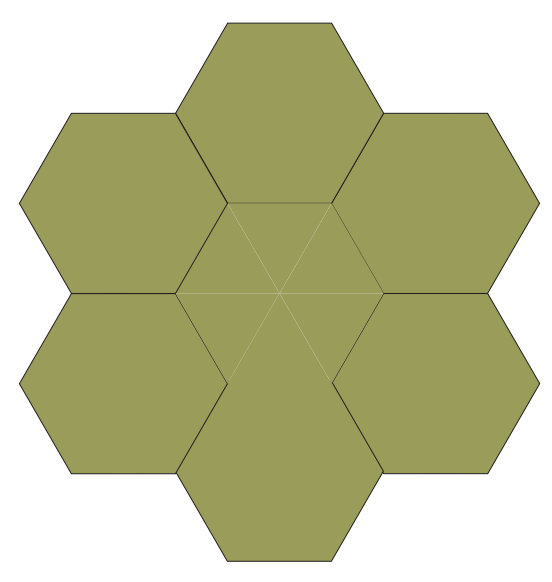

Natural building is of course not limited to hexagonal housing, and just as I have separated my research into sextants, the results of each area of inquiry can be utilised autonomously, or combined as with this project.

\section{Research Summary}

\section{Density \& Configuration}

Scarcity of productive land compels us to look to higher densities of housing and reduce the number of low density developments.

\section{Materials}

More indepth research and care should be taken when introducing manufactured products to market. Longer term effects on health and the environment need to be understood before products or materials are released which later may lead to problems or disasters such as leaky homes or asbestosis.

\section{Sustainability}

Longevity should appear more prominently in sustainability. Maintenance and replacement can be minimised, reducing the load on finite and limited resources by designing and building with a longer life expectancy for the buildings.

\section{Natural Materials}

It can be adequately argued that healthy building options require no defence. They are an obvious choice when looking to reduce harm to occupants and the environment. Natural materials are plentiful and inexpensive. They are minimally processed and cheaper to manufacture, and biodegradable when finished with. This is a better option than the $40 \%$ of all landfill currently being produced by the building industry being left for future generations to contend with.

As the use of natural materials gains momentum there will be a complementary advancement in technologies improving efficiency and reducing the currently labour intensive aspect of natural building. 


\section{Precedents}

Globally the return to natural materials, higher in local labour cost but significantly cheaper in environmental impact, is gathering momentum.

Developed countries are introducing earth, timber and straw bale constructions to mainstream building. Lesser developed countries are already conversant with natural building, usually out of their necessity to make use of what they have at hand. New Zealand, an advocate of healthy living on a healthy planet, endeavours to maintain a clean green image, would do well to accelerate natural building as a way to be seen to strengthen its resolve to be environmentally responsible.

\section{The Hexagon}

This thesis endeavours to encourage the use of neglected technologies and materials in new modern ways. The introduction of the hexagon as a site configuration alone, is not going to resolve low and medium density building issues. It does however give us another tool to consider. It is another example of looking to the past for ideas, reminding us to think outside the square, or rectangle in the case of many housing estates, and realising that most of what we design are new iterations of previously explored ideas.

Hexagonal design is scaleable, and at a meso scale as applied here, presents a variety of potential solutions for site development. The real site applications demonstrate integration with conventional housing models, and can be achieved with beneficial and pleasing results. 


\section{Reflection}

Building healthier, resilient housing is long overdue. For too long home owners have been experimented on, with far too little understanding of the potential for harm their homes contain. The building industry has avoided genuine eco and sustainable practices with pseudo justifications around cost, sustainability and resilience of materials.

Humanity has an uncertain future. Many groups and countries are acknowledging the need to change how we build and how we function within society.

Initiatives such as Architecture $2030^{56}$, and its associated tool the 2030 Palette are one group bringing architects and other professionals together to actively discuss, design and apply methods and materials, providing potential solutions. Their mission statement asks for:

'the dramatic reduction in global fossil fuel consumption and GHG emissions of the built environment by changing the way cities, communities, infrastructure, and buildings, are planned, designed, and constructed and; the regional development of an adaptive, resilient built environment that can manage the impacts of climate change, preserve natural resources, and access low-cost, renewable energy resources.' 57 
'There is incredible generosity in the potentialities of Nature. We only have to discover how to utilize them.'

\author{
E.F. Schumacher
}




\section{Projection}

In the short term, social pressure and environmental awareness will increase the trend toward more eco and bio friendly building materials and methods.

Climate change, social evolution and emerging technologies will affect material choices, as well as how and what we shall build in the future.

Increasingly unpredictable and severe weather events suggest that we will require more protected outdoor areas.

Eden ${ }^{58}$ style biodomes (see chapter 6) may become commonplace with shared large enclosed 'outdoor' spaces. Internal and integral housing reliant on the dome for protection from the elements will reduce the need for durability and weathertightness, allowing for greater flexibility in material choice and finish to external building components which will be envoloped in an outer protective layer.

Advanced materials like Graphene and bioplastics will eventually replace fossil fuel based technologies, greatly expanding our palette of materials with enhanced physical properties, enabling structural feats well beyond anything we have imagined to date. Minimalism could be taken to extremes, rooms of micro thin graphene and bioplastic floors, ceilings, and walls requiring no supporting structure, transparent or opaque at the flick of a switch, and light enough to be reconfigured manually to suit purpose.

The future will see CNC style robot printers taking instruction directly from the architects software, recycling natural bioplastic building elements that are no longer required, regurgitating them in new forms when they are required, with no detrimental affect on humanity or the environment before during or after their use. 
'Architecture 2030'. N. p., n.d. Web. 11 Dec. 2013.

'Architecture, Green Building'. N. p., n.d. Web. 20 Jan. 2014.

'Asbestos - Testing for It in a Building - Health Risks'. BRANZ. n.d. Web. 3 Sept. 2013.

Asher, M.I. et al. 'International Study of Asthma and Allergies in Childhood (ISAAC): Rationale and Methods'. European Respiratory Journal 8.3 (1995): 483-491. CrossRef. Web. 24 Mar. 2014.

'Asthma in New Zealand | Asthma Foundation New Zealand'. N. p., n.d. Web. 15 Feb. 2014.

Ben-Joseph, Eran, and Gordon, David. 'Hexagonal Planning in Theory and Practice'. Journal of Urban Design 5.3 (2000): 29. Print.

'Benefits of the Cupolex Dome System | Cupolex Building Systems'. N.p., n.d. Web. 19 Oct. 2014.

Bentley, Ian. Responsive Environments: A Manual for Designers. London: Architectural Press, 1985. Print.

Chiras, Daniel D. The new ecological home : a complete guide to green building options. White River Junction, Vt.: Chelsea Green Pub. Co., 2004. Print.

Clarence C Eckel. Cements, Limes and Plasters; Their Materials, Manufacture and Properties. second edition. London: Chapman \& Hall Ltd, 1922. Print.

Craven, Jackie. 'Monolithic Dome Homes'. N.p., n.d. Web. 19 Oct. 2014.

Journal of Environmental Health 72.1 (2009): n. pag. Print. 
De Vuyst, P. et al. 'Respiratory Health Effects of Man-Made Vitreous (mineral) Fibres'. European Respiratory Journal 8.12 (1995): 2149-2173. CrossRef. Web. 24 Mar. 2014.

'Density: Definition of Density in Oxford Dictionary (British \& World English)'. N. p., n.d. Web. 24 Mar. 2014

Donn, Michael. 'Life Cycle Potential of Strawbale and Timber for Carbon Sequestration in House Construction.' Academia.edu. n.d. Web. 3 Sept. 2013.

Downton, Peter. Design research. Melbourne: RMIT Pub., 2003. Print.

'Ecodesign.' Wikipedia. n.d. Web. 10 July 2013.

'Eco Housing Plan Gains Council Support.' Stuff.co.nz. n.d. Web. 3 June 2013.

Escher, M. C et al. M.C. Escher: His Life and Complete Graphic Work; with a Fully Illustrated Catalogue. New York: Abradale Press/Harry N. Abrams, 1992. Print.

'Facts About Lime Plaster, the Benefits of It's Use and the History of Lime.' Albarius Heritage Limited. n.d. Web. 3 Sept. 2013.

Food and Agriculture Organization of the United Nations. World Agriculture: Towards 2015/2030: An FAO Perspective. London: Earthscan Publications, 2003. Print.

Fuller, R. Buckminster. Utopia or Oblivion: The Prospects for Humanity. London: Allen Lane, 1970. Print.

‘Graphene Properties, Graphenea'. N. p., n.d. Web. 24 Feb. 2014.

'Green Building Elements | From Brick and Mortar Shops to City Planning, We Cover Sustainable Trends in Construction, Renovation, and More.' N. p., n.d. Web. 9 Dec. 2013.

Guelberth, Cedar Rose. The Natural Plaster Book: Earth, Lime and Gypsum Plasters for Natural Homes. Gabriola, B.C: New Society Publishers, 2003. Print.

Jaycock, S. Moisture Retention and Migration Monitoring Within Straw Bale 
Jones, Barbara. Building with Straw Bales: a Practical Guide for the UK and Ireland. Totnes: Green Books, 2009. Print.

Kanuka-Fuchs, Reinhard. Healthy Home and Healthy Office: Sick Building Syndrome, Indoor Pollution and Solutions. Bermagui, N.S.W.: H. Tietze, 1996. Print.

King, Bruce, and Mark Aschheim. Design of straw bale buildings : the state of the art. San Rafael, CA: Green Building Press, 2006. Print.

Lana. 'Lime as a Timber Preservative'. The Sydney Mail 1899 : n. pag. Print.

'LILAC: UK's First Strawbale Co-Housing Project Opens in Leeds | Inhabitat - Sustainable Design Innovation, Eco Architecture, Green Building'. N. p., n.d. Web. 20 Jan. 2014.

'Medium-density Housing in New Zealand.' Ministry for the Environment. n.d. Web. 2 June 2013.

Michael Johannes Ochs. Tadelakt. W. W. Norton \& Company, 2009. Print.

Nicholas Grimshaw and Partners. The Architecture of Eden. London: Eden Project Books in association with Grimshaw, 2003. Print.

'PAKSBAB - Pakistan Straw Bale and Appropriate Building | PAKSBAB Home'. N. p., n.d. Web. 19 Feb. 2014

Plescia, Silvio. Relationship between Moisture Content and Mechanical Properties of Gypsum Sheathing. Canada: Canada mortgage and housing corporation, 2007. Print. Research Highlights.

'PVC Governmental Policies.' Center for Health, Environment \& Justice. n.d. Web. 3 Sept. 2013. 
R, C. 'Why Are Straw Houses Making a Come Back'. The Economist. n.d. 28 Nov. 2013: n. pag. Print.

Rael, Ronald. Earth Architecture. New York, N.Y.: Princeton Architectural Press, 2009. Print.

Roodman, David Malin, Nicholas K Lenssen, and Jane A Peterson. A Building Revolution: How Ecology and Health Concerns Are Transforming Construction. Washington, DC:

Worldwatch Institute, 1995. Print.

Schuldenfrei, Robin. 'Capital Dwelling: Industrial Capitalism, Financial Crisis, and the Bahaus's Haus Am Horn'. Architecture and Capitalism 1845 to the Present. First. London: Routledge, 2014. Print.

Searle, Alfred B. Limestone \& Its Products Their Nature, Production, and Uses. London: Ernest Benn Ltd, 1935. Print.

Stafford Holmes, \& Michael Wingate. (2002). Building with lime: a practical introduction. Intermediate Technology.

Stajanca M, Estokova A. Environmental Impacts of Cement Production. N. p., 2012. Print.

'Straw Bale House: NEES@Nevada: University of Nevada, Reno'. N. p., n.d. Web. 19 Feb. 2014.

'Straw House North Kesteven'. North Kesteven District Council. n.d. Web. 7 Sept. 2013.

'Sustainable Adjective - Definition in the British English Dictionary \& Thesaurus - Cambridge Dictionaries Online'. N. p., n.d. Web. 29 Mar. 2014.

'Sustainable Housing Design Guide for Scotland | Home Page - Introduction'. Web. 7 Sept. 2013.

'Ten Straw-Bale Homes - an Eco-Friendly Alternative to Explore'. N. p., n.d. Web. 16 Feb. 2014.

'The Economist Explains: Why Are Straw Houses Making a Comeback? | The Economist'. N. p., n.d. Web. 6 Dec. 2013. 
Vitruvius Pollio. The Ten Books on Architecture. [s.I.]: [Empire Books], 2011. Print.

Weismann, Adam, and Katy Bryce. Using Natural Finishes: Lime- \& Earthbased Plasters, Renders \& Paints : a Step-by-step Guide. Totnes: Green, 2008. Print.

'Why Use Lime?' Traditional Lime Company. n.d. Web. 3 Sept. 2013

Wilkie, Kim. The Saxon Villages of Transylvania, Romania, A Future for the Mediaeval Landscape. The Mihai Eminescu Trust, 2001. Print.

Woolley, Tom. Low Impact Building: Housing with Renewable Materials. Chichester, West Sussex, UK: Wiley-Blackwell, 2013. Print.

Yost, Nathan. Frequently Asked Questions about Mold. Washington, DC: National Association of Realtors, 2011. Print.

Ziesemann, Gerd, and Martin Krampfer. Tadelakt. Sehlem: KreidezeitEigenverl., 2007. Print.

'2030 Palette @2011 2030, Inc. / Architecture 2030'. N. p., n.d. Web. 11 Dec. 2013

'27 June 2013 Media Release.' University of Otago, New Zealand. N. p., n.d. Web. 15 Feb. 2014. 
1. Jaycock, S. “Thorndon Mews." 2013. JPEG file.

2. Jaycock, S. “Earthsong 1." 2013. JPEG file.

3. Straw House | North Kesteven. N. p., n.d. Web. 7 Sept. 2013.

4. LILAC-Strawbale-Co-Housing-Project.jpg (JPEG Image, $537 \times 302$ Pixels). N. p. Web. 4 Apr. 2014.

5. 'Forbes Road, Foxton Beach, Manawatu-Wanganui - Google Maps'. N. p., n.d. Web. 16 Dec. 2013.

6. The mediaeval street and courtyard patterns of Viscri. N.d. The Mihai Eminescu Trust, The Saxon Villages of Transylvania, Romania, A Future for the Mediaeval Landscape. By Wilkie, Kim. The Mihai Eminescu Trust, 2001. Print.

7. Jaycock, S. "Earthsong 2." 2013. JPEG file.

8. 800px-Federal_Hill_row_houses_(5136609199).jpg (JPEG Image, $800 \times 532$ Pixels) - Scaled (0\%). N. p. Web. 3 Apr. 2014.

9. 'File:Pantheon Chiesa, Roma fc01.jpg - Wikimedia Commons'. N. p., n.d. Web. 3 Apr. 2014.

10. 'File:OCULUS IN THE PANTHEON.JPG - Wikimedia Commons'. N. p., n.d. Web. 3 Apr. 2014.

11. 'Strawbale-Construction.jpg (JPEG Image, $600 \times 450$ Pixels)'. N. p., n.d. Web. 4 Apr. 2014. 
11. 'Earthquake-Resistant-homes5.jpg (JPEG Image, $600 \times 451$ Pixels)'. N. p., n.d. Web. 4 Apr. 2014.

12. 'Strawbale-Lake.jpg (JPEG Image, $600 \times 397$ Pixels)'. N. p., n.d. Web. 4 Apr. 2014.

14. 'Modecell-Bale-House.jpg (JPEG Image, $600 \times 452$ Pixels) - Scaled (0\%)'. N. p. Web. 22 Feb. 2014.

15. Jaycock, S. “Colorado Strawbale School 1.” 2013. JPEG file.

16. Jaycock, S. “Colorado Strawbale School 2." 2013. JPEG file.

17. Jaycock, S. “Colorado Strawbale School 3." 2013. JPEG file.

18. Jaycock, S. “Colorado Strawbale Home 1." 2013. JPEG file.

19. Jaycock, S. “Colorado Strawbale Home 2." 2013. JPEG file.

20. Jaycock, S. “Colorado Strawbale Home 3." 2013. JPEG file.

21. Jaycock, S. “Gisborne NZ Strawbale 1." 2013. JPEG file.

22. Jaycock, S. “Gisborne NZ Strawbale 2." 2013. JPEG file.

23. Jaycock, S. “Hawkes Bay NZ Strawbale 1.” 2013. JPEG file.

24. Clay-Ss-2005.jpg (JPEG Image, $800 \times 595$ Pixels). N. p. Web. 25 Feb. 2014. GNU Free License

25. Clay-Ss-2005.jpg (JPEG Image, $800 \times 595$ Pixels). N. p. Web. 25 Feb. 2014. GNU Free License

26. Large-Limestone-Quarry.jpg (JPEG Image, $1000 \times 751$ Pixels). N. p. Web. 25 Feb. 2014. GNU Free License 
27. Straw_of_the_rice.080ct9.jpg (JPEG Image, $2600 \times 1733$ Pixels). N. p. Web. 25 Feb. 2014. CCL Public Domain

28. Gelugu_(coconut_wood)_in_Klaten,_Java.jpg (JPEG Image, $2576 \times 1920$ Pixels). N. p. Web. 25 Feb. 2014. GNU Free License

29. Jaycock, S. "Strawbale wall prepped." 2010. JPEG file.

30. Jaycock, S. “Decorative Plaster NZ.” 2010. JPEG file.

31. Jaycock, S. “West Coast Test Bale." 2012. JPEG file.

32. 'M. C. Escher // Verbum Art Print'. N. p., n.d. Web. 3 Apr. 2014.

33. Brouwer, B. 'Leeuwarden - Tegeltableau Escher.jpg - Wikimedia Commons' N. p., n.d. Web. 9 Apr. 2014.

34. 'Monolithic Dome Homes'. N. p., n.d. Web. 24 Feb. 2014.

35. 'Eden_Project_geodesic_domes_panorama.jpg (JPEG Image, $3700 \times 1155$ Pixels)'. N. p. Web. 7 Apr. 2014.

35A. Hexagonopolis (JPEG Image, $126 \times 201$ Pixels) - Scaled (0\%). N. p. Web. 25 Apr. 2014.

35B. BazettPlan.jpg (JPEG Image, $700 \times 768$ Pixels) - Scaled (0\%). N. p. Web. 25 Apr. 2014.

36. Bartel, L. “Cob Couch.” 2013. JPEG file.

37. Jaycock, S. “Applying Plaster." 2013. JPEG file.

38. Bartel, L. “Stone Polishing." 2013. JPEG file.

39. Bartel, L. "Colorado Tadelakt Class." 2013. JPEG file. 
40. "Tadelakt Bathroom Vanity." n.d. JPEG file.

41. "Bar Shelving". n.d. JPEG file.

42. Jaycock, S. “Bathroom Tadelakt 1.” 2013. JPEG file.

43. Jaycock, S. "Bathroom Tadelakt 2." 2013. JPEG file.

44. Jaycock, S. “Kitchen Splashback." 2010. JPEG file.

45. "Garden Wall \& Seating." n.d. JPEG file.

46. Jaycock, S. “Tadelakt Ball.” 2013. JPEG file. 


\section{Appendices}

1 PHYSICAL MODELLING

2 COMPOSITE TESTING

3 TADELAKT COURSE

Appendices include additional modelling and rendering that were part of the design and research. They are included here as a more complete record of some of the variations and research undertaken over the duration of this thesis.

4 NZ TADELAKT TRIALS

5 SITE STUDIES

6 ADDITIONAL RENDERS 


\section{Physical Modelling}

Physical 3D polystyrene and cardboard modelling enabled me to experiment with configurations of adjoining houses and study how they affected each other, in particular, in regard to privacy, view shafts and access to sunlight. This process lead to the chain and flower configurations which were then further developed.
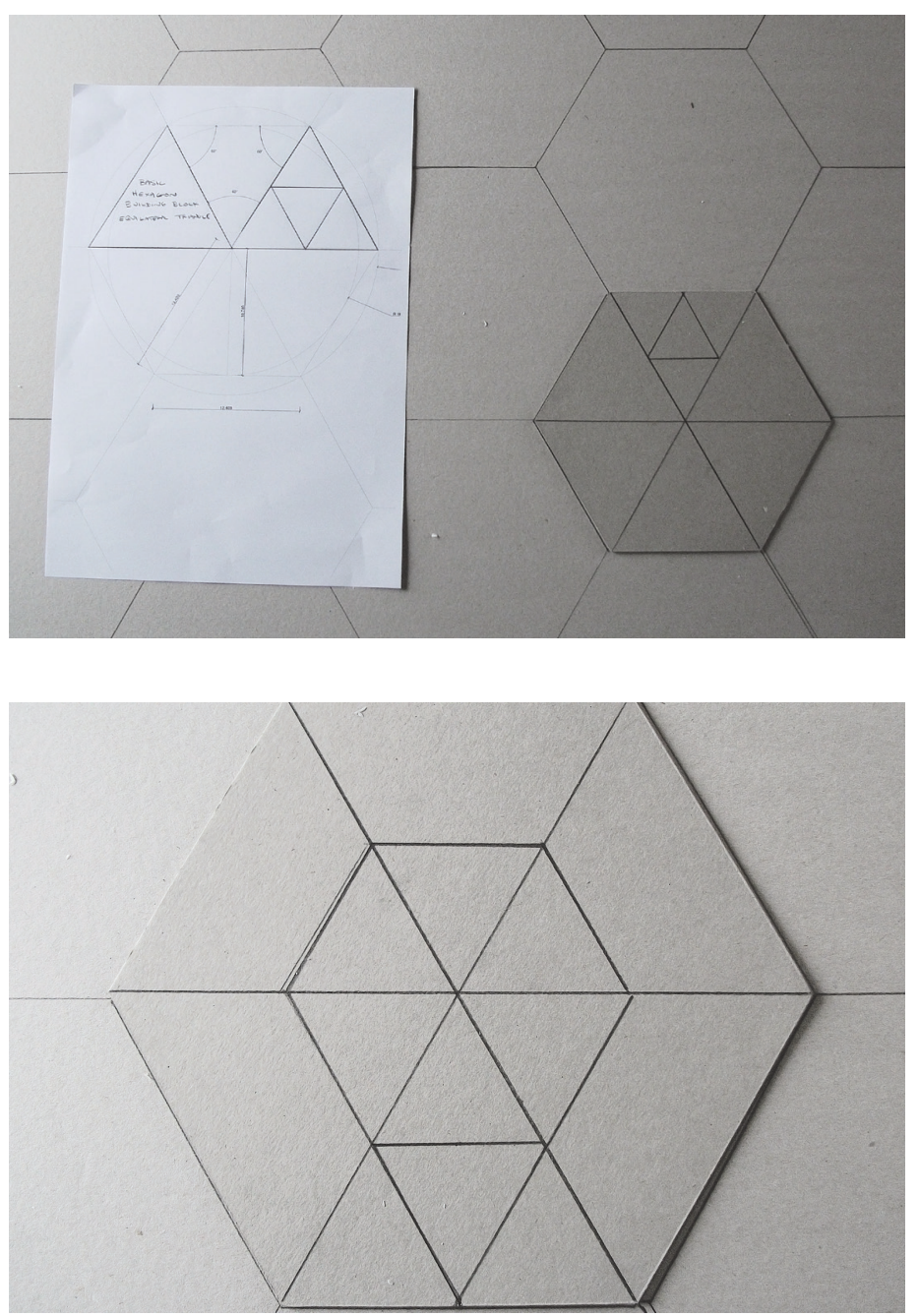

Left. Simple geometric study of hexagon.

Below. Concept model of bay window seat.

\section{Right.}

Building distribution and preliminary sun studies.
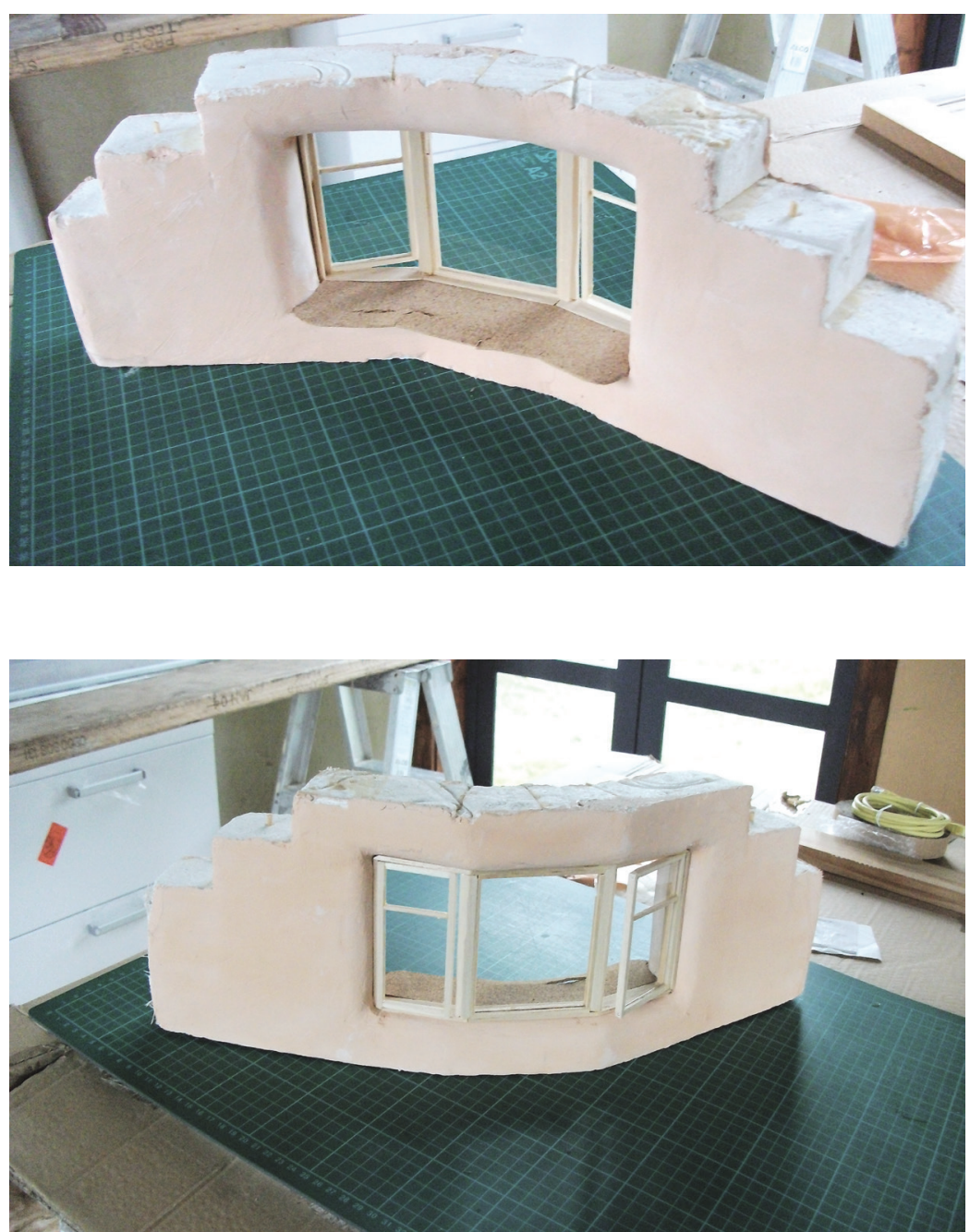

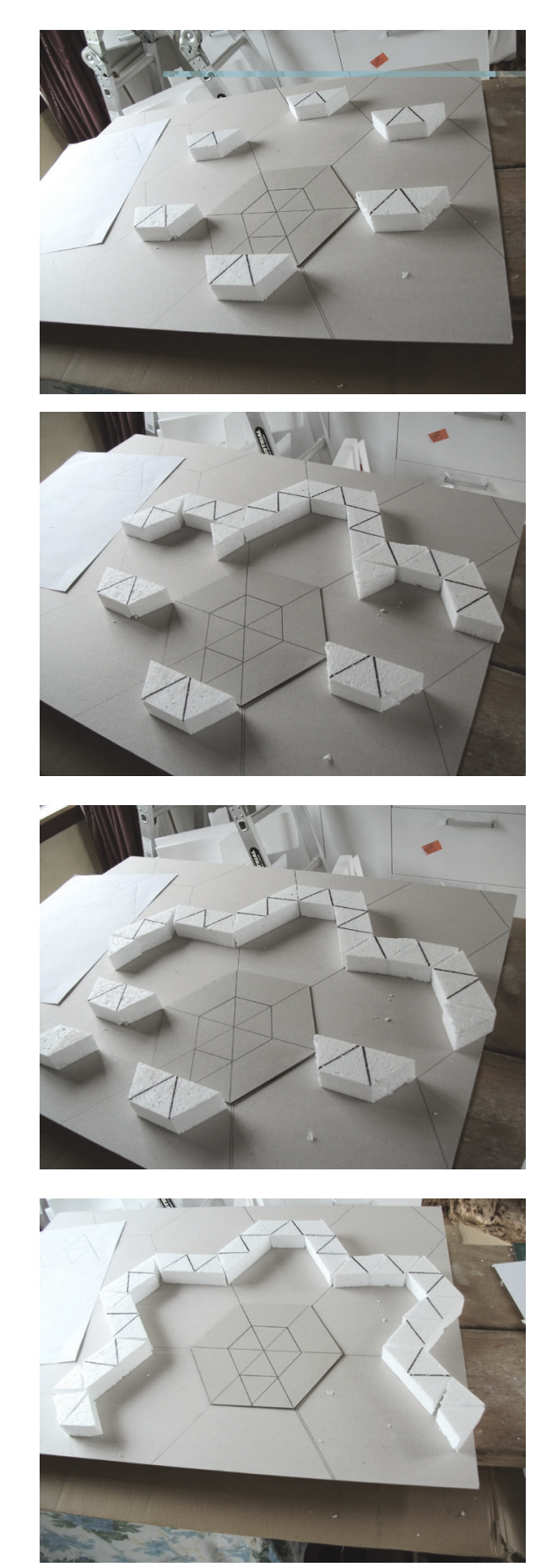
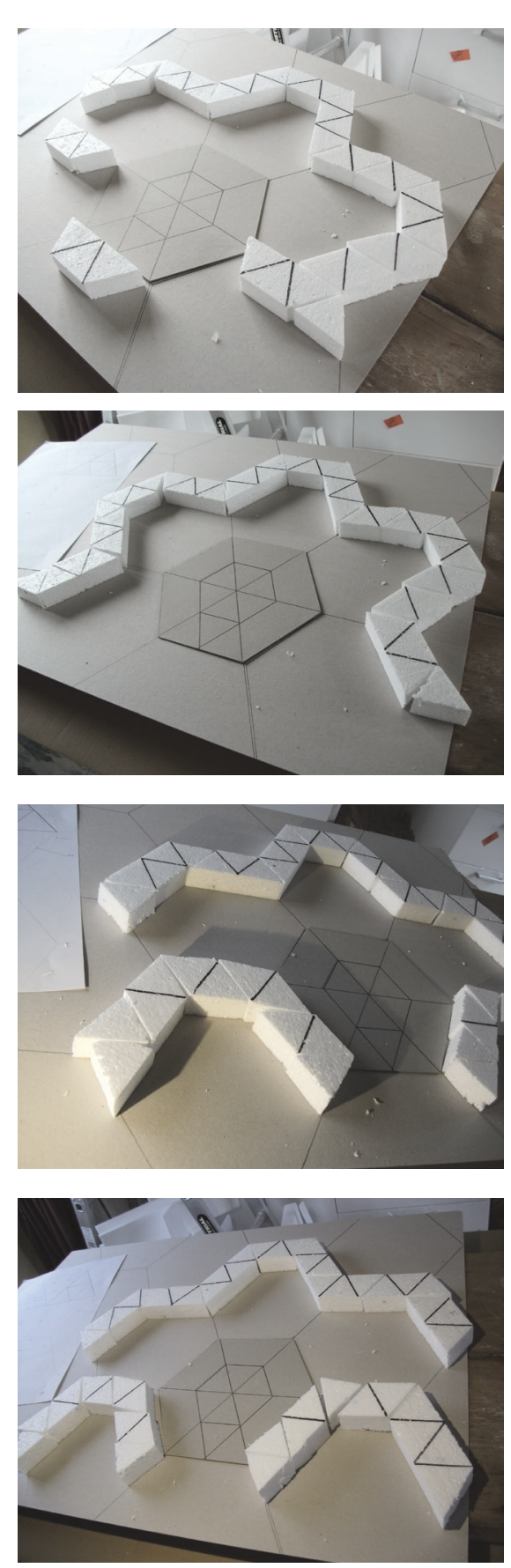
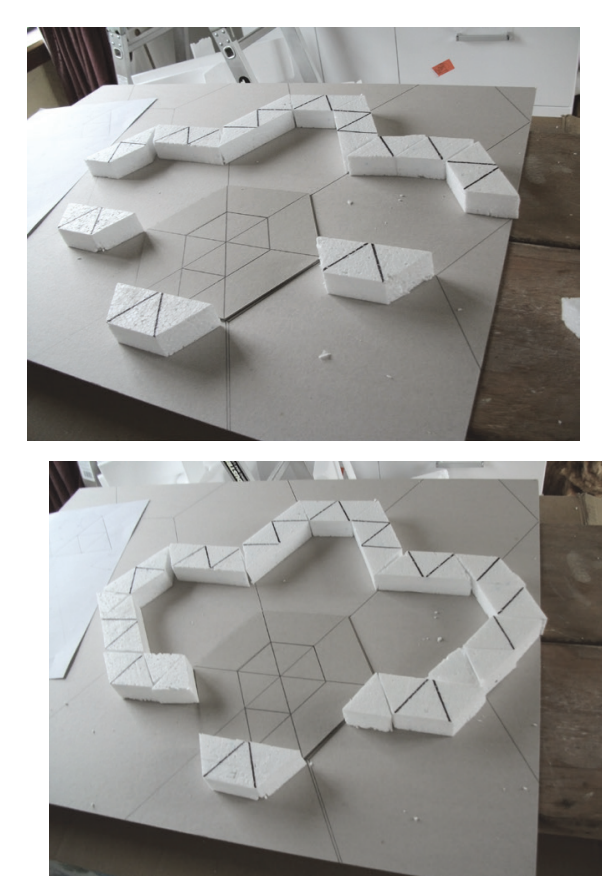

P A
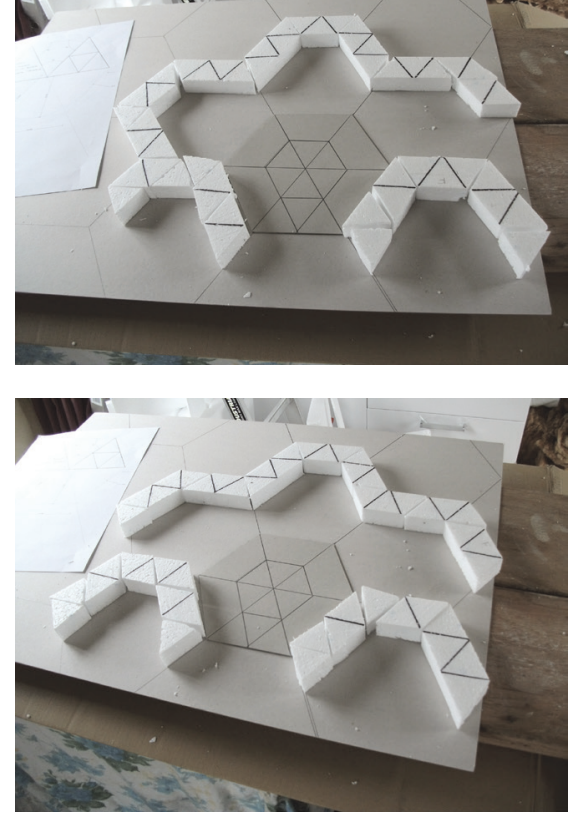
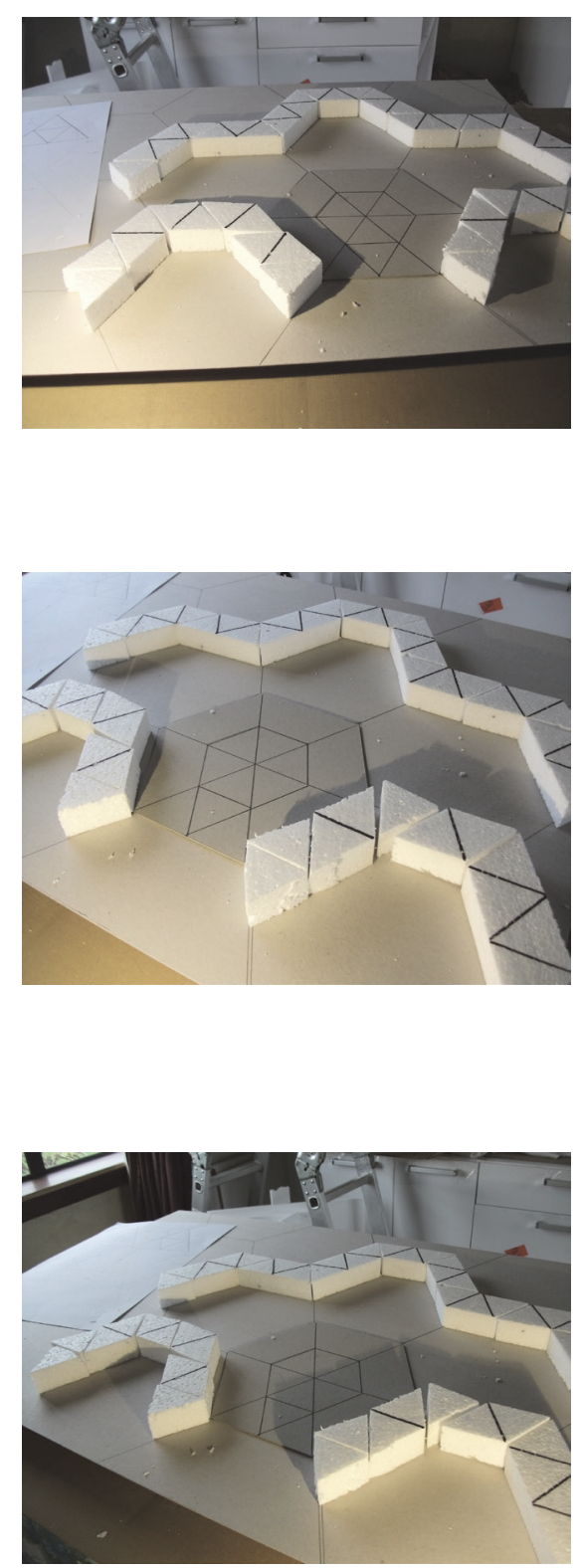


\section{Composite Testing}

It is essential, when working with locally sourced materials, to test the elements in the final composite combination to identify compatibility issues or changes that might benefit the final formul
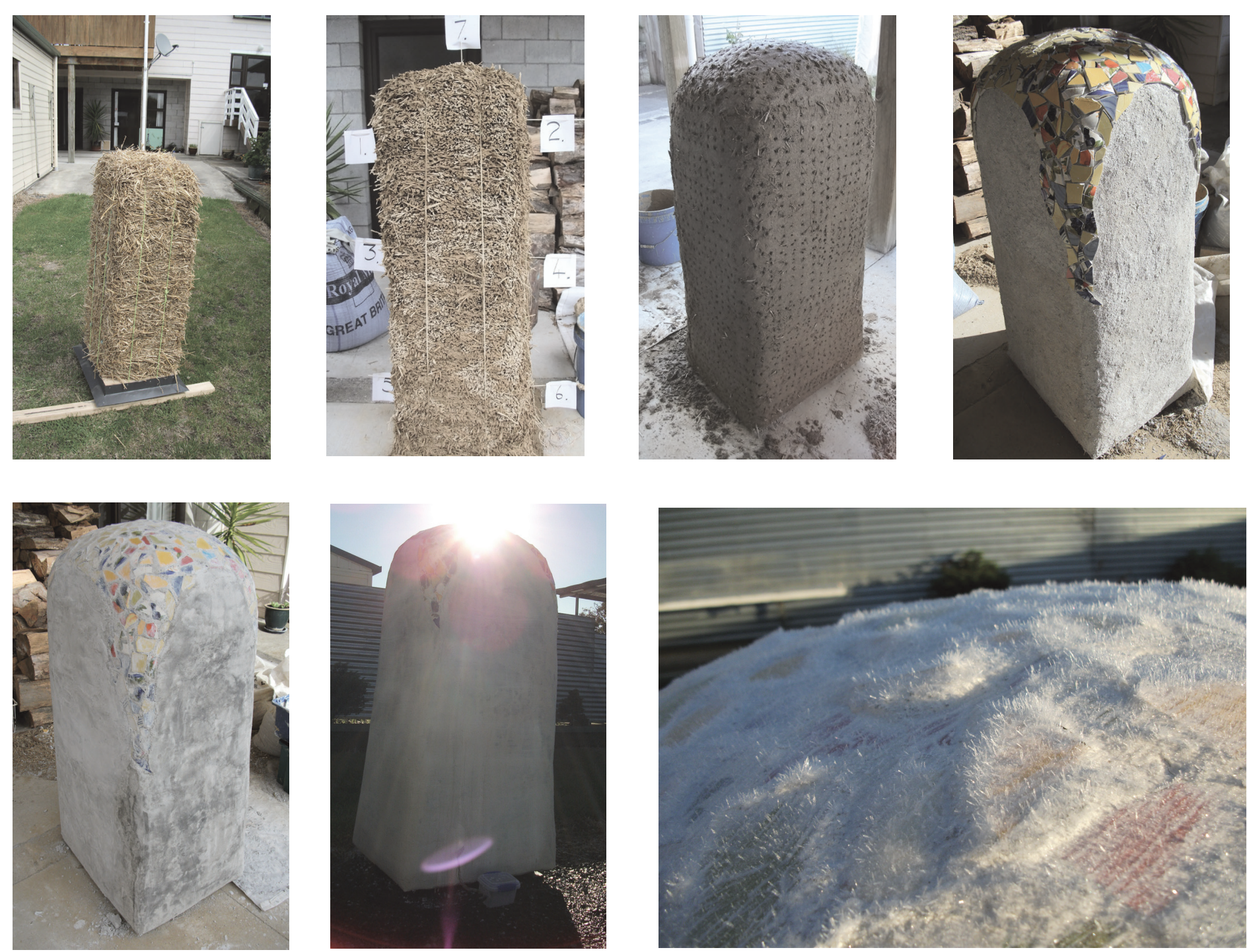

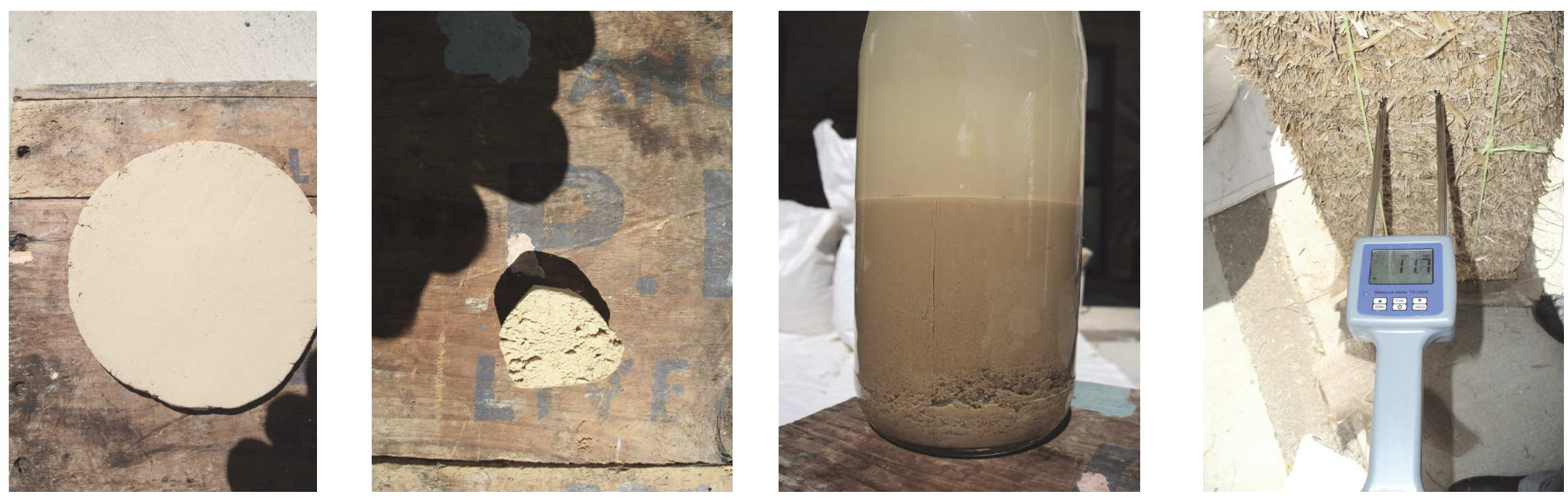

Left to right.

The pancake test, shear test, sediment settling test are all used to establish properties of clays and earths

\section{Far right.}

An industrial moisture sensor and below a simple home made sensor which provides suitable information for wall moisture montioring.

\section{Facing page.}

Progression of composite bale wall construction with local materials. The far right is a close up of the top after a particularly frosty morning.

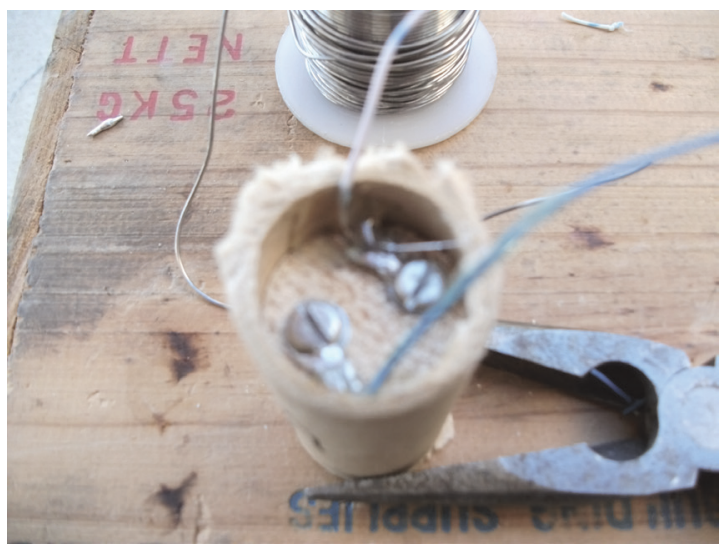




\section{Tadelakt Course}

Hands on is the only way to learn tadelakt, just like riding a bike you cant learn it without doing it.
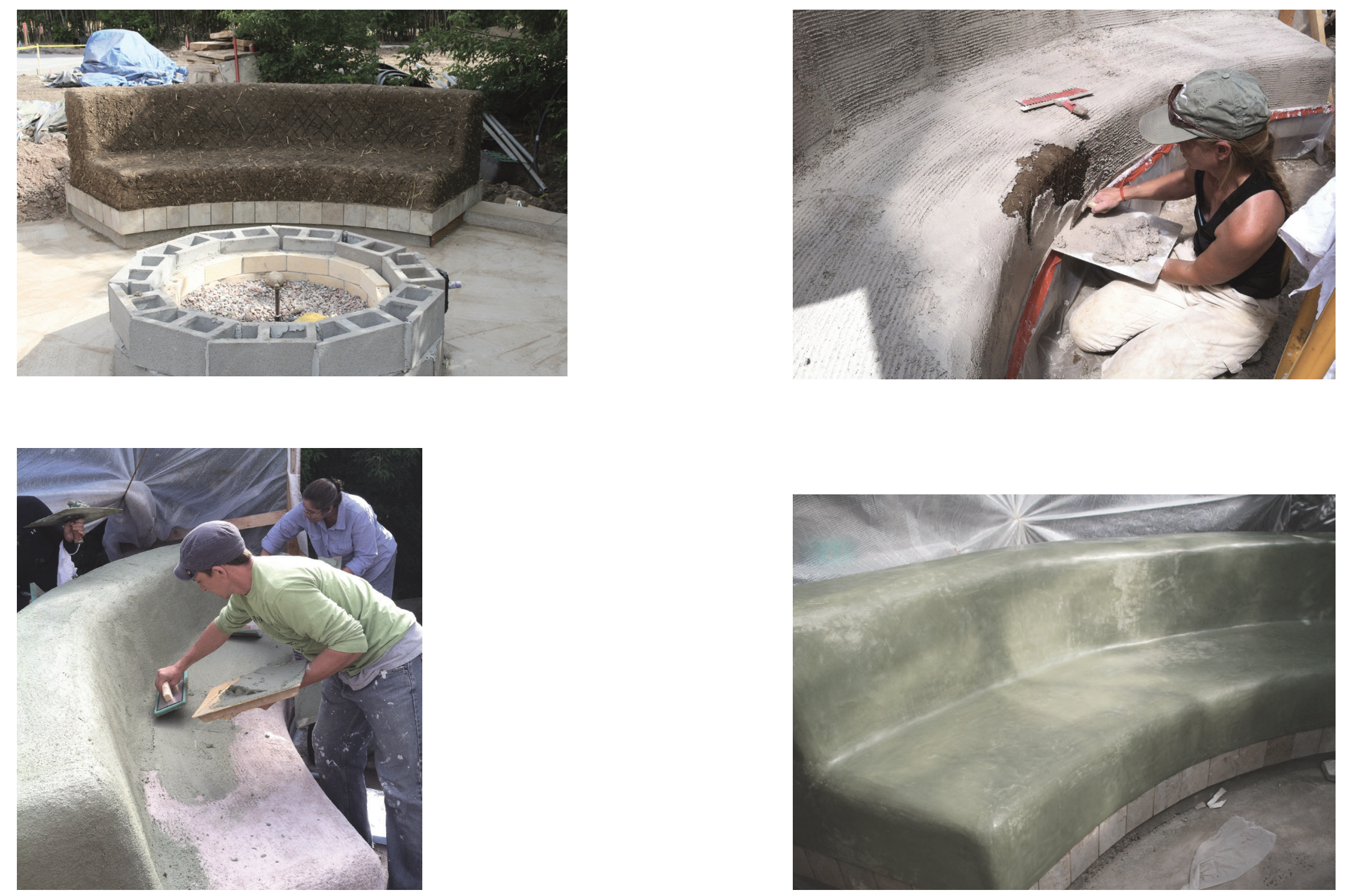

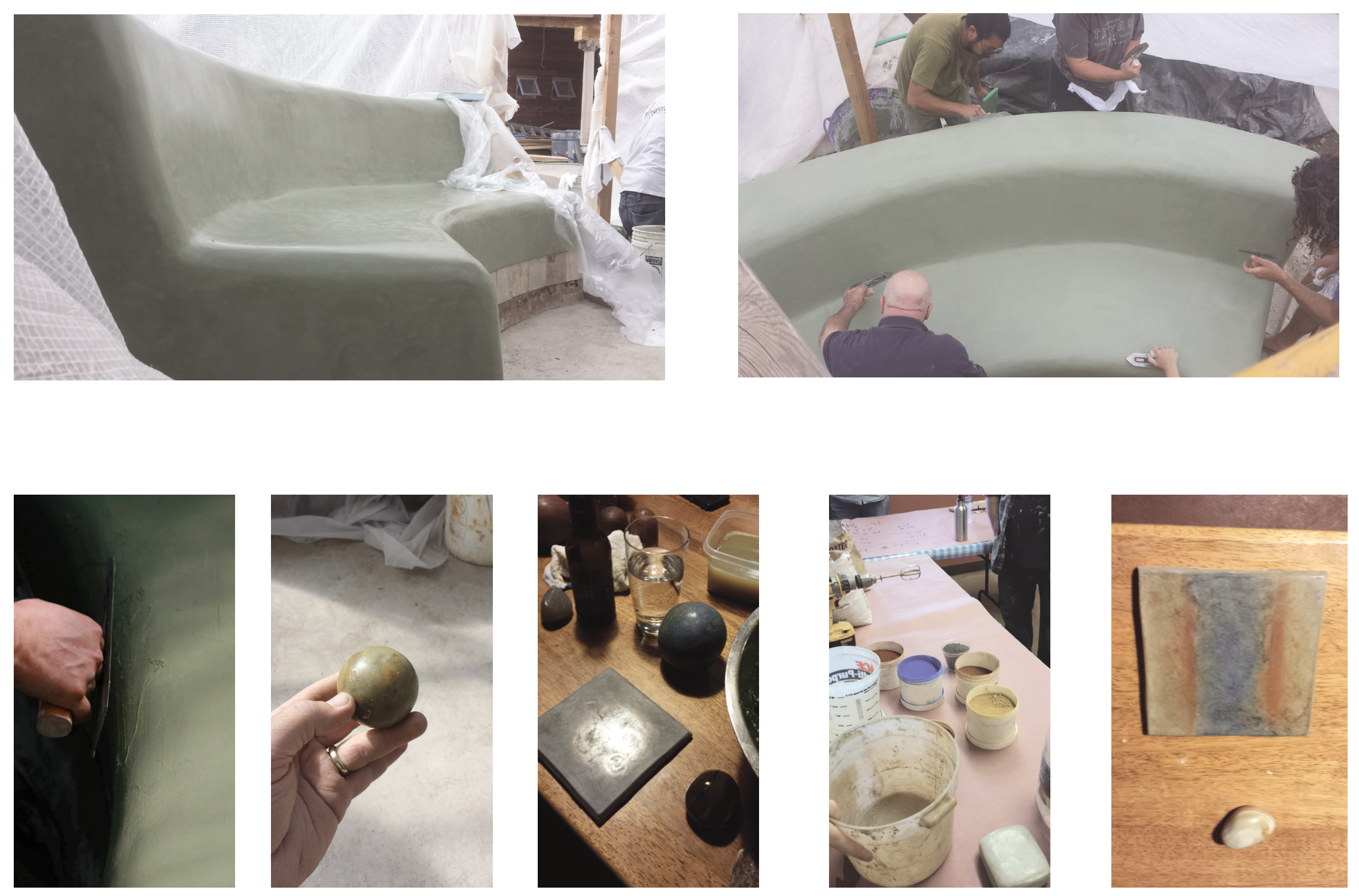


\section{NZ Tadelakt Trial}

As with composite testing I found local materials differed from those I learnt with in Colorado. The biggest obstacle was the New Zealand limes which are not manufactured with the same process resulting in a less creamy consistency when using the basic formula. The formula had to be customised, through a series of tests and variations to find combinations that suit NZ materials.
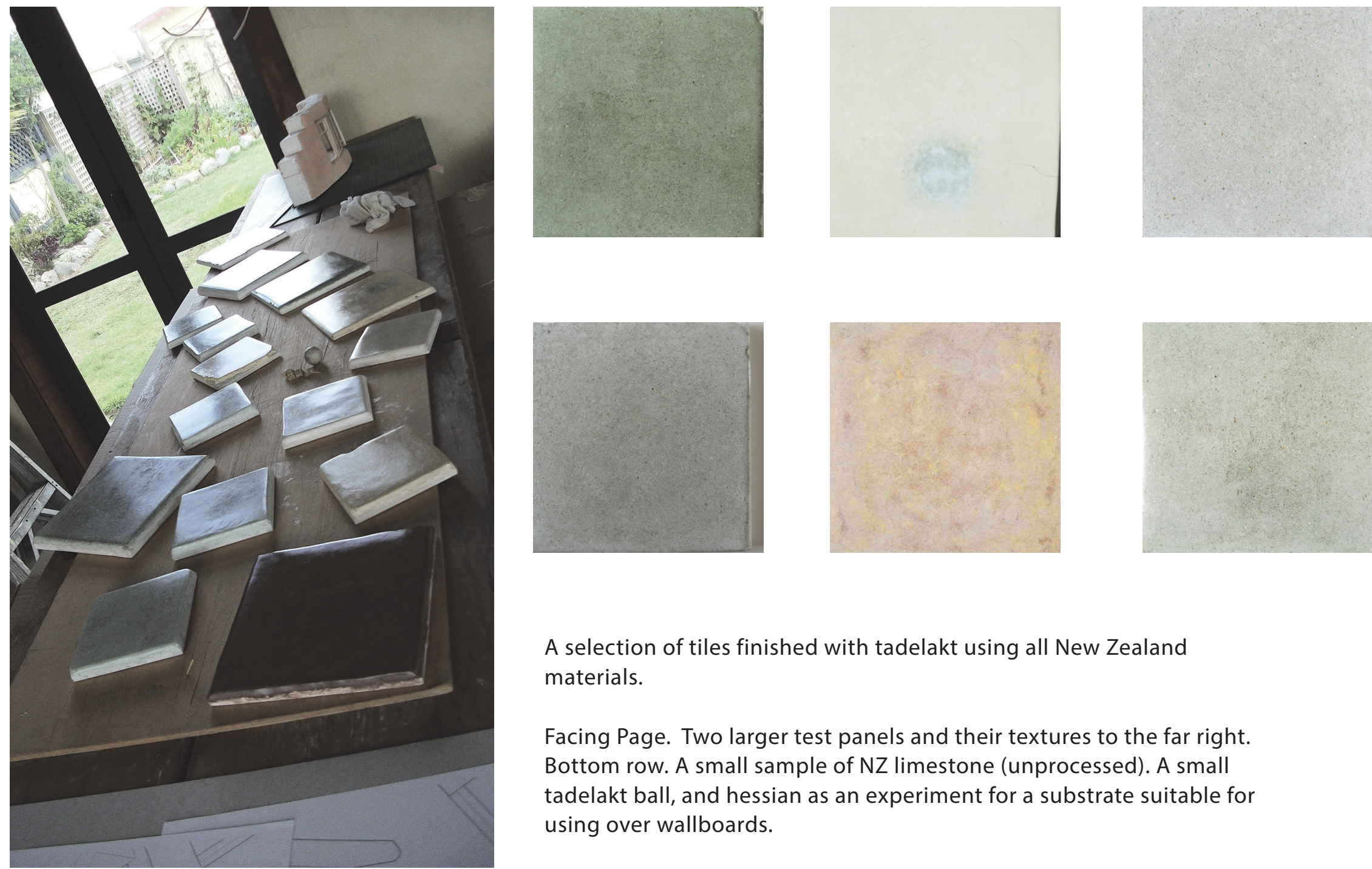

A selection of tiles finished with tadelakt using all New Zealand materials.

Facing Page. Two larger test panels and their textures to the far right. Bottom row. A small sample of NZ limestone (unprocessed). A small tadelakt ball, and hessian as an experiment for a substrate suitable for using over wallboards. 

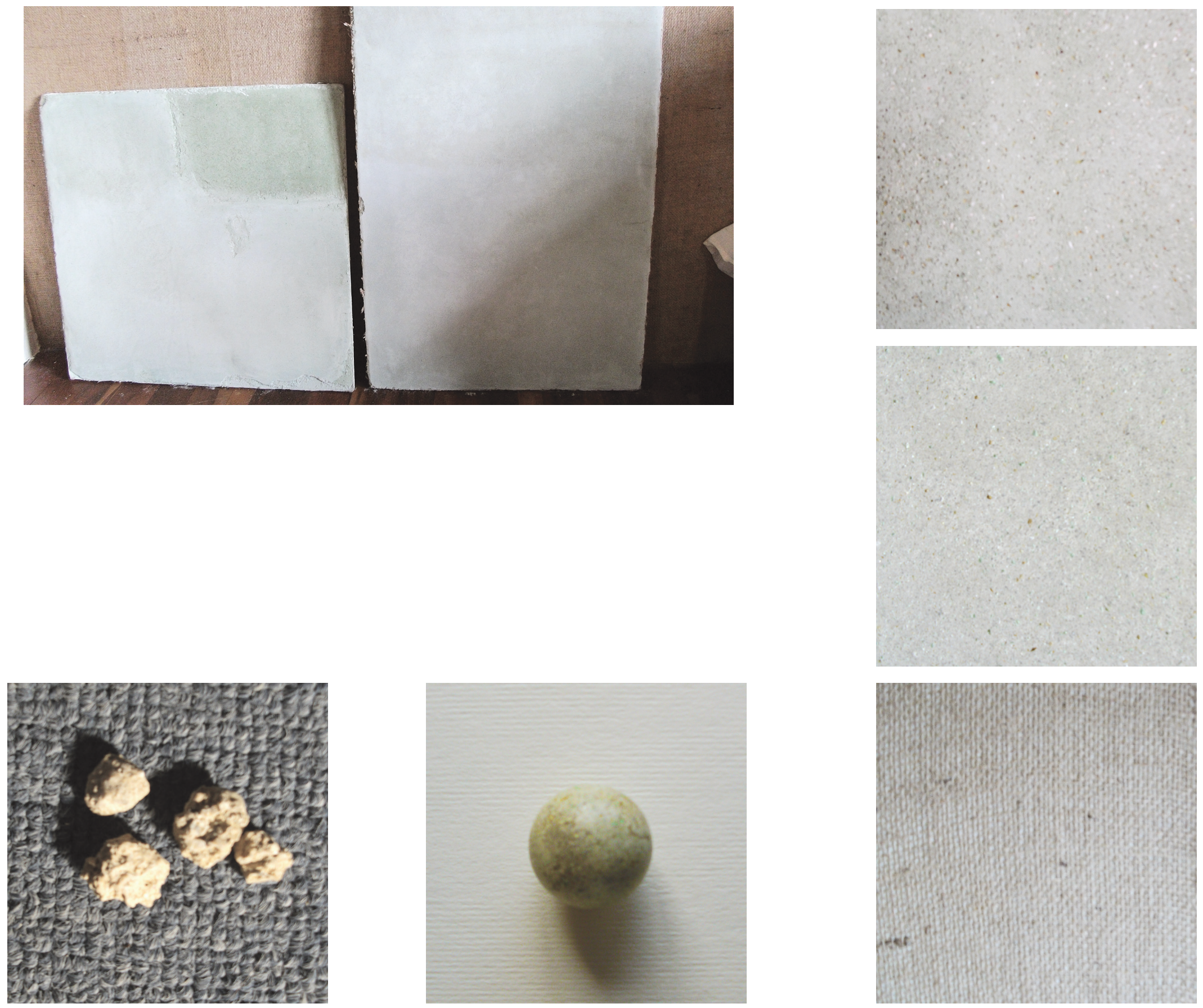


\section{Site Studies - Site Configuration Analysis}

A comparison between current and proposed site configurations and densities, including infill housing.

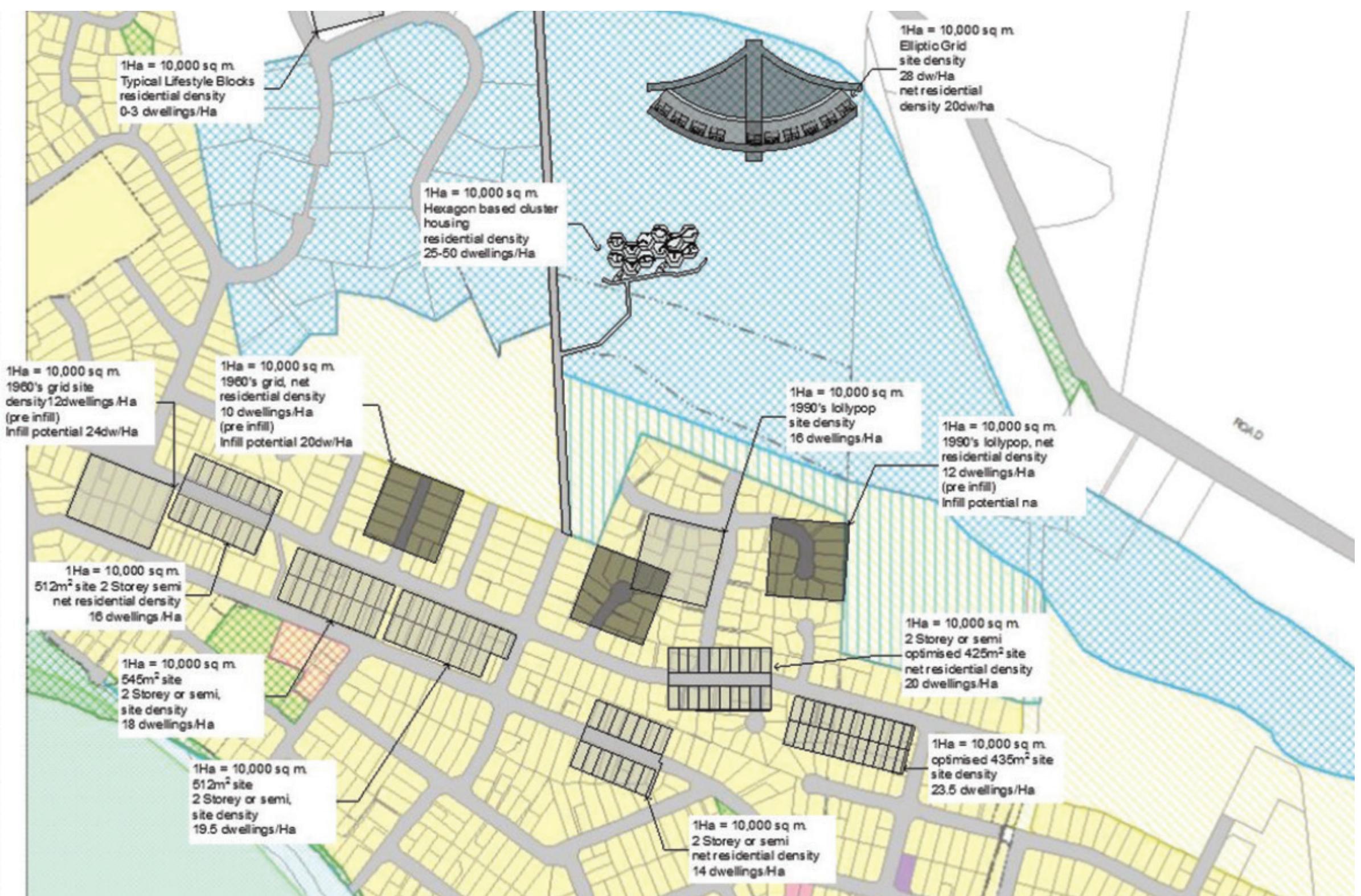




\section{Site Studies - Sun Study}

Early sun study analysis demonstrating how the obtuse angled wings allow for full sun on the north of the central body of the home for most of the day and how the more northerly structures can be set at a lower level improving solar access to the outdoor areas. The three images to the right are taken from a computerised sun study.

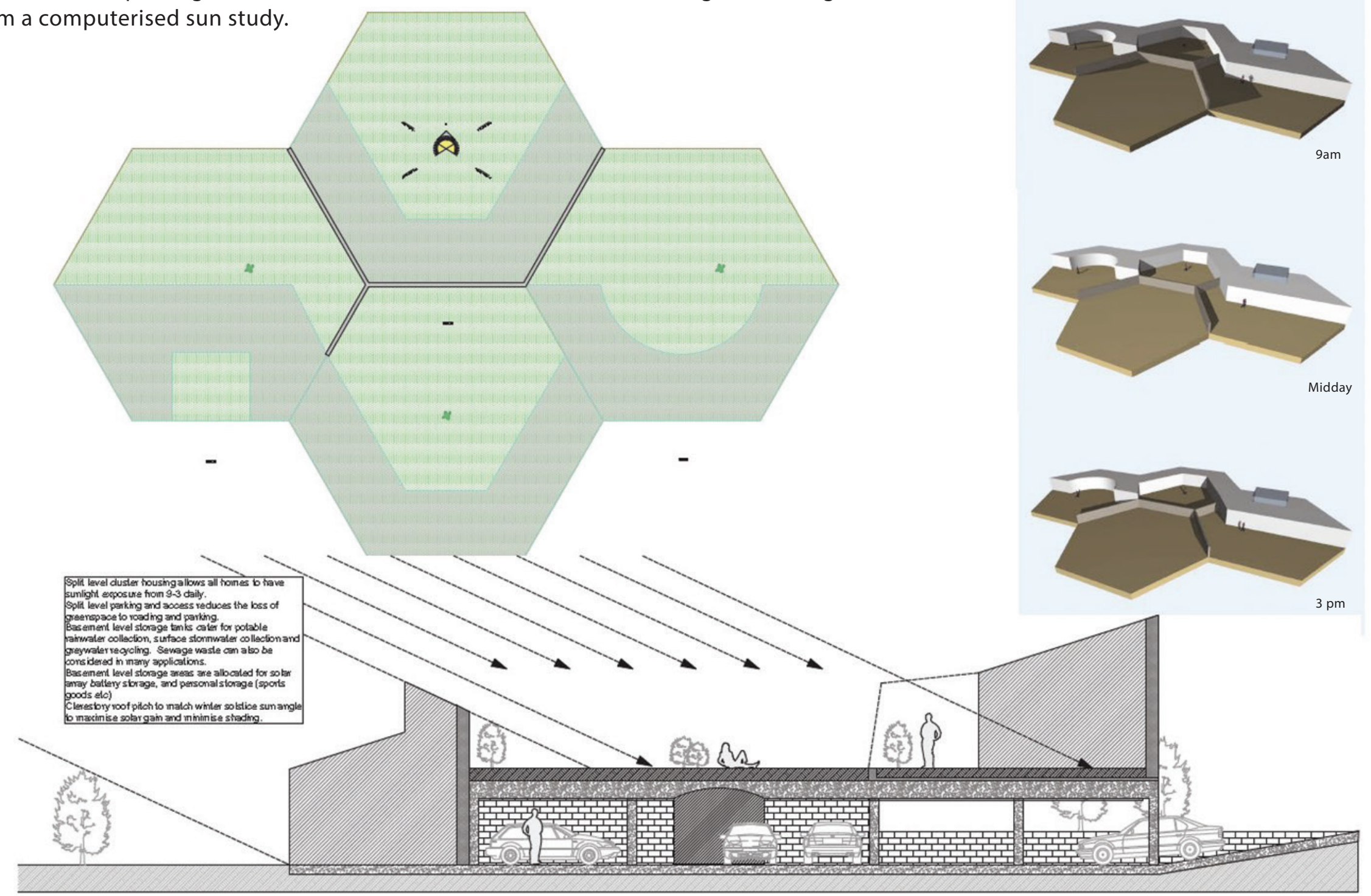




\section{Additional Renders}

A selection of omitted and partially completed renders and earlier design studies included here as this appendix.
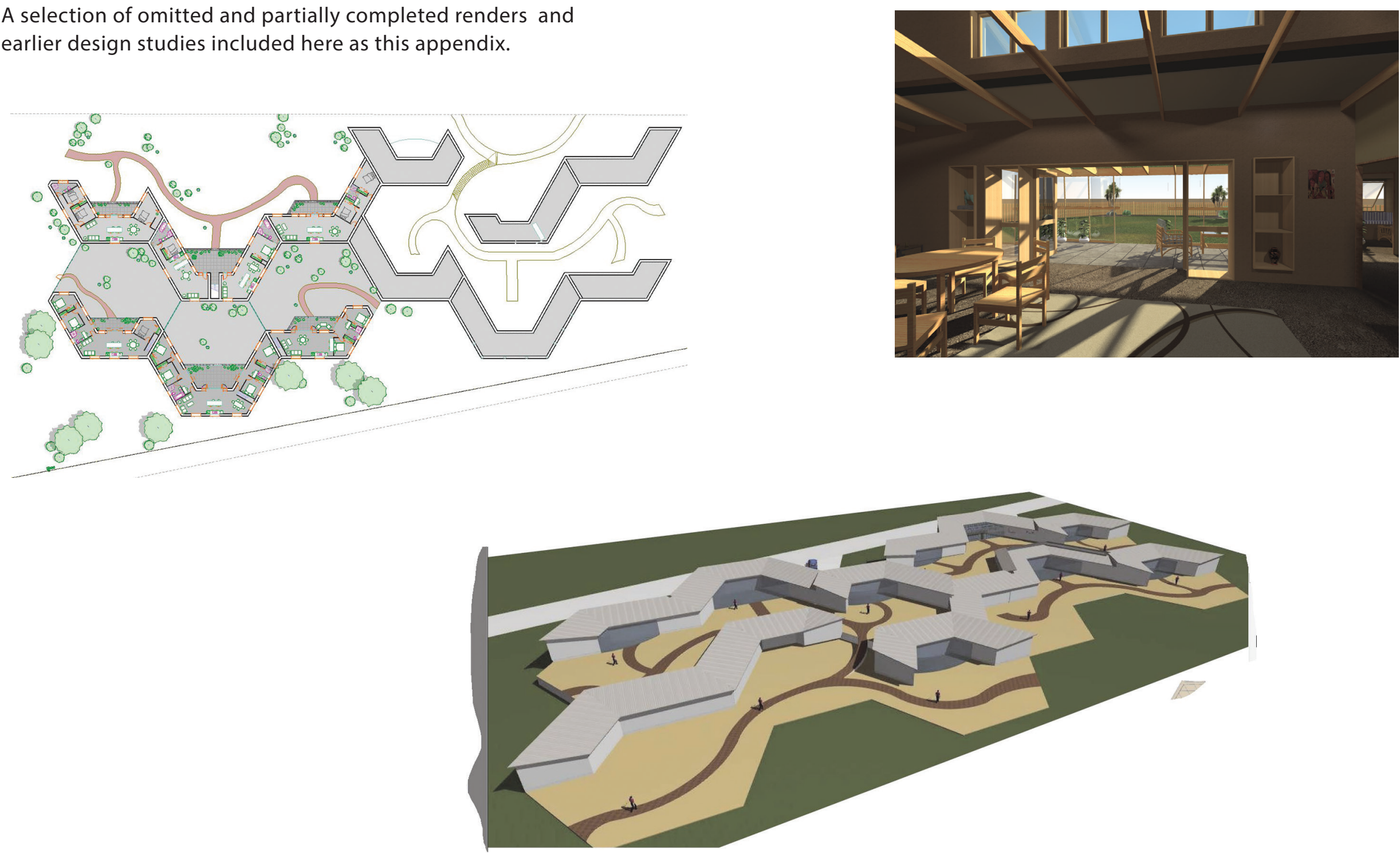

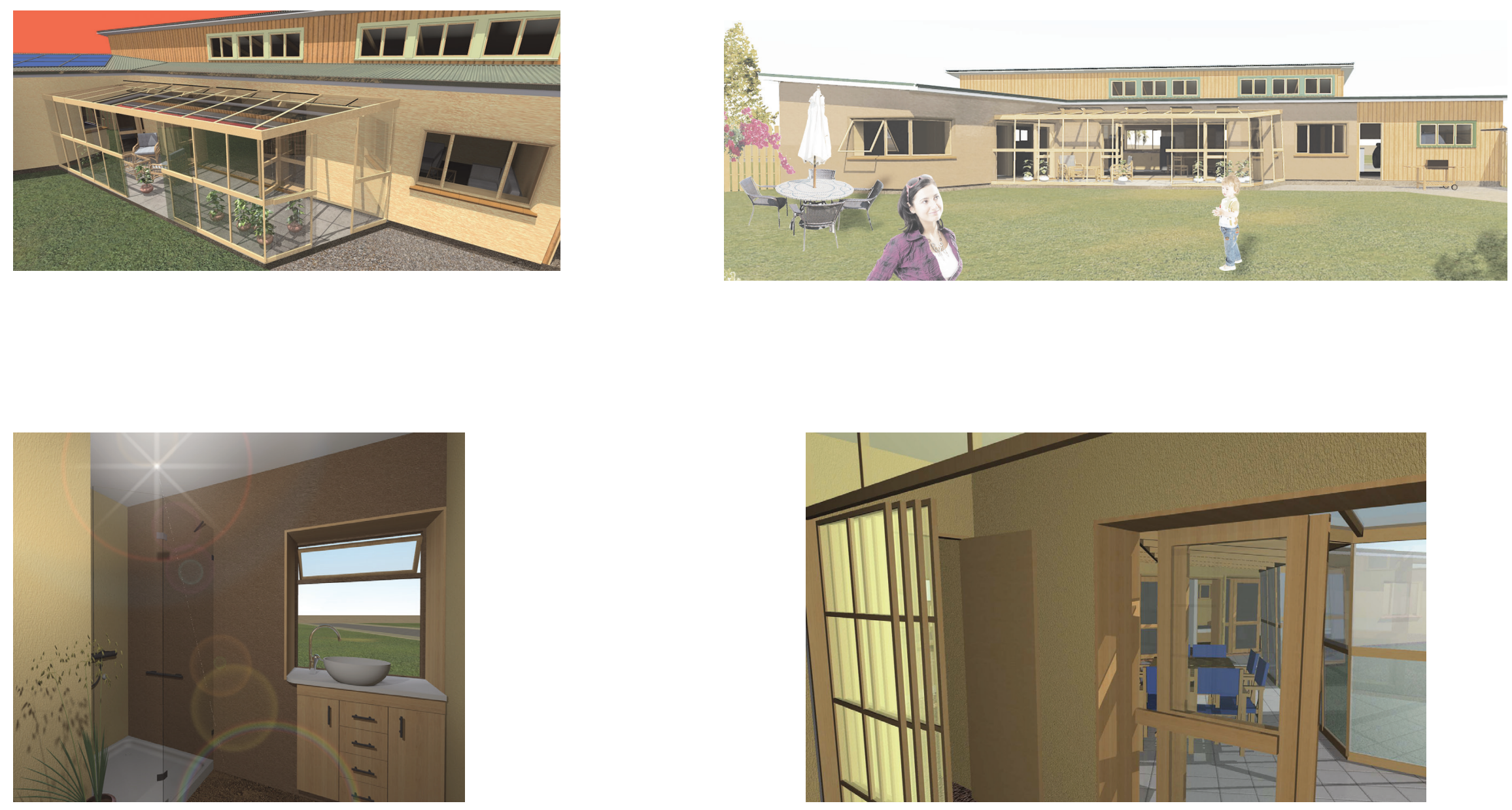

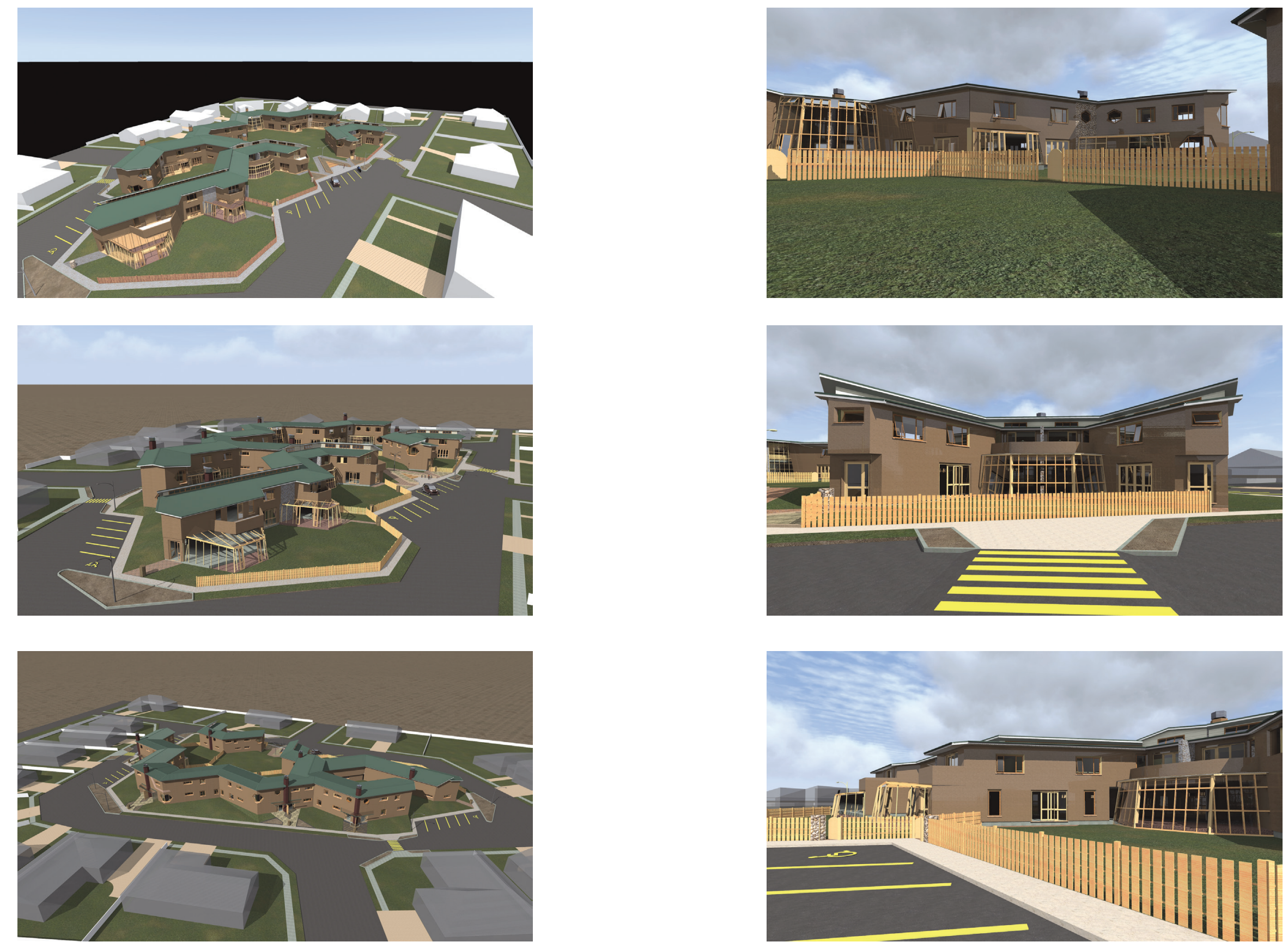

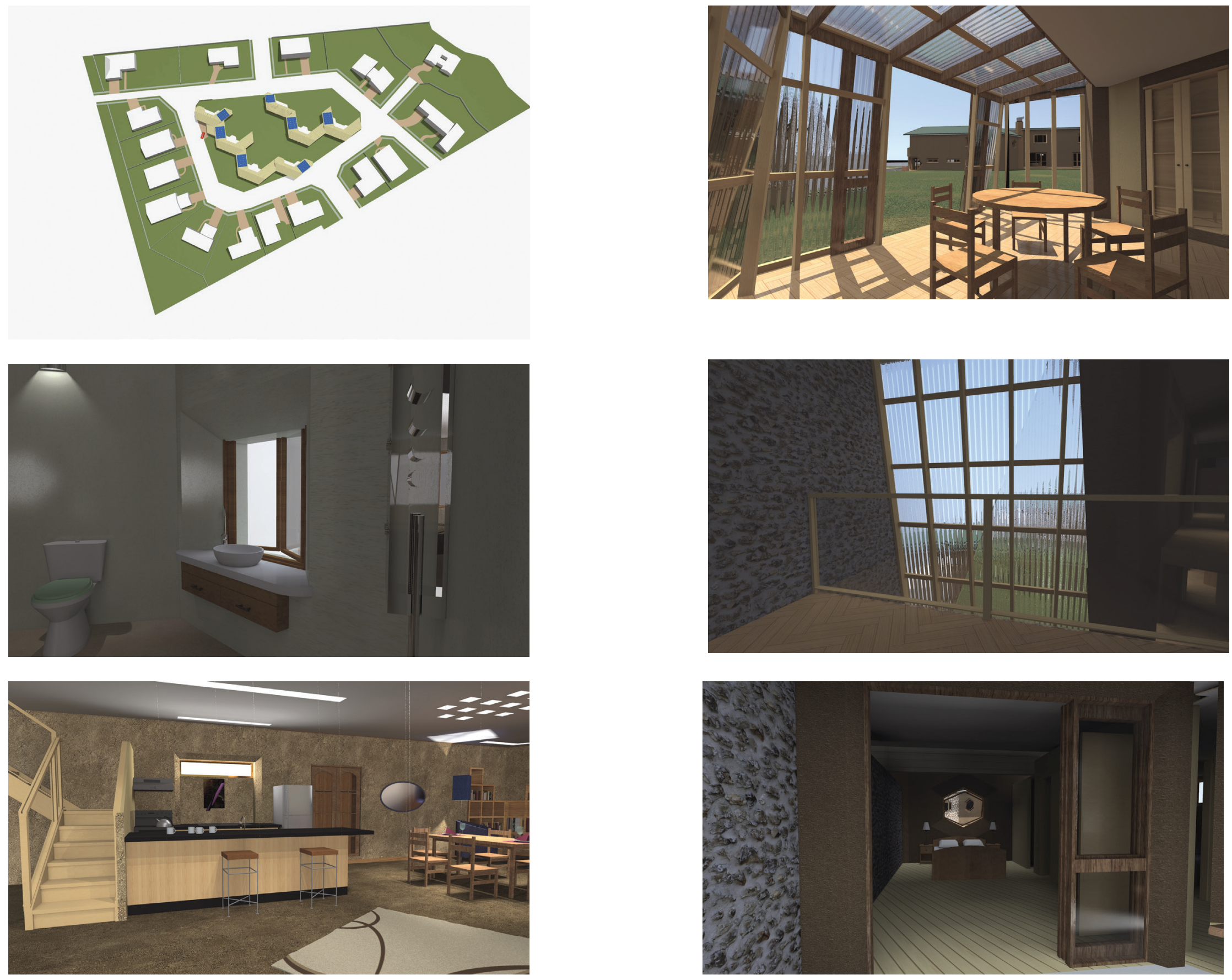